JS-CE-C property of the

United States Government

\title{
Loading Cycles for the Fatigue Reliability Analysis of Miter Gates
}

\author{
by Bilal M. Ayyub, Mark P. Kaminskiy, \\ $B M A$ Engineering, Inc. \\ Robert C. Patev, Mary Ann Leggett, \\ WES
}

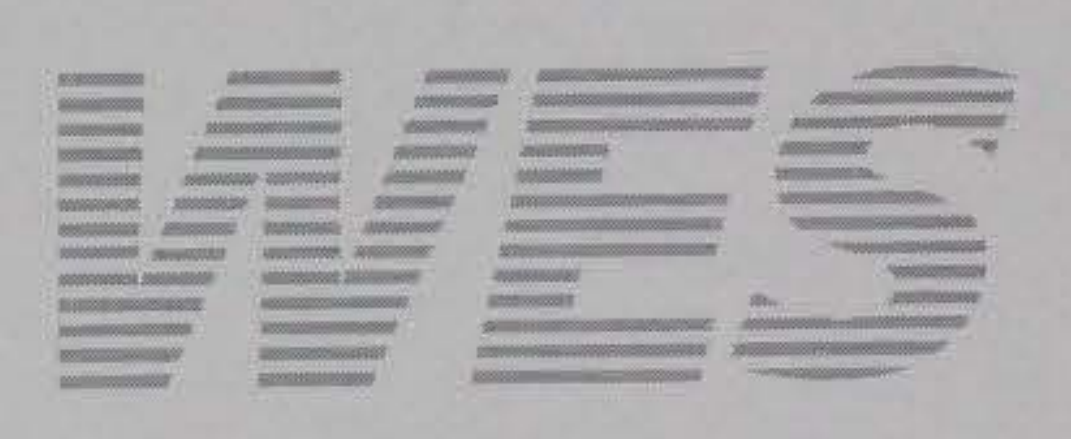

Approved For Public Release; Distribution Is Unlimited

\author{
Research Library \\ US Army Eiginee? Waterways \\ Experiment Station \\ Vick-1'yg. Mississippl
}



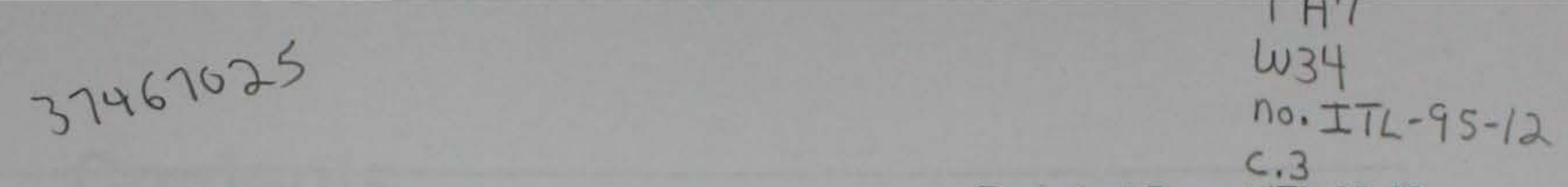

Technical Report ITL-95-12

December 1995

\section{Loading Cycles for the Fatigue Reliability Analysis of Miter Gates}

by Bilal M. Ayyub, Mark P. Kaminskiy

BMA Engineering, Inc.

14205 White Water Way

Darnestown, MD 20878-3974

by Robert C. Patev, Mary Ann Leggett

U.S. Army Corps of Engineers

Waterways Experiment Station

3909 Halls Ferry Road

Vicksburg, MS 39180-6199

Final report

Approved for public release; distribution is unlimited 


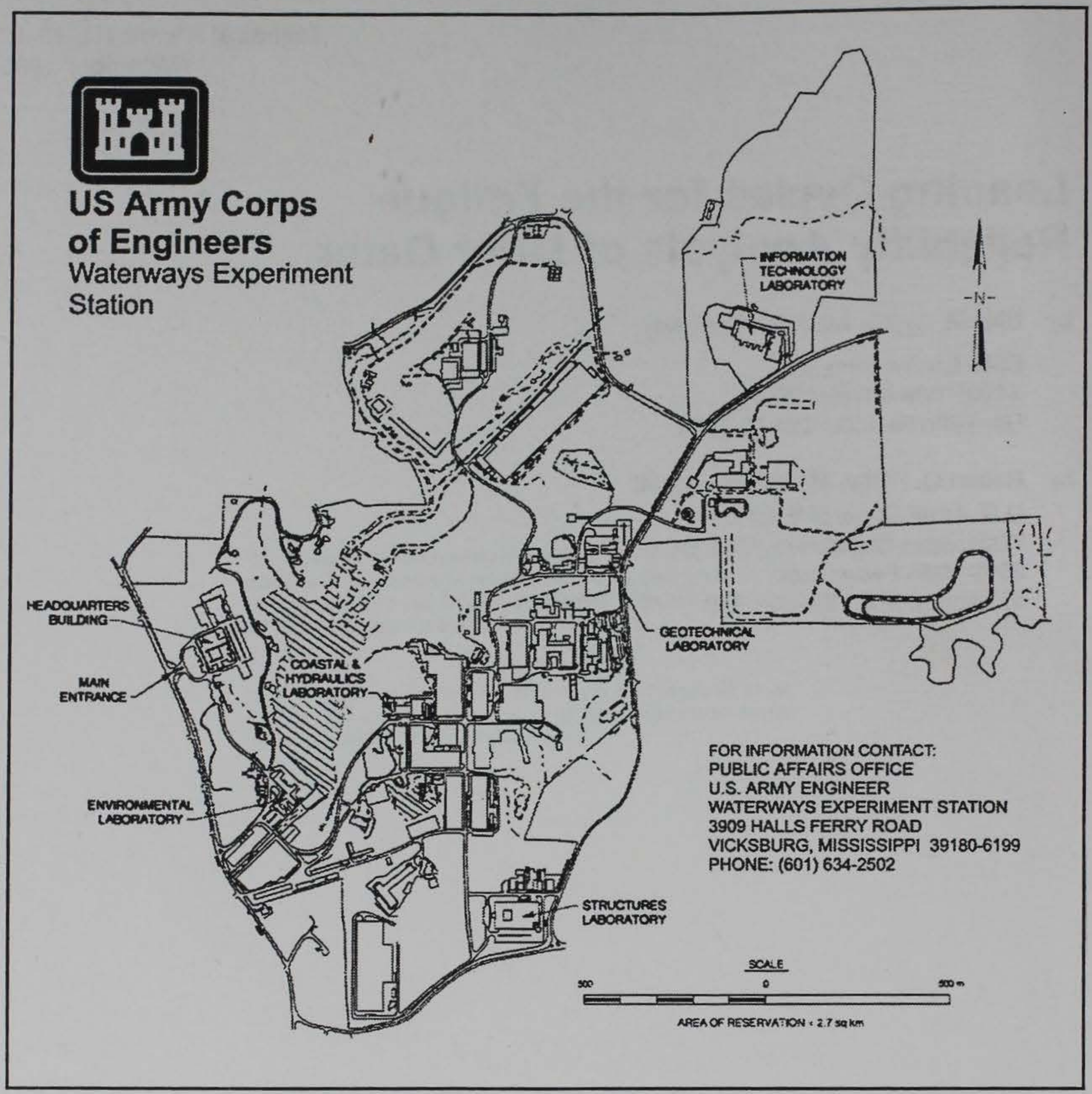

Waterways Experiment Station Cataloging-in-Publication Data

Loading cycles for the fatigue reliability analysis of miter gates / by Bilal M. Ayyub ... [et al.] ; prepared for U.S. Army Corps of Engineers.

91 p. : ill. ; $28 \mathrm{~cm}$. -- (Technical report ; ITL-95-12)

Includes bibliographic references.

1. Hydraulic gates. 2. Load factor design. 3. Locks (Hydraulic engineering) I. Ayyub, Bilal M. II. United States. Army. Corps of Engineers. III. U.S. Army Engineer Waterways Experiment Station. IV. Information Technology Laboratory (U.S. Army Engineer Waterways Experiment Station) V. Series: Technical report (U.S. Army Engineer Waterways Experiment Station); ITL-95-12.

TA7 W34 no.ITL-95-12 


\section{Contents}

Preface viii

Conversion Factors, Non-SI to SI Units of Measurement ................................... ix

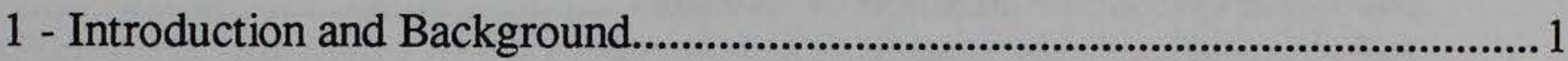

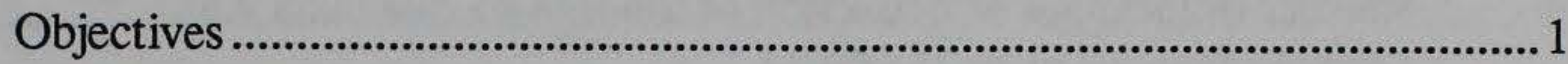

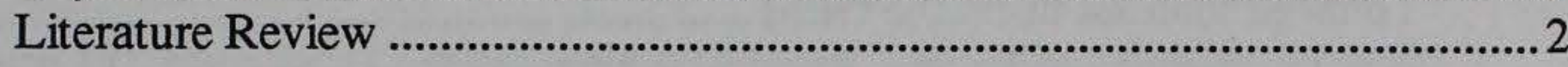

2 - Factors Affecting Loading Cycles.................................................................... 4

3 - Information Sources for Assessing Loading Cycles ........................................ 6

Lock Performance Monitoring System (LPMS)............................................ 6

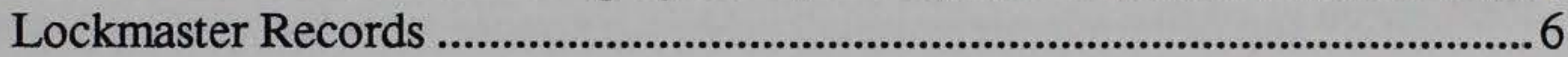

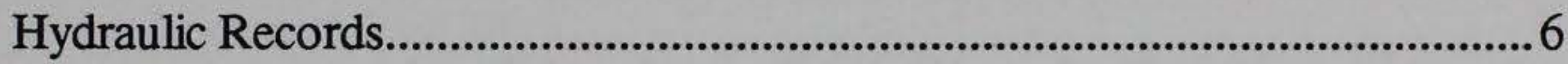

Uncertainty in Loading Cycles....................................................................... 7

4 - Methodology for Determining Loading Cycles .............................................. 8

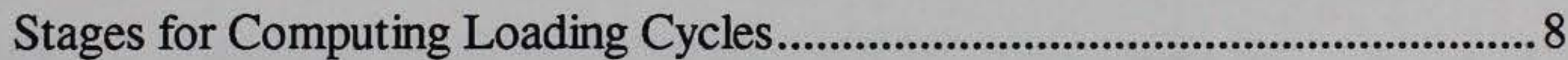

Loading cycles for Stage 3 (start of LPMS to present) ................................ 9

Loading cycles for Stage 1 (start of life to 1948) ......................................... 13

Loading cycles for Stage 2 (1948 to start of LPMS)................................... 14

Loading cycles for Stage 4 (present to planned end of design life or

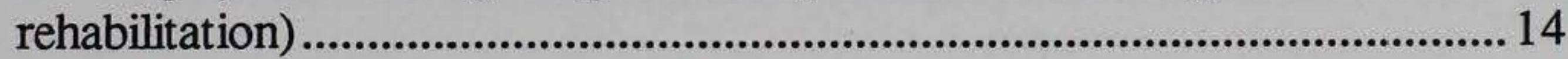

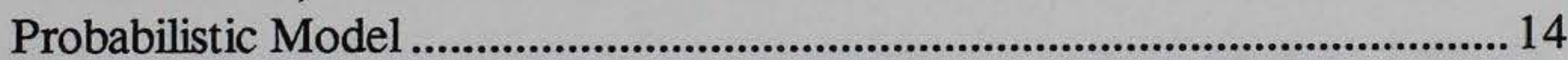

Relationship between number of hardware cycles and number of vessels.... 15 Increase in number of hardware cycles due to cutting of long vessels........ 15 Decrease in number of hardware cycles due to simultaneous lockages of

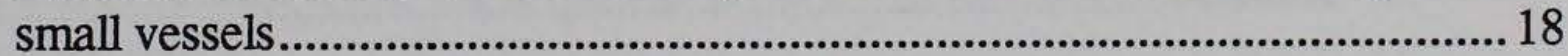

Decrease in number of hardware cycles due to travel in opposite directions

Hardware cycles due to environmental conditions.

Relationship between hardware cycles and lockages using regression

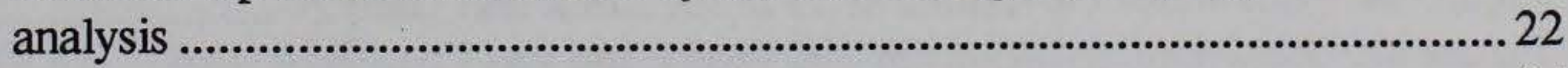

Trend analysis of annual number of lockages ...............................................24

Number of lockages as a function of tonnage...............................................2

Estimating the cumulative number of hardware cycles .................................. 30 
5 - Lock and Dam 24 - Case Study...................................................................... 31

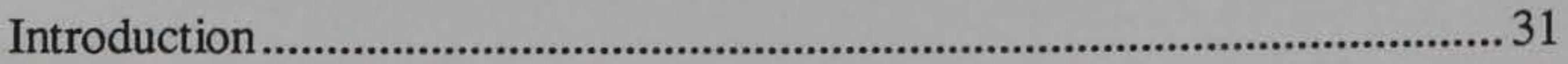

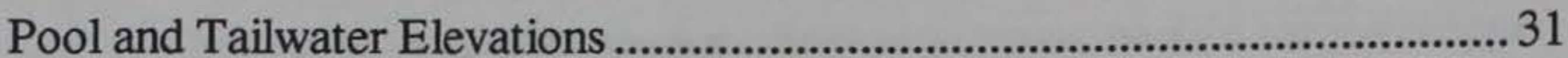

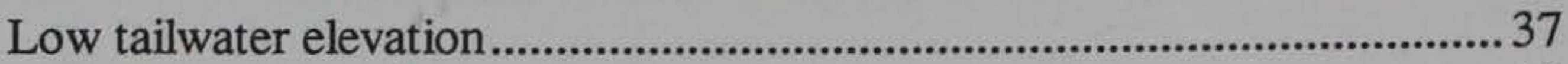

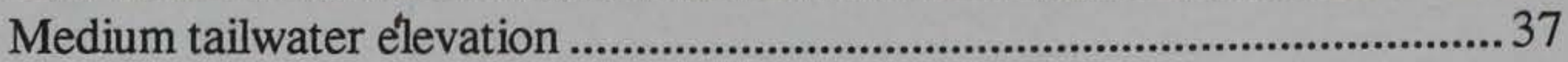

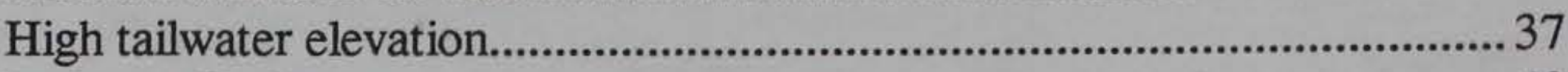

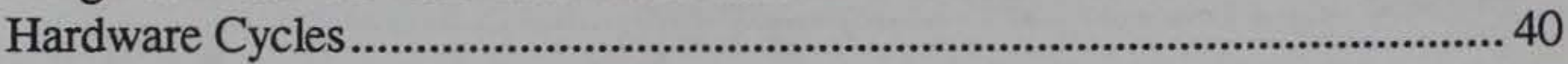

Tailwater-Hardware Cycles Analysis .............................................................40

Relationships Among Tonnage, Lockages, Hardware Cycles, and Time........53

Hardware cycles as a function of lockages ....................................................58

Trend analysis of annual number of lockages .................................................59

Number of lockages as a function of tonnage...............................................59

Tonnage forecast using the GEM ...............................................................59

Impact of Results on Fatigue Reliability Assessment ......................................63 63

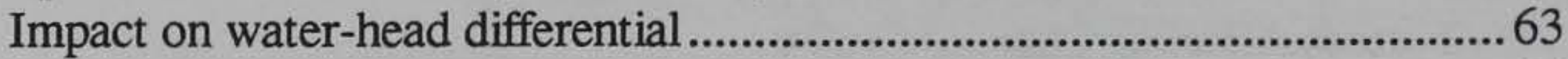

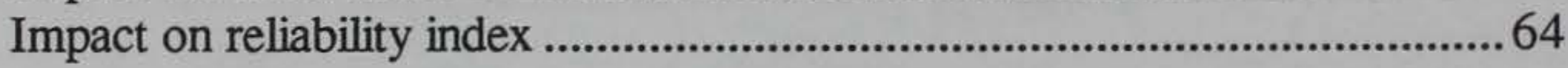

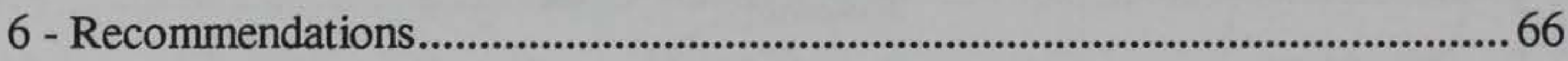

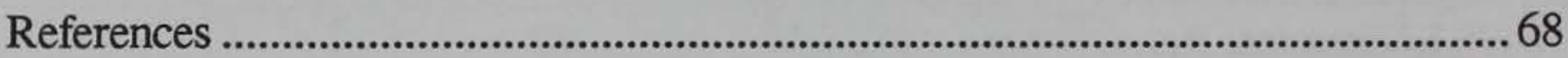

Appendix A. Daily Hardware Cycles for Lock and Dam 24 .............................. A1

Appendix B. Notation ...................................................................................... B1

\section{List of Figures}

Figure 1. Annual lockages and hardware cycles ...............................................2 23

Figure 2. Observed and fitted annual numbers of lockages for Lock and Dam 24

Figure 3. Observed and fitted annual numbers of lockages for Lock and Dam 22 and Lock and Dam 11

Figure 4a Pool water elevations in 1975 for Lock and Dam 24 ........................ 32

Figure 4b. Tailwater elevations in 1993 for Lock and Dam 24 ......................... 33

Figure 5a. Tailwater elevations for Lock and Dam 24_........................................ 34

Figure 5b. Pool water elevations for Lock and Dam 24.......................................35 
Figure 6. Water elevations for 1975 to 1994 - Lock and Dam 24 36

Figure 7. Model for water elevations for 1975 to 1994 - Lock and Dam 24 ....... 38

Figure 8. Summary (3-dimensional) of lockages for 1980 to 1994 - Lock and Dam 24

Figure 9. Summary (2-dimensional) of lockages for 1980 to 1994 - Lock and Dam 24

Figure 10. Summary (3-dimensional) of hardware cycles for 1980 to 1994 Lock and Dam 24.

Figure 11. Summary (2-dimensional) by month of hardware cycles for 1980 to 1994 - Lock and Dam 24

Figure 12. Summary (2-dimensional) by year of hardware cycles for 1980 to 1994 - Lock and Dam 24.

Figure 13. Daily tailwater elevation and hardware cycles for 1985 and 1986 Lock and Dam 24.

Figure 14. Daily tailwater elevation and hardware cycles for 1980 to 1994 Lock and Dam 24.

Figure 15. Histogram of tailwater elevation and hardware cycles for Lock and Dam 24.

Figure 16. Histogram of tailwater elevation and hardware-cycle fraction for Lock and Dam 24.

Figure 17. Histogram of tailwater elevation and hardware-cycle fraction with function fits to data for Lock and Dam 24

Figure 18. Tonnage trend for Lock and Dam 24 54

Figure 19. Trend of lockages for Lock and Dam 24.........................................54

Figure 20. Trend of hardware cycles for Lock and Dam 24...............................55

Figure 21. Trend of the ratio of tonnage to lockages for Lock and Dam 24........55

Figure 22. Trend of the ratio of tonnage to hardware cycles for Lock and Dam 24 
Figure 23. Trend of the ratio of lockages to hardware cycles for Lock and

Figure 24. Tonnage and lockages from 1940 to 1994 - Lock and Dam 24 .57

Figure 25. Tonnage and hardware cycles from 1980 to 1994 - Lock and Dam 24 .57

Figure 26. Lockages and hardware cycles from 1980 to 1994 - Lock and Dam 24 .58

Figure 27. Tonnage and lockages from 1940 to 1994 with regression model Lock and Dam 24 60

Figure 28. Forecast of annual tonnage for Lock and Dam 24 62

Figure 29. Forecast of annual lockages for Lock and Dam 24 62

Figure 30. Forecast of annual hardware cycles for Lock and Dam 24 63

Figure 31. Fraction of days for water-head differential from 1975 to 1994 Lock and Dam 24. 64

Figure 32. Fraction of total hardware cycles for water-head differential from 1980 to 1994 - Lock and Dam 24

\section{List of Tables}

Table 1. Selected fields from the LPMS 12

Table 2. Estimates of Hardware-Cycle Reduction for Selected Values of $\delta t$ and $N_{v}$ Using $\alpha=0.5$.

Table 3. Observed and Fitted Annual Numbers of Lockages for Lock and Dam 24

Table 4. Observed and Fitted Annual Numbers of Lockages for Locks 22 and 11

Table 5. Total of Lockages and Hardware Cycles for Lock and Dam 24 
Table 5. Total of Lockages and Hardware Cycles for Lock and Dam 24............ 30

Table 6. Summary of Lockages from 1980 to 1994 for Lock and Dam 24 ......... 41

Table 7. Summary of Hardware Cycles from 1980 to 1994 for Lock and Dam 24

Table 8. Data for Tailwater Elevation and Hardware Cycles Histogram ..............51

Table 9. GEM Forecasts of Tonnage and Computed Lockages for Lock and

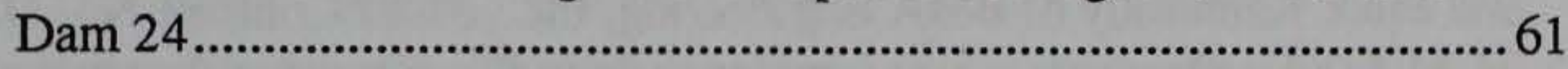

Table 10. GEM Forecasts of Tonnage and Computed Hardware Cycles for Lock and Dam 24 ................................................................................ 61

Table 11. Impact of Water-Head Differential on Fatigue Reliability ....................65 


\section{Preface}

The work reported herein was funded under the Operations and Maintenance (O\&M) Reliability Models Research Program at the U.S. Army Engineer Waterways Experiment Station (WES). It was performed by Drs. Bilal M. Ayyub and Mark Kaminskiy of BMA Engineering, Inc., under Contract No. DACW-3994-M-5483 with assistance and guidance from Dr. Mary Ann Leggett and Mr. Robert C. Patev, Computer-Aided Engineering Division (CAED), Information Technology Laboratory (ITL), WES. The work was coordinated with Headquarters, U.S. Army Corps of Engineers (HQUSACE), by Mr. Anil Chowdury of the Operations Division, Directorate of Civil Works, and Messrs. Don Dressler and Jerry Foster of the Engineering Division, Directorate of Civil Works. The authors of the report are Drs. Ayyub and Kaminskiy of BMA Engineering, Inc., and Mr. Patev and Dr. Leggett, WES. The work was performed under the general supervision of Mr. H. Wayne Jones, Acting Chief, CAED, ITL, and Dr. N. Radhakrishnan, Director, ITL.

At the time of publication of this report, Director of WES was Dr. Robert W. Whalin. Commander was COL Bruce K. Howard, EN. 


\section{Conversion Factors, Non-SI to SI Units of Measurement}

Non-SI units of measurement used in this report can be converted to SI (System Internationale) units by applying the following factors:

\begin{tabular}{|l|l|l|}
\hline Multiply & By & To Obtain \\
\hline \hline feet & 0.3048 & meters \\
\hline miles (U.S. statute) & 1.6094 & kilometers \\
\hline tons & 907.185 & kilograms \\
\hline
\end{tabular}




\section{Introduction and Background}

This report describes the prediction of loading cycles on miter gates for use in the assessment of fatigue reliability for miter gates. The report explains the correlation of field data for pool and tailwater elevations and barge traffic to form a loading histogram to be utilized to better predict the loading history of a miter gate.

Miter gates at navigation locks experience loading cycles from emptying and filling of a lock's chamber as they are opened to allow traffic through the navigation locks. Reliability analysis of miter gates at navigation locks requires the definition of: (a) nonperformance modes, (b) loads, (c) structural strength, and (d) methods of reliability analysis. Due to the cyclic-loading nature of miter gates, the fatigue of critical details requires examination using reliability methods. The assessment of fatigue reliability of these details as a function of time requires the knowledge of strength, stress ranges, and loading cycles for these details.

The strength of fatigue details can be expressed in the form of Stress-range versus Number of cycles (S-N) curves. The determination of stress ranges requires analyzing the reliability of miter gates under different loading conditions. The number of loading cycles needs to be determined also because it constitutes an important component in the reliability analysis, in addition to its use in determining the reliability as a function of time. As a result of the analysis, an evaluation of the remaining life of critical fatigue details in miter gates can be made. The accuracy of the assessed remaining life depends in part on the accuracy in the utilized loading cycles in the reliability analysis.

\section{Objectives}

The study that is reported herein had the following objectives:

a. Reviewing previous U.S. Army Corps of Engineers (USACE) studies for determining loading cycles for miter gates at navigation locks.

$b$. Determining the factors that affect the loading cycles of miter gates at navigation locks. 
c. Developing a methodology for computing the number of loading cycles of miter gates at navigation locks.

d. Assessing future traffic using the General Equilibrium Model (GEM) ${ }^{1}$, and relating its results to loading-cycles number for miter gates.

e. Demonstrating the use of the GEM for assessing future traffic, and in relating its results to the number of loading cycles.

f. Demonstrating the methodology using a case study.

\section{Literature Review}

The fatigue failure mode is commonly considered in detail design, after principal structural members have been sized. Several procedures have been used for the assessment of fatigue damage (Wirsching 1984, Wirsching and Chen 1987), such as deterministic methods, Spectral method, Weibull model, and NolteHasford model. For example, the Spectral method was used for marine structures. As was demonstrated by Chen and Mavrakis (1988), the Spectral method is more accurate than the Weibull model for the case of offshore platforms because its results are less sensitive with respect to the variability in the shape of the wave spectra compared to the results of the Weibull model. However, the Spectral method is also the most computationally intensive. Fatigue reliability can be evaluated by using Munse's model (Munse et al. 1982), Wirsching's model (Wirsching 1984), or advanced second moment methods (Madsen, Skjong, and Moghtaderi-Zadeh 1986). A reliability-based design format for fatigue was demonstrated by White and Ayyub (1987).

Fatigue can result from the cyclic loading applied to miter gates of navigation locks as they are operated to perform lockages of vessels going through the locks. Cyclic loading on a gate is generated by the cyclic head and tailwater pressures on the gate. Therefore, variable amplitude stress ranges are applied to critical fatigue details of the gate. These stress ranges cause damage to the details that is cumulative in nature until a crack initiates, then propagates to a possible failure of the affected structural members of the gate. Miner's rule of cumulative fatigue damage under variable amplitude stress range with stress-range versus number of cycles to failure ( $\mathrm{S}-\mathrm{N}$ ) information about fatigue details can be used to assess the reliability of the details (American Society of Civil Engineers (ASCE), Committee on Fatigue and Fracture Reliability 1982; White and Ayyub 1987; Ricles and Leger

\footnotetext{
'For convenience, symbols and abbreviations are listed in the notation (Appendix B).
} 
1993; Sommer, Nowak, and Thoft-Christensen 1993; USAEWES 1994). The details of fatigue analysis of miter gates are provided in ETL 1110-2-346 (Headquarters, Department of the Army 1993a). Also, ETL 1110-2-351 (Headquarters, Department of the Army 1993b) covers fatigue analysis of spillway gates.

Fatigue reliability requires the definition of the S-N curves for the fatigue details with their associated uncertainties, and the cyclic variable amplitude stress ranges with their modeling uncertainty in the form of stress range histograms (Ayyub and White 1990; Ayyub, White, and Purcell 1989; Ayyub et al. 1990; USACE 1994; White and Ayyub 1987). Therefore, the data needed for fatigue reliability assessment are (a) types of fatigue details, (b) statistical description of the S-N curves for the fatigue details (Fisher et al. 1970, 1974), (c) materials and their strength and stiffness properties such as the modulus of elasticity and Poisson ratio, (d) structural geometry and dimensions, (e) joint histograms of loading cycles and water heads on both sides of the gate as a function of time, and (f) modeling uncertainties in Miner's rule and computed stresses. The applied loads can also include impact and vibration loads. Their effect on fatigue depends on the occurrence frequency of their stress ranges. Several recent USACE studies on fatigue and concrete deterioration include information on loading cycles of miter gates at navigation locks. These studies were examined for any information and techniques that pertain to this study (Headquarters, Department of the Army 1993a; Headquarters, Department of the Army 1993b; USAEWES 1994). 


\section{Factors Affecting Loading Cycles}

The number of loading cycles for miter gates is a random variable with inherent uncertainty resulting from sources that include the following:

a. Navigation traffic volume.

b. Traffic composition primarily in terms of tow length.

c. Length and capacity of navigation locks.

d. Traffic direction and pattern.

e. Weather-related conditions, e.g., ice buildup and debris.

f. Impact loads.

The loading cycles need to be expressed in a form that is suitable for computing variable-amplitude stress ranges with associated loading cycles. Therefore, the loading cycles should be related to pool and tailwater elevations.

The navigation traffic volume is an important factor in determining the number of cycles. The number of cycles is increased by increasing the traffic volume. However, the relationship is complicated by the traffic composition in terms of tow-length distribution. Tows are typically longer than most navigational locks, and are passed through a lock in several sections or cuts and reassembled afterwards. The number and length of the cuts in a tow is dependent upon the lock's dimensions.

Traffic in navigation locks can be in either an upstream or downstream direction or both. In cases where the traffic includes the simultaneous upstream and downstream movements, the gates can be operated more efficiently by alternating between the two types of traffic, hence utilizing each loading cycle of the gates in moving the traffic.

Winter weather conditions affect the loading cycles, especially ice buildup in the upper approach regions of locks. Some locks are completely closed to river traffic during the winter because of ice buildup on the river; other locks are operated year-round. Sometimes, miter gates are operated for the purpose of passing ice flows to reduce ice buildup in the upper approach, and to relieve any pressure on 
the gates. The loading cycles for managing the ice flow are usually not recorded in operational logs (Patev 1995).

Sometimes barges or boats apply a load to miter gates due to unintentional impact resulting from poor judgment of tow operators, poor hydraulic conditions, or inclement weather. Even though these impact loads can cause damage to the gates, they are not considered in this report for assessing fatigue reliability. 


\section{Information Sources for Assessing Loading Cycles}

\section{Lock Performance Monitoring System (LPMS)}

The USACE Lock Performance Monitoring System (LPMS) includes information such as lock number, lockage date, start of lockage, direction of lockage, number of cuts, entry type, exit type, end of lockage, and tonnage. LPMS entries can be used to compute loading cycles needed for fatigue-reliability evaluation. However, the computation of these cycles from the LPMS can require a significant level of effort due to the structure of LPMS.

\section{Lockmaster Records}

Lockmasters maintain records that might contain information on loading cycles of miter gates. For this study several navigation locks were selected for a field trip after consultation with USACE. A field trip to the sites of these locks was undertaken. The records of the locks were examined. Information that can be used in developing the methodology for this study was gathered. The field trip included Locks and Dams 22, 24, and 25 on the Mississippi River.

\section{Hydraulic Records}

Hydraulic-operation records include pool and tailwater elevations that can be obtained on daily basis. These records are needed for assessing loading cycles with associated water heads. The USACE records were found to be suitable for water-head load estimation. The pool elevation (or height) of water $\left(H_{p}\right)$ and the tail elevation (or height) of water $\left(H_{t}\right)$ are needed. These quantities need to be computed on a daily basis starting from the beginning of the LPMS (i.e., January $1980)$ to the present. The heights $\left(H_{p}, H_{t}\right)$ can be used to compute stresses and stress ranges at critical fatigue locations, whereas the number of repetitions of the pairs $\left(H_{p}, H_{t}\right)$ produces the needed frequency of the corresponding stress ranges. Therefore, stress-range frequency histograms necessary for fatigue analysis can be produced. The number of repetitions of the pairs $\left(H_{p}, H_{t}\right)$ can be computed from data in the LPMS. 


\section{Uncertainty in Loading Cycles}

The number of loading cycles for miter gates is considered in this study to be a random variable. The sources of uncertainty in assessing loading cycles are due to the factors discussed previously. The uncertainty in the number of loading cycles can be expressed using a probability distribution for this number. Also, the water elevations with the associated loading cycles need to be expressed in probabilistic terms. Prediction models that can be developed based on statistical analyses of data include statistical variability that needs to be assessed. Modeling uncertainty that is associated with computing stresses at critical fatigue locations of miter gates needs also to be considered in performing fatigue reliability assessment. 


\section{Methodology for Determining Loading Cycles}

\section{Stages for Computing Loading Cycles}

The methods needed for determining loading cycles for miter gates is dependent upon the nature of available information. The type of available information depends on the years (i.e., time period) of interest. Loading cycle estimates should cover the entire life of a gate since these estimates are needed for fatigue analysis. The life of the gate can be viewed to consist of its present age plus the planned remaining life. Estimates of loading cycles up to the present can be determined using methods that depend on the type of available information. Estimates of future loading cycles need to be based on forecasting models of future traffic in navigation channels.

In this chapter, the terms lockage, lockage cut, hydrostatic loading cycles, and hardware cycles are used. In general, a lockage is defined as a series of events required to transfer a tow or vessel with all its barges through a lock in a single direction. For the purposes of this report, a lockage cut is defined as a process of passing one cut of a tow or several vessels together through a lock. This process requires the operation of the gates of the lock (the emptying and filling of a lock's chamber) once, if the gates are favorably positioned to an inbound cut of a vessel. If a vessel can be accommodated in the lock in its entirety, then one emptying and one filling of the lock's chamber are required. Also, if several vessels can be simultaneously accommodated in the lock, then one emptying and one filling of the lock's chamber are required. However, if a vessel is too large to be accommodated in the lock, it is separated in two or more cuts. Several lockage cuts in this case are required in order to pass through all the cuts by emptying and filling the lock's chamber several times. The number of lockage cuts in this case is equal to the number of cuts passed in the lock. If a lock's state is not in a favorable position to receive an inbound vessel, an additional cycle of emptying and filling of the lock's chamber is required. A hydrostatic loading cycle consists of a complete emptying and filling of a lock's chamber that produces a hydrostatic water-head differential on the gates. A hardware cycle is a complete emptying or filling of a lock's chamber that produces a hydrostatic water-head differential on the gates. Therefore, a hydrostatic loading cycle consists of two hardware cycles. 
A key source of information for estimating loading cycles on miter gates is the USACE LPMS. The LPMS generally covers the period from 1980 to present.

The time period before 1980 can be broken down into several stages depending on the available information. For example, it can be broken down into two stages, start of life (completion of construction, e.g., around late 1930's and early 1940's for most locks on the Mississippi River) to 1948 , and 1948 to 1980 . It seems that formal traffic record keeping for these locks was not established until the late 1940 's.

In consideration of the above description of the nature of available information on the utilization of locks, the following stages can be identified for developing methods for estimating loading cycles:

Stage 1: Start of life (e.g., 1940) to 1948.

Stage 2: 1948 to start of the LPMS (i.e., 1980).

Stage 3: Start of LPMS (1980) to present.

Stage 4: Present to planned design (or rehabilitation) life.

In this chapter, methods for assessing loading cycles for these stages were developed. Stage 3 (i.e., the LPMS stage) contains information of the highest levels of data quality and certainty. Therefore, this stage can be used as a basis for estimating some of the parameters in other stages as described below.

\section{Loading cycles for Stage 3 (start of LPMS to present)}

This stage contains the best and needed information to evaluate loading cycles on miter gates. The primary source of information is the LPMS; therefore, this stage is called hereafter the LPMS stage.

In the LPMS stage, the following quantities are of interest: (a) pool elevation (or height) of water $\left(H_{p}\right)$, (b) tail elevation (or height) of water $\left(H_{t}\right)$, and (c) the corresponding number of repetitions of the pair $\left(H_{p}, H_{t}\right)$. Due to the observed daily variability in the water elevations, these quantities need to be computed on a daily basis starting from January 1980 to present. The heights $\left(H_{p}, H_{t}\right)$ can be used to compute stresses and stress ranges at critical fatigue locations, whereas number of repetitions of the pairs $\left(H_{p}, H_{t}\right)$ produces the needed frequency of the corresponding stress range. Therefore, stress-range frequency histograms that are necessary for fatigue analysis are produced. The daily upper and lower water pool 
heights $\left(H_{p}, H_{t}\right)$ can be obtained from the hydraulic records of a lock as discussed in Chapter 3.

The number of repetitions of the pairs $\left(H_{p}, H_{t}\right)$ can be computed from data in the LPMS. The fields of the LPMS that are shown in Table 1 can be utilized for this purpose. These fields are defined in the LPMS user's manual (USACE 1990). The number of hardware cycles in a day (LR-SHFT-DY) for a selected month (LR-SHFT-MO), a selected year (LR-SHFT-YR), and a selected lock (LR-LOCK) can be computed from Table 1 by considering for the start of lockage, end of lockage, entry type, exit type, vessel type, and direction of traffic in its computation. Several algorithms were developed to compute hardware cycles from the fields in Table 1. Some of these algorithms produced erroneous results due to some ambiguity in the meaning of some fields of the LPMS. Considering these trials, some fields of the LPMS can be improved to facilitate the computations of hardware cycles. For example, the following observations are made:

a. The current entry and exit types do not necessarily reflect the turnback type, if it was delayed, i.e., not immediate to an entry or exit, respectively. Depending on the use of these fields in their current forms, either new fields should be developed that correct for the delayed turnback occurrence, or the current fields should be revised.

b. Sometimes several vessel records were entered in the LPMS as separate lockages, but these vessels were serviced in the same operation of opening and closing of miter gates. The LPMS does not keep track of these cases, thereby complicating the computation of hardware cycles. The start of a lockage and end of a lockage were used to account and correct for this factor.

c. Ice and debris lockages are not included in the LPMS. The results of time-lapsed videotapes of Locks 22 and 25 were used to assess these cycles (Patev 1995).

d. The operations of the gates for service, inspection, or performance evaluations are not recorded in the LPMS.

Considering the above, the daily numbers of hardware cycles were computed using the following logic:

a. The number of cuts NC (i.e., LR-NO-CUTS field) was corrected to account for cases that involve several vessels serviced by the same lockage. Therefore, a new field was added to Table 1 called the corrected number of cuts (CNC). The entry of this field for the $i$ th record in a 
month was computed using the following logic statement in spreadsheet form:

$\mathrm{CNC}(i)=\operatorname{IF}(\mathrm{AND}(\mathrm{DY}(i)=\mathrm{DY}(i+1), \mathrm{OR}(\mathrm{ABS}(\mathrm{SOL} 1(i+1)-\operatorname{SOL} 1(i))$ $<=13, \operatorname{ABS}(\operatorname{EOL} 1(i+1)-\operatorname{EOL1}(i))<=10), \mathrm{NC}(i+1)=\mathrm{NC}(i), \operatorname{VT}(i)<>$ "R"), $\mathrm{NC}(i)-1$, $\mathrm{NC}(i))$

The variables in Equation 1 are defined in Table 1, where, for example, DY $(i)=$ day of shift for the $i$ th record in a month, and VT $(i)<>$ "R" means the vessel type of this record does not equal " $R$ " which corresponds to a recreational vessel. Equation 1 is based on an EXCEL $\left(\right.$ Microsoft $\left.^{\circ}\right)$ logical statement of the following type:

$\mathrm{IF}($ logical expression, expression if TRUE, expression if FALSE)

b. Another new field was introduced called hardware cycles (HC) for the $i$ th record in a month. This field was computed using the following logic statement:

$$
\mathrm{HC}(i)=2 * \mathrm{CNC}(i)-1+\operatorname{IF}(\mathrm{DR}(i)=\mathrm{DR}(i+1), 1,0)
$$

c. The daily number of hardware cycles was then computed by totaling the values of $\mathrm{HC}(i)$ over all $i$ values (i.e., records) that are in the same day.

d. The daily number of lockages (LG) was then computed by totaling the values of $\mathrm{CNC}(i)$ over all $i$ values (i.e., records) that are in the same day.

e. The daily hardware-cycle and lockage numbers were then corrected by adding cycles needed to pass through ice and debris. These additional cycles can be estimated based on time-lapsed videotapes, if available.

$f$. The monthly number of hardware cycles was then computed by totaling the values of items $c$ and $e$ over each month.

g. The monthly number of lockages was then computed by totaling the values of items $d$ and $e$ over each month. 


\begin{tabular}{|c|c|c|}
\hline \multicolumn{3}{|c|}{$\begin{array}{l}\text { Table } 1 \\
\text { Selected Fields from the LPMS }\end{array}$} \\
\hline Field Number & Field Name & Description \\
\hline 1 & LR-LOCK & Lock Number (LN) \\
\hline 7 & LR-SHFT-MO & Month of Shift (MO) \\
\hline 8 & LR-SHFT-DA & Day of Shift (DY) \\
\hline 9 & LR-SHFT-YR & Year of Shift (YR) \\
\hline 10 & LR-SOL-1 & $\begin{array}{l}\text { Start of Lockage Time }(24 \mathrm{hr}) 1 \mathrm{st} \text { Cut } \\
\text { (SOL1) }\end{array}$ \\
\hline 12 & LR-DIR & Direction of Lockage (up or down) (DR \\
\hline 13 & LR-NO-CUTS & Number of Lockage Cuts (NC) \\
\hline 14 & LR-LCKG-TYPE & Lockage Type (LT) \\
\hline 15 & LR-VSL-TYPE & Vessel Type (VT) \\
\hline 18 & LR-ENTRY-TYPE & Entry Type (ET) \\
\hline 19 & LR-EXIT-TYPE & Exit Type (XT) \\
\hline 26 & LR-EOL-1 & $\begin{array}{l}\text { End of Lockage Time }(24 \mathrm{hr}) \text { First Cut } \\
\text { (EOL1) }\end{array}$ \\
\hline 31 & LR-EOL-2 & $\begin{array}{l}\text { End of Lockage Time }(24 \mathrm{hr} \text { ) Last Cut } \\
\text { (EOL2) }\end{array}$ \\
\hline 78 & LR-TONS & Tonnage (TN) \\
\hline
\end{tabular}

The logic above is based on the assumption that the idle gate position of a lock is its position at the end of the previous lockage. The logic above accounts for the additional hydrostatic loading cycles needed to position the gates in a favorable position for receiving incoming vessels to the lock. This effect was accounted for by considering the sequences for the direction of traffic. The entry and exit types recorded in the LPMS were found to be unsuitable for this purpose because these entries show only the immediate entry or exit types, respectively.

The data reduction and analysis of the hydraulic records and the LPMS's fields produce daily quantities for pool water elevation $\left(H_{p}\right)$, tailwater elevation $\left(H_{t}\right)$, number of hardware cycles (HC), and number of lockage cuts (LGC). These results can be used to compute the loading cycles of interest by following the steps below:

Step 1. Use curve-fitting to develop a relationship between pool water elevation and tailwater elevation. The result can be expressed as pool water elevation as a function of tailwater elevation.

Step 2. Sum the numbers of hardware cycles for intervals of tailwater elevations. Normalizing the number of hardware cycles by the total number of hardware cycles produces tailwater elevations with associated fractions of hardware cycles, i.e., a histogram of tailwater elevation in which tailwater elevation is treated as a loading.

Step 3. Fit a probability density function to the histogram from Step 2. 
Step 4. Determine the total number of hardware cycles and lockage cuts on monthly and yearly bases from the daily records.

Step 5. Use curve-fitting to establish relationships among the following variables: hardware cycles, lockage cuts, tonnage, and time. The tonnage for a lock over some time period can be computed from the fields of LPMS as the total weight of commodities that pass through the lock within this time period. These relationships are needed in other stages as discussed below. The relationships can be developed using monthly or annual records.

The models that result from Steps 3 and 5 constitute the basis for assessing the loading cycles. These models can be expressed in dimensionless format by normalizing them with respect to corresponding design values. For example, the tailwater loading probability density function (Step 4) can be normalized with respect to the tailwater elevation design value for an investigated lock. The benefit of expressing the results in a normalized format is in potentially increasing the range of applicability of the results to other locks. In general, locks and dams along a river can be classified into groups (or reaches). A typical lock can be analyzed from each reach and several locks in a selected reach can be analyzed to produce a complete understanding of loading cycles on miter gates. Future work in this area can examine the relationships and variability among the reaches and within reaches.

\section{Loading cycles for Stage 1 (start of life to 1948)}

Stage 1 is defined as the stage from the start of life of a lock to about 1948. The end of this stage (i.e., 1948) was established based on the record-keeping practices of the USACE for locks on the Mississippi River. This stage can be characterized as a stage with inadequate records that are needed to compute loading cycles. Generally, the information available from records in this stage is limited to annual tonnage. Therefore, the relationships of hardware cycles and lockage cuts as functions of tonnage that were developed in the LPMS (third) stage can be used to estimate hardware cycles and lockage cuts, respectively, for this stage. Alternatively, the number of hardware cycles as a function of time and the number of lockage cuts as a function of time that were developed in the LPMS stage can be used to estimate these quantities by extrapolation. The former approach is recommended in this report because its results are partly based on data in the first stage. 


\section{Loading cycles for Stage 2 (1948 to start of LPMS)}

Stage 2 is defined as the stage from about 1948 to the start of the LPMS stage. The start of this stage (i.e., 1948) was established based on the record-keeping practices of the USACE for locks on the Mississippi River. This stage can be characterized as a stage with better records than the first stage that are needed to compute loading cycles. Generally, the available information in this stage is limited to annual lockages and annual tonnage. Therefore, the relationships of hardware cycles and lockage cuts as functions of tonnage that were developed in the LPMS (third) stage can be used to estimate hardware cycles and lockages, respectively. Alternatively, the number of hardware cycles as a function of time and the number of lockages as a function of time that were developed in the LPMS stage can be used to estimate these quantities using extrapolation.

\section{Loading cycles for Stage 4 (present to planned end of design life or rehabilitation)}

Stage 4 starts from the present and ends with the planned end of design (or rehabilitation) life of a lock. The models in this stage can be based on forecasting techniques. The scope of this report does not include the development of forecasting models. However, the USACE General Equilibrium Model (GEM) (USACE 1994) can provide forecasts of annual tonnage as a function of time based on a set of input variables. The predictions of traffic volumes are expressed in the forms of low, medium, and high tonnage predictions as functions of time. Therefore, the relationships of hardware cycles and lockages as functions of tonnage that were developed in the LPMS (third) stage can be used to estimate hardware cycles and lockage cuts, respectively, for this stage.

\section{Probabilistic Model}

The objective of the model proposed below is to predict the number of hardware cycles on miter gates as a function of either the number of vessels passing through a lock or the number of lockage cuts that occur at a lock. The model accounts for the following factors: (a) navigation traffic volume, (b) traffic composition in terms of vessel lengths, (c) length and capacity of navigation locks, (d) traffic pattern (in terms of upstream/downstream ratio), and (e) non-vessel lockages (loading cycles connected with passing ice and debris). 


\section{Relationship between number of hardware cycles and number of vessels (i.e., traffic volume)}

The development of the relationship between the number of hardware cycles and the number of vessels (or traffic volume) is divided into the following four cases:

a. The increase in the number of hardware cycles due to cutting of long vessels, assuming the traffic is in one direction.

b. The effect of simultaneous lockages of light boats or recreational vessels.

c. The decrease in the number of hardware cycles due to travel in opposite (upstream and downstream) directions.

d. The effect of environmental conditions (debris and ice lockages).

These four cases are discussed below.

Increase in number of hardware cycles due to cutting of long vessels. The maximum length $\left(l_{\max }\right)$ of a vessel that can be locked in one operation of a lock and the cumulative distribution function of length of the vessel population $\left(F_{L}(l)\right)$ determine the number of needed cuts. The length of the vessel population is a discrete random variable with the following cumulative distribution function:

$$
F_{L}(l)=\sum_{\text {for } 1_{\mathrm{i}} \leq l} p_{L}\left(l_{i}\right) \quad \text { for } i=1,2, \ldots, N L
$$

where $p_{L}\left(l_{i}\right)=$ probability mass value for a vessel of a length $l_{i}$ for $N L$ possible discrete vessel lengths. The continuous approximation of this distribution function is an integral of the corresponding probability density function $f_{L}(l)$ :

$$
F_{L}(l)=\int_{0}^{l} f_{L}(x) d x
$$

The arrival of vessels in one direction at a lock can be assumed to follow a Poisson distribution with a rate $\lambda$. For a time period of interest $(T)$, which is nonrandom, the mean number of vessels that arrives at the lock during the time $T$ is

$$
\bar{N}_{v}=\lambda T
$$


where $\bar{N}_{v}=$ mean number of vessels arriving in time $T$. The probability $\left(P_{1}\right)$ that a vessel is not cut in two or more parts is given by

$$
P_{1}=F_{L}\left(l_{\max }\right)
$$

The probability $\left(P_{2}\right)$ that a vessel is cut in two parts is given by

$$
P_{2}=F_{L}\left(2 l_{\max }\right)-F_{L}\left(l_{\max }\right)
$$

Analogously, the probability $\left(P_{k}\right)$ that the vessel is cut in $k$ parts is given by

$$
P_{k}=F_{L}\left(k l_{\max }\right)-F_{L}\left[(k-1) l_{\max }\right]
$$

where $k=$ number of parts into which vessels can be cut. In general, the probability that for a given number of vessels $N_{v}$ exactly $N_{l}$ vessels will not be cut, $\mathrm{N}_{2}$ will be cut in two parts, and so on, is given by the multinomial distribution with parameters $N_{v}, P_{1}, P_{2}, \ldots, P_{k}$.

The probabilities $P_{1}, P_{2}, \ldots, P_{k}$ should satisfy the following condition:

$$
\sum_{i=1}^{k} P_{i}=1
$$

If $N_{v}$ (the number of vessels that arrive at a lock in one direction during reference time period $T$ ) is a nonrandom variable, the number of vessels with one or more parts $\left(i=1,2, \ldots, k\right.$ parts) due to cutting has the following mean $\left(\bar{N}_{1}\right)$, and variance $\left(\operatorname{Var}\left(N_{l}\right)\right)$, respectively:

$$
\bar{N}_{1}=N_{\nu} P_{1}
$$

and

$$
\operatorname{Var}\left(N_{1}\right)=N_{\nu} P_{1}\left(1-P_{1}\right)
$$

The number of vessels which are cut in two parts has the following mean $\left(\bar{N}_{2}\right)$ and variance $\left(\operatorname{Var}\left(\mathrm{N}_{2}\right)\right)$, respectively:

$$
\bar{N}_{2}=N_{v} P_{2}
$$


and

$$
\operatorname{Var}\left(N_{2}\right)=N_{v} P_{2}\left(1-P_{2}\right)
$$

The number of vessels which are cut in $k$ parts has the following mean $\left(\bar{N}_{k}\right)$ and variance $\left(\operatorname{Var}\left(N_{k}\right)\right)$, respectively:

$$
\bar{N}_{k}=N_{\nu} P_{k}
$$

and

$$
\operatorname{Var}\left(N_{k}\right)=N_{\nu} P_{k}\left(1-P_{k}\right)
$$

For an inbound vessel to a lock with its gates in a favorable position (i.e., a fly entry with lock chamber pool at incoming elevation) that needs to be cut into $i$ parts, the number of hardware cycles $\left(\bar{N}_{H C i}\right)$ is related to $N_{v}$ and $P_{i}$ according to Equation 3 as

$$
\bar{N}_{H C i}=(2 i-1) N_{v} P_{i} \quad \text { for } i=1,2, \ldots, k
$$

Therefore, the mean of the total number of hardware cycles $\left(\bar{N}_{H C}\right)$ can be related to the number of vessels as

$$
\bar{N}_{H C}=N_{v}\left(P_{1}+3 P_{2}+5 P_{3}+\ldots+(2 k-1) P_{k}\right)
$$

or

$$
\bar{N}_{H C}=N_{v}\left[\left(\sum_{i=1}^{k} P_{i}\right)+2 P_{2}+4 P_{3}+\ldots+2(k-1) P_{k}\right]
$$

Using Equation 10, the mean total hardware cycles can be expressed as

$$
\bar{N}_{\Sigma l c}=N_{l o c}\left[1+\sum_{i=2}^{k}(i-1) P_{i}\right]
$$


The variance of the total number of hardware cycles can be written as

$$
\operatorname{Var}\left(\dot{N}_{H C}\right)=N_{v}^{2} \sum_{i=1}^{k} 4(i-1)^{2} P_{i}\left(1-P_{i}\right)
$$

Decrease in number of hardware cycles due to simultaneous lockages of small vessels. It is common in operating locks to simultaneously service a number of small vessels, as is the case for light boats and recreational boats. The effect of this practice on hardware cycles is a reduction in its total number. Therefore, the above approach can be generalized to take this decrease into account. Let $p_{s}$ be the probability that a given boat is being serviced simultaneously with other boats, then the mean total number of hardware cycles should be decreased by the value $\Delta N_{H C}$

$$
\Delta N_{H C}=N_{v} p_{s}
$$

The combination of Equations 19 and 22 produces

$$
\bar{N}_{H C}=N_{v}\left[1+\sum_{i=2}^{k} 2(i-I) P_{i}-2 p_{s}\right]
$$

In this case, the following condition needs to hold

$$
\sum_{i=1}^{k} P_{i}+p_{s}=1
$$

The mean of the total number of hardware cycles according to Equation 23 is a linear function of the number of vessels for traffic in one direction. For cases where $\bar{N}_{H C}>N_{v}$, the increase in the number of hardware cycles due to the cutting of long vessels prevails over the decrease in the number of hardware cycles due to simultaneous lockages of small vessels, and vice versa.

In the LPMS database, the number of lockage cuts $\left(N_{l o c}\right)$ for vessels is defined as

$$
N_{l o c}=N_{\text {cuts }}
$$


where $N_{\text {cuts }}=$ number of cuts, then Equation 25a can be rewritten using Equations 11,13 , and 15 as

$$
N_{l o c}=N_{v} \sum_{i=1}^{k} i P_{i}
$$

where $N_{\text {cuts }}$ takes the values of $1,2,3, \ldots, k$, in which 1 corresponds to a vessel without a cut. In this case, Equations 17, 22, and 23 produce the following:

$$
\bar{N}_{H C}=\left(2 N_{l o c}-1\right)-N_{v} p_{s}
$$

Equation 26a can be rewritten using Equation $25 \mathrm{~b}$ to produce the following relationship between mean total hardware cycles and number of lockages cuts:

$$
\bar{N}_{H C}=\left(2 N_{l o c}-1\right)-p_{s} \frac{N_{l o c}}{\sum_{i=1}^{k} i P_{i}}
$$

\section{Decrease in number of hardware cycles due to travel in opposite}

directions. In order to model the effect of two-direction traffic on hardware cycles, let $\lambda_{u}$ be the Poisson rate of traffic moving upstream, $\lambda_{d}$ be the Poisson arrival rate to a lock for traffic moving in the downstream direction, and $N_{v d}$ and $N_{v u}$ be the overall number of vessels arriving to a lock from downstream and upstream directions during the reference period $T$, respectively. If $\delta t_{d}$ is the service time in the lock for a vessel in the downstream traffic, the mean decrease in the number of hardware cycles $\left(\Delta N_{H C d}\right)$ for a steady-state traffic is

$$
\Delta N_{H C d}=N_{v d} \lambda_{u p} \delta t_{d}
$$

Since $N_{v d}+N_{v u}=N_{v}$, the downstream number of vessels $N_{v d}=N_{v}(1-\alpha)$, where $0 \leq$ $\alpha \leq 1, N_{v u}=\alpha N_{v}$, and $\alpha=$ fraction of traffic moving upstream. Using the estimate $\lambda_{u}=N_{v} / T$, Equation 27 can be expressed as

$$
\Delta N_{H C d}=\frac{\alpha(1-\alpha) N_{v}^{2} \delta t_{d}}{T}
$$

Analogously, the mean decrease in the number of hardware cycles due to the traffic in the opposite (upstream) direction is

$$
\Delta N_{H C u}=\frac{\alpha(1-\alpha) N_{v}^{2} \delta t_{u}}{T}
$$


where $\delta t_{u}$ is the service time in the lock for a vessel in the upstream traffic, and $\Delta N_{H C u}$ is the mean decrease in the number of hardware cycles in the upstream traffic. The sum of Equations 28 and 29 is the total decrease in the number of hardware cycles $\left(\Delta N_{H C t}\right)$, which can be expressed as

$$
\Delta N_{H C t}=\frac{\alpha(1-\alpha) N_{v}^{2}\left(\delta t_{u}+\delta t_{d}\right)}{T}
$$

Equation 30 makes sound physical sense. For example, the total decrease has a maximum value when the upstream traffic is equal to the downstream traffic, i.e., $\alpha=0.5$. Equation 30 can be re-written as

$$
\Delta N_{H C t}=\frac{\alpha(1-\alpha) N_{v}^{2} 2 \delta t}{T}
$$

where $\delta t=\delta t_{\text {up }}+\delta t_{\text {down }} / 2$. Table 2 shows estimates of hardware-cycle reduction for selected values of $\delta t$ and $N_{v}$ using $\alpha=0.5$, and $\mathrm{T}=8,760$ hours (i.e.,

\begin{tabular}{|c|c|c|}
\hline \multicolumn{3}{|c|}{$\begin{array}{l}\text { Table } 2 \\
\text { Estimates of Hardware-Cycle Reduction for Selected Values of } \delta t \\
\text { and } N_{v} \text { Using } \alpha=0.5\end{array}$} \\
\hline$d t$ (hours) & For $N_{v}=1,000$ vessels per year & $\begin{array}{l}\text { For } N_{v}=2,000 \text { vessels per } \\
\text { year }\end{array}$ \\
\hline 0.25 & 14 & 57 \\
\hline 0.5 & 29 & 114 \\
\hline 1 & 57 & 228 \\
\hline 2 & 114 & 457 \\
\hline 3 & 171 & 685 \\
\hline 4 & 228 & 913 \\
\hline
\end{tabular}
one year).

A strong seasonal variation in the number of vessels can result in considerable variation of $\alpha$. Thus, in this case, the number of vessels passing through the lock cannot be considered to be a Poisson process. Under this restriction, Equation 6 needs to be used as follows:

a. The reference time period in this case can be taken as a month, i.e., $T_{i}$ where $i=1,2, \ldots, 12$.

$b$. The fraction of upstream traffic is $\alpha_{i}$, which is related to the $i$ th month. 
c. The number of vessels in the ith month is $N_{v i}$, so that if $N_{v}$ is the annual number of vessels, then

$$
N_{v i}=\beta_{i} N_{v}
$$

where $\beta_{i}$ is the fraction of vessels in the ith month from the traffic of a year. Therefore, the following condition needs to be satisfied:

$$
\sum_{i=1}^{12} \beta_{i}=1
$$

The set of $\beta_{i}$ values expresses the monthly distribution of annual traffic in both directions. It should be noted that neither $\beta_{i}$ nor $\alpha_{i}$ depends on the absolute value of the annual number of vessels $N_{v}$. Thus, in this case, Equation 31 takes on the following form:

$$
\Delta N_{H C t}=\frac{2 \delta t N_{v}^{2}}{T} \sum_{i=1}^{12} \alpha_{i}\left(1-\alpha_{i}\right) \beta_{i}^{2}
$$

or

$$
\Delta N_{H C t}=\frac{2 \delta t N_{v}^{2}}{T} K
$$

where $K=\sum_{i=1}^{12} \alpha_{i}\left(1-\alpha_{i}\right) \beta_{i}^{2}$ is a coefficient for expressing seasonal variation in traffic volume and direction.

Hardware cycles due to non-vessel lockages. Some of the hardware cycles for miter gates can be attributed to non-vessel lockages such as the passing of debris and ice especialy during the winter months. If these lockages are recorded in the LPMS as real lockages with the appropriate numbers of hardware cycles, they can be taken into account by the model by adding a term to Equation 23 . If these lockages are not recorded in the LPMS, then their hardware cycles can be taken into account by adding a positive constant term in any developed regression models to fit real data for the number of hardware cycles and annual tonnage as described below. 


\section{Relationship between hardware cycles and lockages using regression analysis}

In this section, an example regression model is developed in order to establish a relationship between hardware cycles and lockage cuts using real data, e.g., based on the LPMS. Equations 23 and 31 can be combined to obtain the following model for monthly data with a constant term (Constant) that corresponds to the hardware cycles associated with non-vessel lockages and can be added to the model. This constant would not be needed if these non-vessel lockages were recorded in the LPMS as actual lockages with the appropriate numbers of hardware cycles. The equation for this model is given by

$$
\bar{N}_{H C}=N_{\nu}\left[1+\sum_{i=2}^{k}(i-1) P_{i}-2 p_{s}\right]-\frac{\alpha(1-\alpha) N_{v}^{2} 2 \delta t}{T}+\text { Constant }
$$

The mean hardware cycles according to Equation 36a can be expressed in terms of $N_{l o c}$ instead of $N_{v}$ based on Equations $25 \mathrm{~b}$ and $26 \mathrm{~b}$ as

$$
\bar{N}_{H C}=\left(2 N_{l o c}-1\right)-p_{s} \frac{N_{l o c}}{\sum_{i=1}^{k} i P_{i}}-\frac{\alpha(1-\alpha) 2 \delta t}{T} \frac{N_{l o c}^{2}}{\left(\sum_{i=1}^{k} i P_{i}\right)^{2}}+\text { Constant }
$$

or

$$
\bar{N}_{H C}=A N_{l o c}-B N_{l o c}^{2}+C
$$

where $A, B, C$ are model coefficients with $B \geq 0$. Figure 1 shows a scatter diagram of lockage cuts and hardware cycles using the annual data that are provided in Chapter 5. The scatter diagram shows a linear relationship between hardware cycles and lockage cuts, i.e., $B=0$ in Equation 37. A linear regression analysis was then performed. For the case $B=0$ and $C=0$, coefficient $A$ has the same meaning as $K_{c}$ used in the GEM (USACE 1994), i.e., the mean hardware cycles per lockage. An estimate of the correlation coefficient was obtained to be 0.999 . The estimates of the coefficients of Equation 37 and their corresponding standard errors are given by

$$
\begin{gathered}
A=1.67898 \pm 0.0213 \\
B=0 \text { (not significant) } \\
C=-55.1587 \pm 134.07 \text { (not significant) }
\end{gathered}
$$




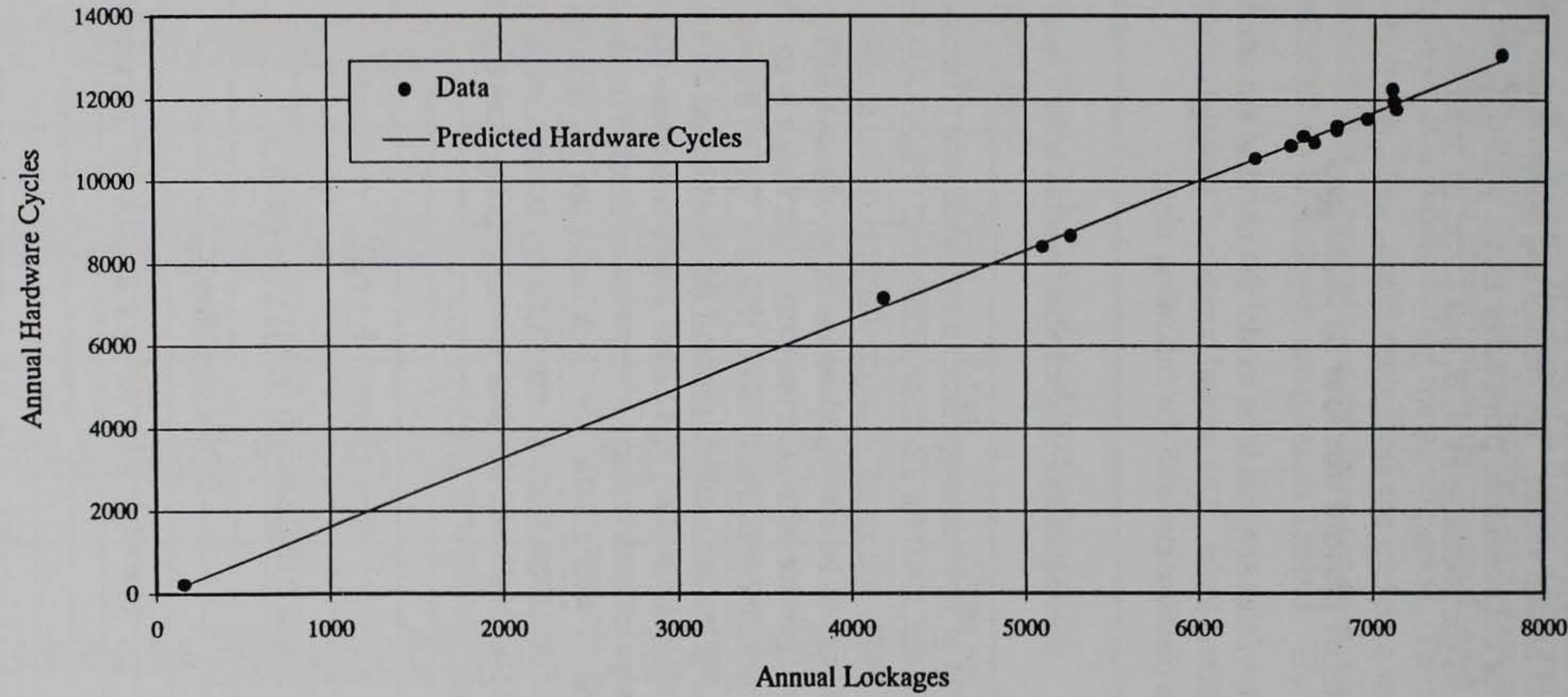


Based on the data used in this analysis, only the coefficient $A$ is significant, and should be kept in the model. The developed model is of an adequate precision level for all practical purposes since the standard error of estimates is 148.85 for a sample size of 15 annual values. The results and observations provided herein are lock-specific. For datá obtained from other locks, with different patterns of traffic, the significance of the coefficients $A, B$, and $C$ can be different.

\section{Trend analysis of annual number of lockages}

The objective of this analysis is to model the trend of the annual number of lockages for selected locks. The annual number of lockages is considered to follow a Poisson distribution with the following mean

$$
N_{l o c}(t)=N_{o} \exp \left(A t+B t^{2}+C t^{3}+\ldots .\right)
$$

where $t$ is the time in years counted from a specified year (for example 1948 for Locks 11 and 22, and 1940 for Lock and Dam 24). Thus $t=0$ for 1948 (or 1940), $t=1$ for 1949 (1941), and so on. The coefficients of the model, i.e., $N_{0}, A, B$, and $C$, are the parameters to be estimated on the basis of curve fitting of the data. In other words, the sequence of annual numbers of lockages is considered to be a realization of a nonhomogeneous Poisson process. To fit the model of Equation 41 to the data, a regression analysis method that was based on counts with logarithmic transformation (Cox and Lewis 1966) was used. The significance of the coefficients was estimated using a stepwise regression procedure. Models for Locks 24, 22, and 11 were fitted. For Lock and Dam 24, the following estimates of the coefficients and their standard errors were obtained using the data in Table 6 for the years 1981 to 1993 and the data provided in the major rehabilitation report for Lock and Dam 24 (USACE 1993c):

$$
\begin{gathered}
N_{o}=1306.66 \pm 1.06 \\
\left.\mathrm{~A}=0.050249 \pm 0.003411 \text { (in years }{ }^{-1}\right) \\
\mathrm{B}=0 \text { (not significant) } \\
\mathrm{C}=-7.4844 \times 10^{-6} \pm 1.2260 \times 10^{-6}\left(\text { in years }^{-3}\right)
\end{gathered}
$$


The correlation coefficient for the model is 0.955 . The variance of the residuals of the annual lockages is 80154.6. The corresponding standard error for the model is 283.1. The accuracy of the model can be also assessed using the sum of fitted values of the number of lockages during the given period. The sum is equal to 225132 which does not differ considerably from the real data value of 227147 (the difference is about $0.9 \%$ ). The observed and fitted (or predicted using the model) values of annual numbers of lockages are given in Table 3 . The results are also shown in Figure 2.

\begin{tabular}{|c|c|c|c|c|c|}
\hline \multicolumn{6}{|c|}{$\begin{array}{l}\text { Table } 3 \\
\text { Observed and Fitted Annual Number of Lockages for } \\
\text { Lock and Dam } 24\end{array}$} \\
\hline Year & Observed & Fitted & Year & Observed & Fitted \\
\hline 1940 & 1718 & 1307 & 1971 & 5250 & 4964 \\
\hline 1941 & 2212 & 1374 & 1972 & 5584 & 5104 \\
\hline 1942 & 1409 & 1445 & 1973 & 4914 & 5242 \\
\hline 1943 & 1050 & 1519 & 1974 & 5157 & 5375 \\
\hline 1944 & 1119 & 1597 & 1975 & 5058 & 5503 \\
\hline 1945 & 1213 & 1678 & 1976 & 5386 & 5625 \\
\hline 1946 & 1817 & 1763 & 1977 & 5235 & 5741 \\
\hline 1947 & 1705 & 1853 & 1978 & 5668 & 5849 \\
\hline 1948 & 2178 & 1946 & 1979 & 5778 & 5949 \\
\hline 1949 & 2551 & 2043 & 1980 & 6601 & 6040 \\
\hline 1950 & 2258 & 2144 & 1981 & 6788 & 6121 \\
\hline 1951 & 1990 & 2249 & 1982 & 6319 & 6193 \\
\hline 1952 & 2027 & 2357 & 1983 & 7108 & 6253 \\
\hline 1953 & 2335 & 2470 & 1984 & 6595 & 6302 \\
\hline 1954 & 2435 & 2587 & 1985 & 5099 & 6338 \\
\hline 1955 & 2981 & 2707 & 1986 & 5262 & 6363 \\
\hline 1956 & 3146 & 2831 & 1987 & 6523 & 6373 \\
\hline 1957 & 3288 & 2959 & 1988 & 7131 & 6370 \\
\hline 1958 & 3386 & 3090 & 1989 & 6787 & 6354 \\
\hline 1959 & 3698 & 3224 & 1990 & 7743 & 6324 \\
\hline 1960 & 3408 & 3362 & 1991 & 6963 & 6280 \\
\hline 1961 & 3365 & 3502 & 1992 & 7228 & 6222 \\
\hline 1962 & 3801 & 3644 & 1993 & 4189 & 6150 \\
\hline 1963 & 3827 & 3789 & 1994 & NA & 6064 \\
\hline 1964 & 4084 & 3935 & 1995 & NA & 5965 \\
\hline 1965 & 3585 & 4083 & 1996 & NA & 5854 \\
\hline 1966 & 4078 & 4231 & 1997 & NA & 5729 \\
\hline 1967 & 4211 & 4379 & 1998 & NA & 5594 \\
\hline 1968 & 4688 & 4527 & 1999 & NA & 5447 \\
\hline 1969 & 4344 & 4675 & 2000 & NA & 5290 \\
\hline 1970 & 4938 & 4820 & $\mathrm{NA}=$ not & cable or not & \\
\hline
\end{tabular}




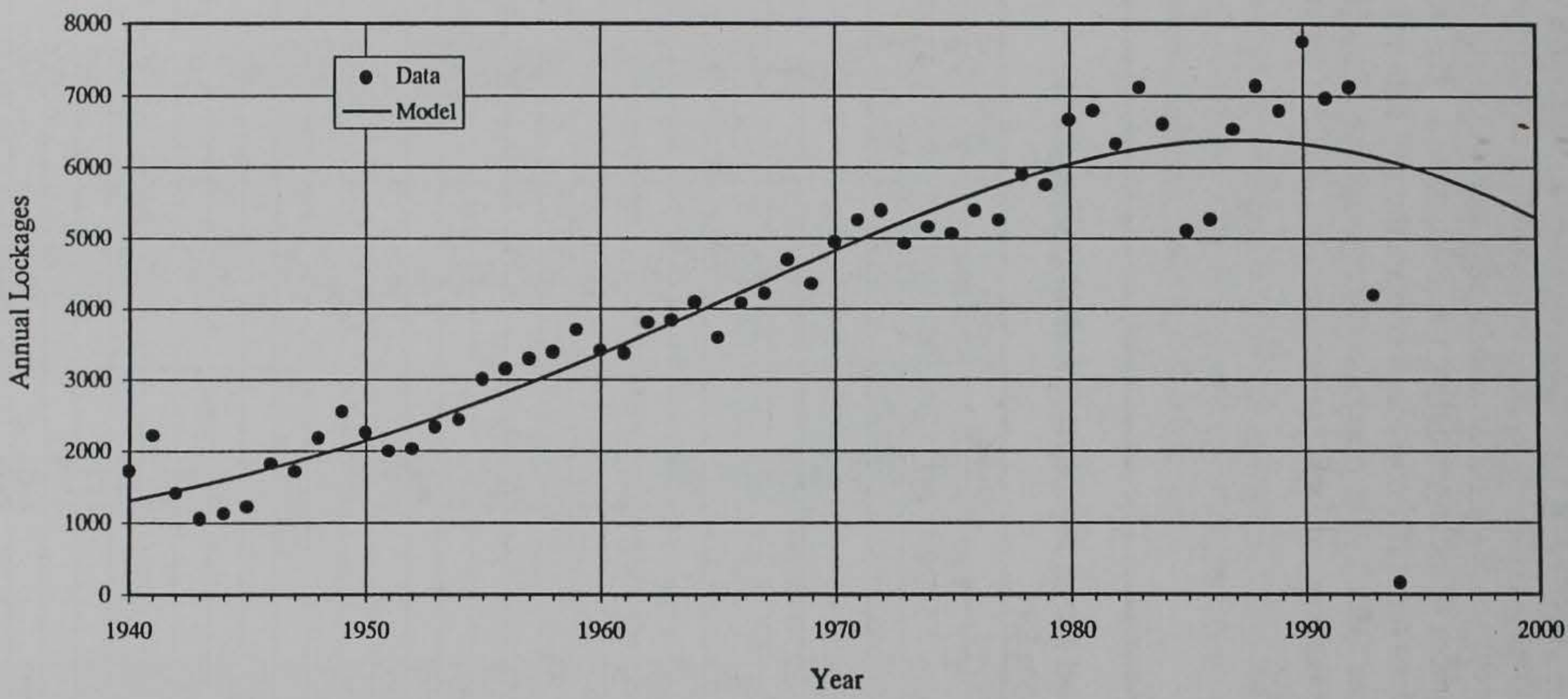

Figure 2. Observed and fitted annual number of lockages for Lock and Dam 24 
For Lock 22 the following estimates of the model coefficients and their standard errors were obtained using data provided by the USACE:

$$
\begin{gathered}
N_{o}=624.53 \pm 1.02 \\
\left.A=0.08392 \pm 0.00256 \text { (in years }{ }^{-1}\right) \\
B=0 \text { (not significant) } \\
\left.C=-0.00002 \pm 2.5 \times 10^{-6} \text { (in years }{ }^{-3}\right)
\end{gathered}
$$

The correlation coefficient for this model is 0.996 . The observed annual number of lockages and the fitted ones using the above models are given in Table 4. The results are also shown in Figure 3.

For Lock 11 the following estimates of the model coefficients and their standard errors were obtained using data provided by the USACE:

$$
\begin{gathered}
\mathrm{N}_{0}=388.00 \pm 1.04 \\
\left.\mathrm{~A}=0.10932 \pm 0.00571 \text { (in years }{ }^{-1}\right) \\
\mathrm{B}=-0.00147 \pm 0.00017 \text { (in years }{ }^{-2} \text { ) } \\
\mathrm{C}=0 \text { (not significant) }
\end{gathered}
$$

In this case, the correlation coefficient for the model is 0.992 . The observed annual number of lockages and the fitted ones using the above models are given in Table 4 . The results are also shown in Figure 3.

\section{Number of lockages as a function of tonnage}

For cases where data on the annual number of lockages are absent but the annual tonnage data are available, the relationship between annual number of lockages and tonnage can be useful to estimate the number of lockages. This relationship can be obtained on the basis of data analysis for the periods where both lockages and tonnage information is available.

The model development requires the knowledge of the number of lockages and the corresponding tonnage for a number of years. For each record value of annual number of lockages, the corresponding annual tonnage value is needed. This model does not explicitly account for recreational boats which do not have tonnage values. Therefore, the 4annual number of lockages $N_{l o c}$ can be related to annual tonnage $T_{n}$ (in kilotons) as 


$$
N_{l o c}=A T_{n}+C
$$

where the coefficient $C$ can be associated with recreational-boat lockages, or with passing ice or debris. The estimation of the coefficients for this model using Lock and Dam 24 annual datá for the period 1940 to 1993 produced the following estimates for the coefficients: $\mathrm{C}=1682.60 \pm 92.13$, and $\mathrm{A}=0.1432648 \pm$ 0.00424 . The standard error of estimates for the model is 395.96 based on 54 annual values. The correlation coefficient between annual tonnage and number of lockages is 0.978 .

\begin{tabular}{|c|c|c|c|c|}
\hline \multicolumn{5}{|c|}{$\begin{array}{l}\text { Table } 4 \\
\text { Observed and Fitted Annual Number of Lockages for Locks } 22 \text { and } 1\end{array}$} \\
\hline Year & \multicolumn{2}{|c|}{ Lock 22} & \multicolumn{2}{|c|}{ Lock 11} \\
\hline & Observed & Fitted & Observed & Fitted \\
\hline 1948 & 630 & 625 & 394 & 388 \\
\hline 1949 & 695 & 680 & 447 & 432 \\
\hline 1950 & 830 & 738 & 525 & 480 \\
\hline 1951 & 782 & 803 & 526 & 531 \\
\hline 1952 & 755 & 872 & 474 & 587 \\
\hline 1953 & 928 & 948 & 585 & 646 \\
\hline 1954 & 1015 & 1029 & 699 & 709 \\
\hline 1955 & 1159 & 1116 & 863 & 776 \\
\hline 1956 & 1197 & 1210 & 870 & 847 \\
\hline 1957 & 1298 & 1309 & 894 & 921 \\
\hline 1958 & 1466 & 1417 & 1092 & 999 \\
\hline 1959 & 1580 & 1531 & 1130 & 1081 \\
\hline 1960 & 1646 & 1651 & 1223 & 1166 \\
\hline 1961 & 1660 & 1779 & 1221 & 1254 \\
\hline 1962 & 1849 & 1914 & 1321 & 1344 \\
\hline 1963 & 2136 & 2056 & 1544 & 1437 \\
\hline 1964 & 2229 & 2204 & 1514 & 1531 \\
\hline 1965 & 2252 & 2358 & 1448 & 1627 \\
\hline 1966 & 2636 & 2517 & 1800 & 1724 \\
\hline 1967 & 2692 & 2681 & 1839 & 1822 \\
\hline 1968 & 2731 & 2851 & 1698 & 1919 \\
\hline 1969 & 3023 & 3023 & 1961 & 2015 \\
\hline 1970 & 3540 & 3198 & 2381 & 2110 \\
\hline 1971 & 3450 & 3374 & 2282 & 2203 \\
\hline 1972 & 3919 & 3550 & 2596 & 2294 \\
\hline 1973 & 3624 & 3724 & 2248 & 2381 \\
\hline 1974 & 3917 & 3895 & 2510 & 2464 \\
\hline 1975 & 3821 & 4061 & 2331 & 2543 \\
\hline 1976 & 3985 & 4221 & 2403 & 2616 \\
\hline 1977 & 4024 & 4371 & 2563 & 2683 \\
\hline 1978 & 4590 & 4512 & 2842 & 2745 \\
\hline 1979 & 4530 & 4641 & 2720 & 2800 \\
\hline 1980 & 5182 & 4756 & 3172 & 2846 \\
\hline
\end{tabular}




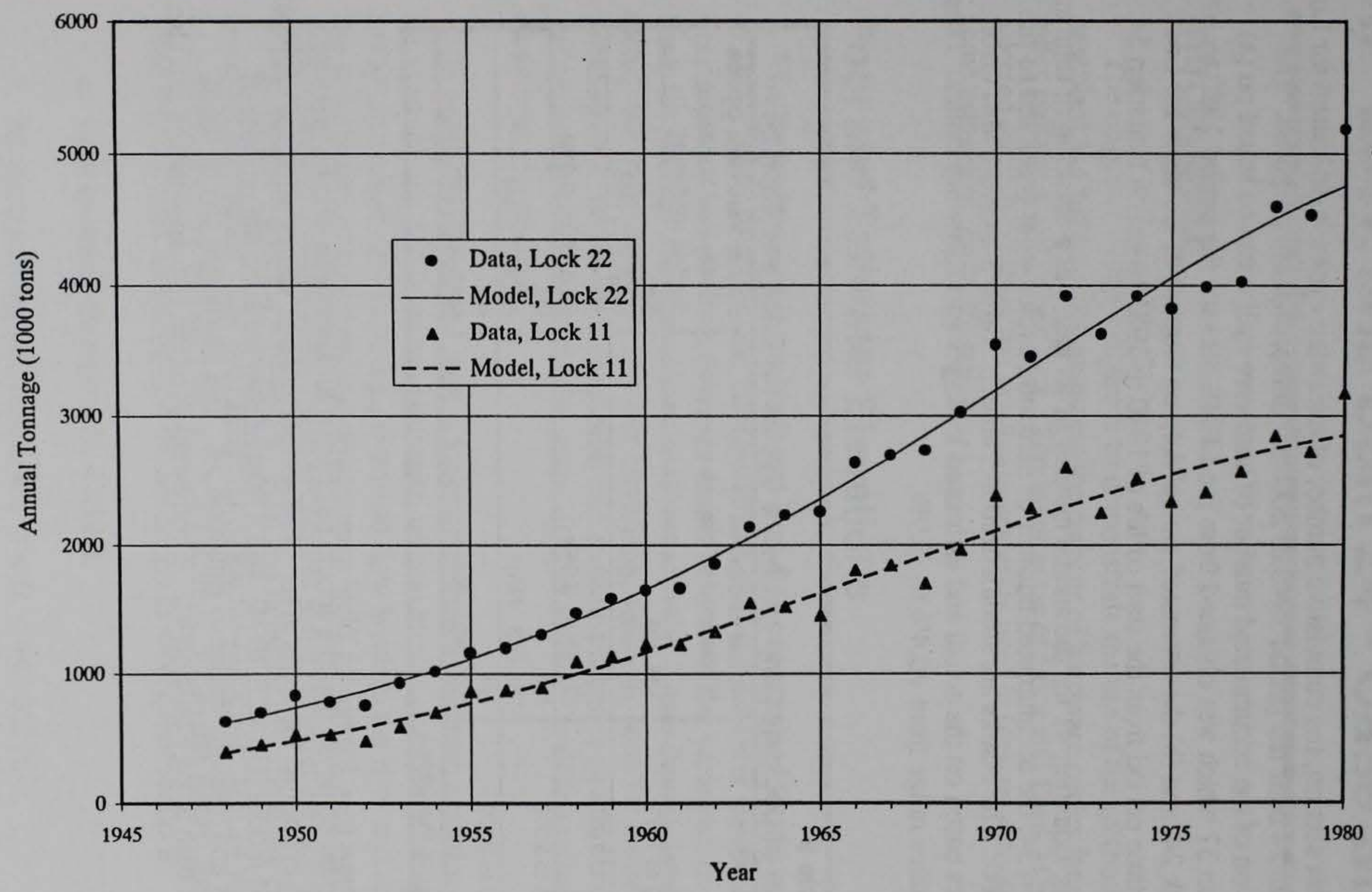

Figure 3. Observed and fitted annual number of lockages for Lock and Dam 22 and Lock and Dam 11 


\section{Estimating the cumulative number of hardware cycles}

In this section, the cumulative number of hardware cycles is estimated for Lock and Dam 24 over the period 1940 to 2000 for demonstration purposes. The estimation of the accumulated number of hardware cycles can be based on (a) Equation 37 which was obtained from the LPMS data for the period 1980 to 1992 for Lock 24, and (b) the estimated annual data on number of lockages for Lock 24 for the time period from the start of life of 1940 to 1981 based on Equation 54.

Using Equation 41 for the annual number of lockages as a function of time and Equation 34, the accumulated number of hardware cycles were predicted to the year 2000. The results are summarized in Table 5. Table 5 includes also error estimates based on the actual and estimated lockages and hardware cycles. These error values range from $+0.4 \%$ to $-2.9 \%$.

\begin{tabular}{|c|c|c|}
\hline \multicolumn{3}{|c|}{$\begin{array}{l}\text { Table } 5 \\
\text { Total of Lockages and Hardware Cycles for Lock and Dam } 24\end{array}$} \\
\hline Time Period & $\begin{array}{l}\text { Actual Lockages } \\
\text { (Estimated Lockages ; \% Error) }\end{array}$ & $\begin{array}{l}\text { Actual Hardware Cycles } \\
\text { (Estimated Hardware } \\
\text { Cycles :\% Error) }\end{array}$ \\
\hline 1940 to 1979 & $\begin{array}{l}136,919 \\
(137,445 ;+0.4 \%)\end{array}$ & $\begin{array}{l}\text { NA } \\
(228,561, N A)\end{array}$ \\
\hline 1980 to 1993 & $\begin{array}{l}90,279 \\
(87,686 ;-2.9 \%)\end{array}$ & $\begin{array}{l}150,805 \\
(146,450 ;-2.9 \%)\end{array}$ \\
\hline 1994 to 2000 & $\begin{array}{l}\text { NA } \\
(39,943 ; N A)\end{array}$ & $\begin{array}{l}\text { NA } \\
(66,677 ; N A)\end{array}$ \\
\hline 1940 to 2000 & $\begin{array}{l}\text { NA } \\
(227,360 ; N A)\end{array}$ & $\begin{array}{l}\text { NA } \\
(441,688 ; N A)\end{array}$ \\
\hline
\end{tabular}

It should be noted that the annual number of lockages can also be predicted based on economic forecasts in terms of annual tonnage values using for example the GEM model (USACE 1994), and a relationship between the number of lockages and tonnage similar to Equation 54. This prediction can be more accurate than using Equation 41. A combination of the two approaches can also be used. 


\section{Lock and Dam 24 - Case Study}

\section{Introduction}

The objective of this chapter is to demonstrate the use of the methodology as described in Chapter 4 for assessing the number of hardware cycles for example miter gates at a navigation lock. The miter gates of Lock and Dam 24 were selected for this purpose and are the sames gates used in Chapter 4 to demonstrate some aspects of the methodology.

\section{Pool and Tailwater Elevations}

The hydraulic records for Lock and Dam 24 were obtained for the period 1975 to 1994 . The daily hydraulic information on pool and tailwater elevations were obtained from the USACE. Figures $4 \mathrm{a}$ and $4 \mathrm{~b}$ show these variations on a daily basis for pool and tailwater elevations, respectively. These figures demonstrate clearly the daily variability in water elevations, hence the need for modeling the problem on a daily basis, not monthly nor annually. Figures $5 \mathrm{a}$ and $5 \mathrm{~b}$ show these variations on a daily basis for the years 1975 to 1994 for pool and tailwater elevations, respectively.

In operating a lock and dam, a lockmaster tries to maintain a pool water level by adjusting the dam's gates. However, several factors contribute to the variability in the pool water elevation; e.g., increased flow levels in the river and actions by the lockmasters of upstream and downstream locks to control pool water levels. Adjustments to a dam's gates result in changes in the tailwater elevation as well as the pool water elevation. Therefore, pool and tailwater elevations are expected to be highly correlated. The pool water elevation for Lock and Dam 24 was plotted as a function of the tailwater elevation in Figure 6. From this figure, the following three regions were identified and are described in subsequent sections:

a. Low tailwater elevation, $H_{t}<439 \mathrm{ft}$.

b. Medium tailwater elevation, $439 \mathrm{ft} \leq H_{t}<445.062 \mathrm{ft}$.

c. High tailwater elevation, $H_{t} \geq 445.062 \mathrm{ft}$. 


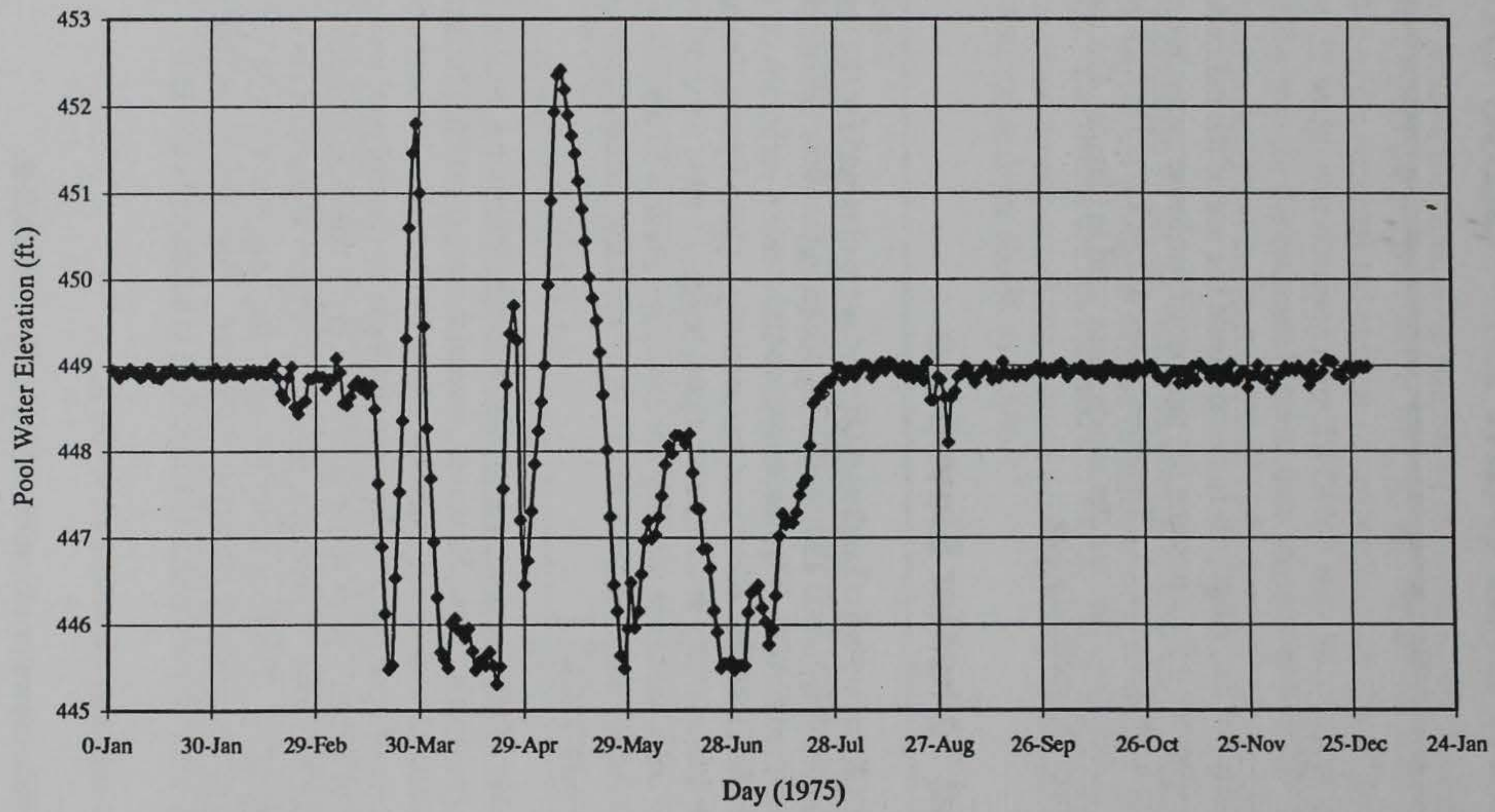

Figure 4a. Pool water elevations in 1975 for Lock and Dam 24 


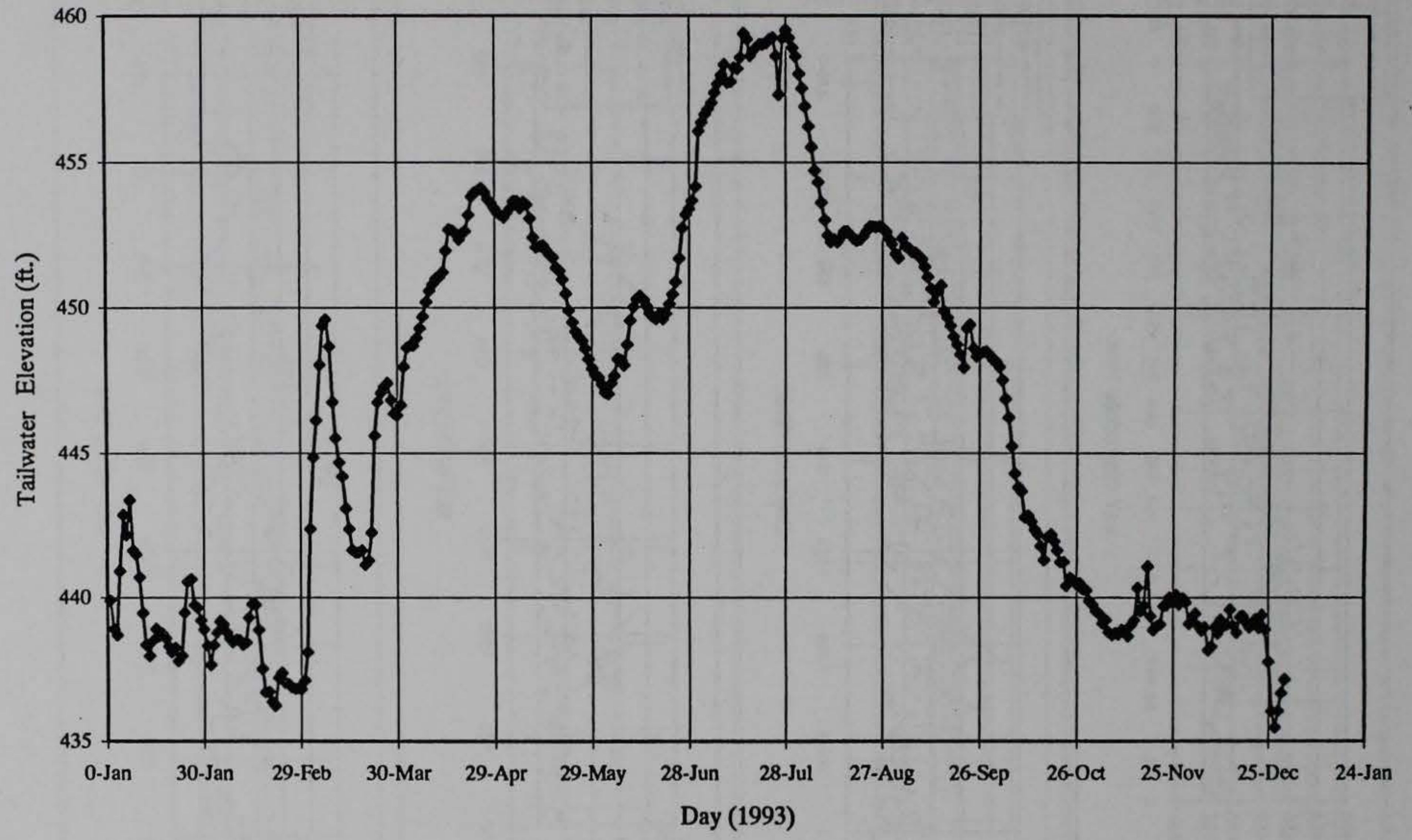

Figure 4b. Tailwater elevations in 1993 for Lock and Dam 24 

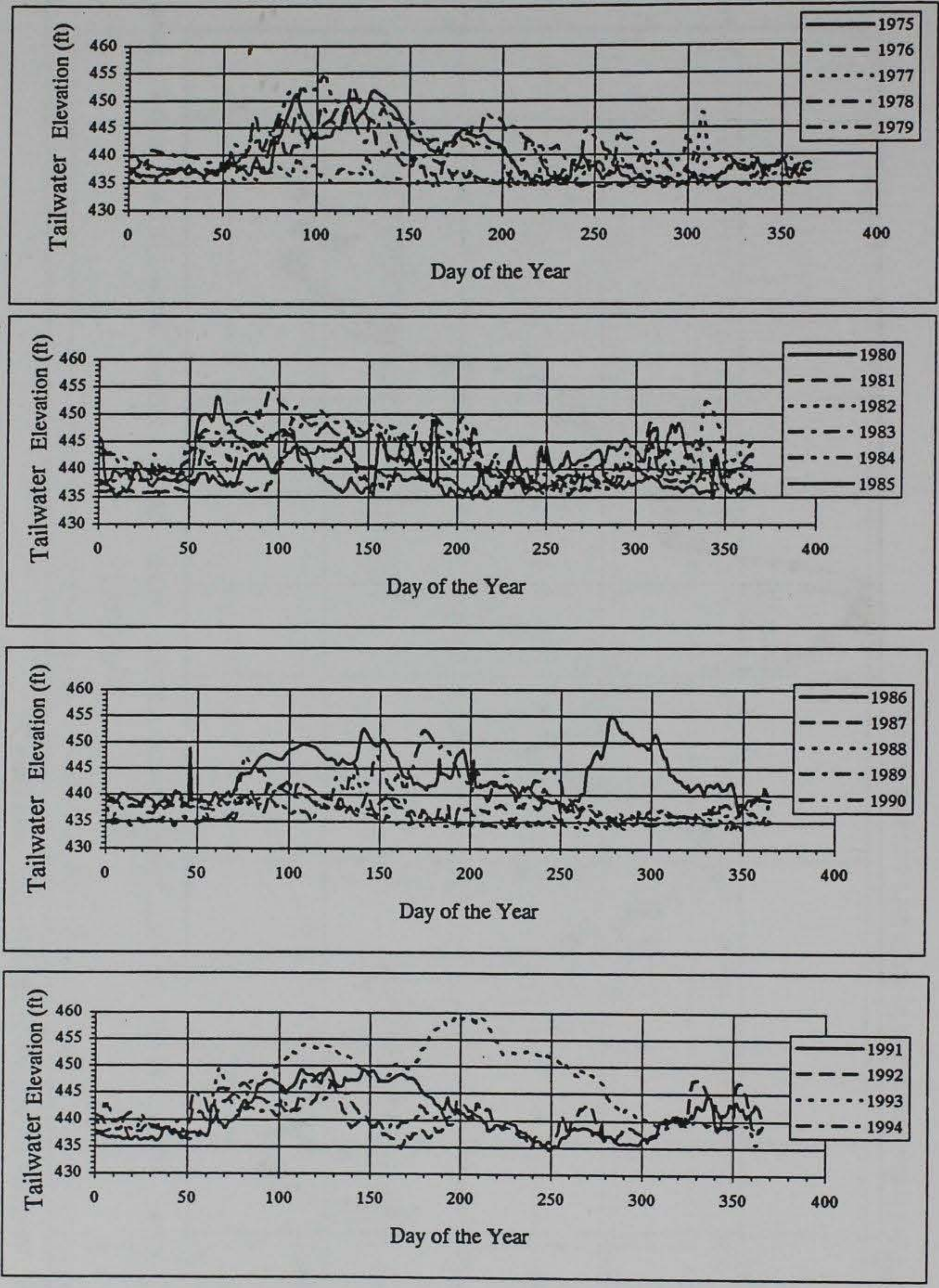

Figure 5a. Tailwater elevations for Lock and Dam 24 

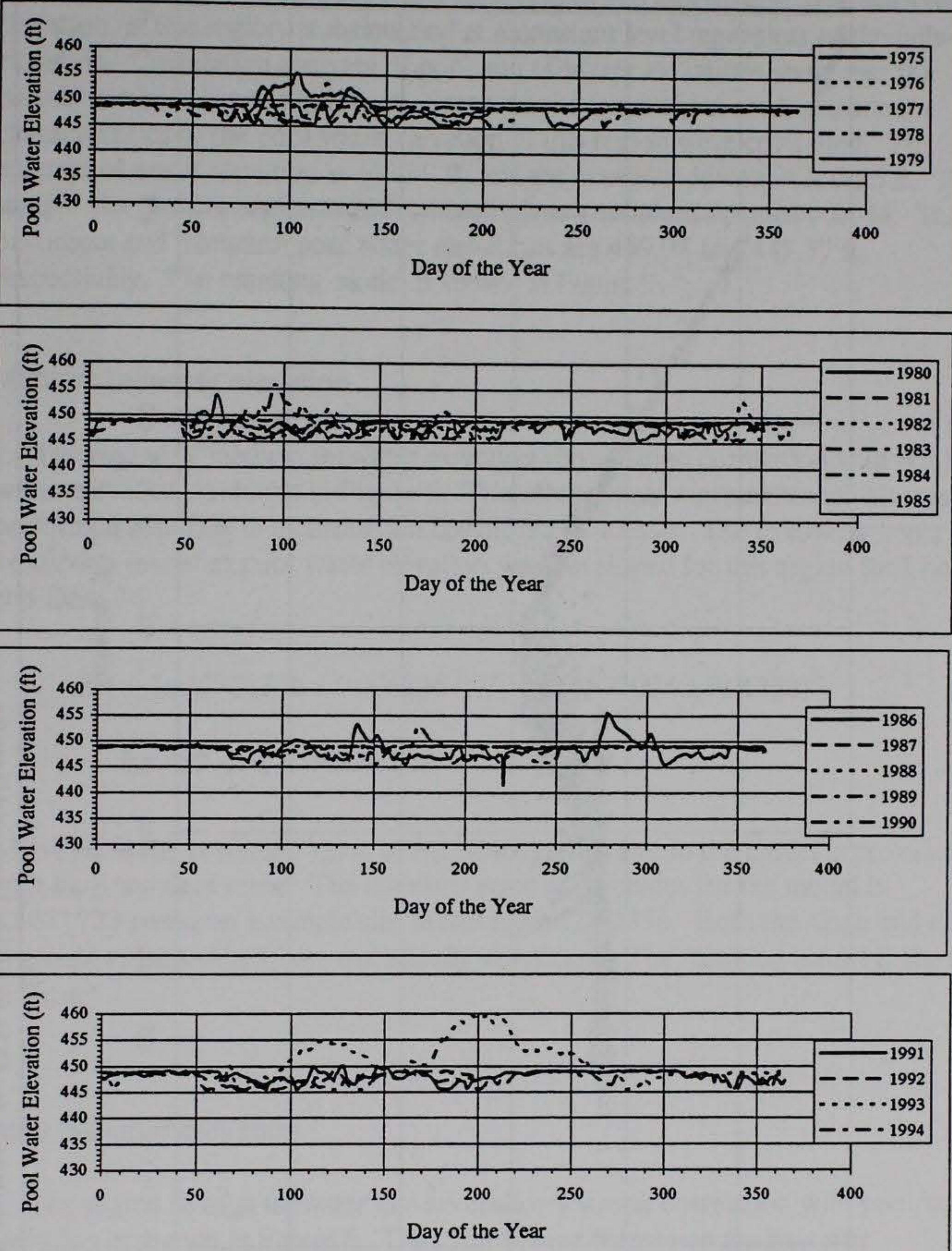

Figure 5b. Pool water elevations for Lock and Dam 24 


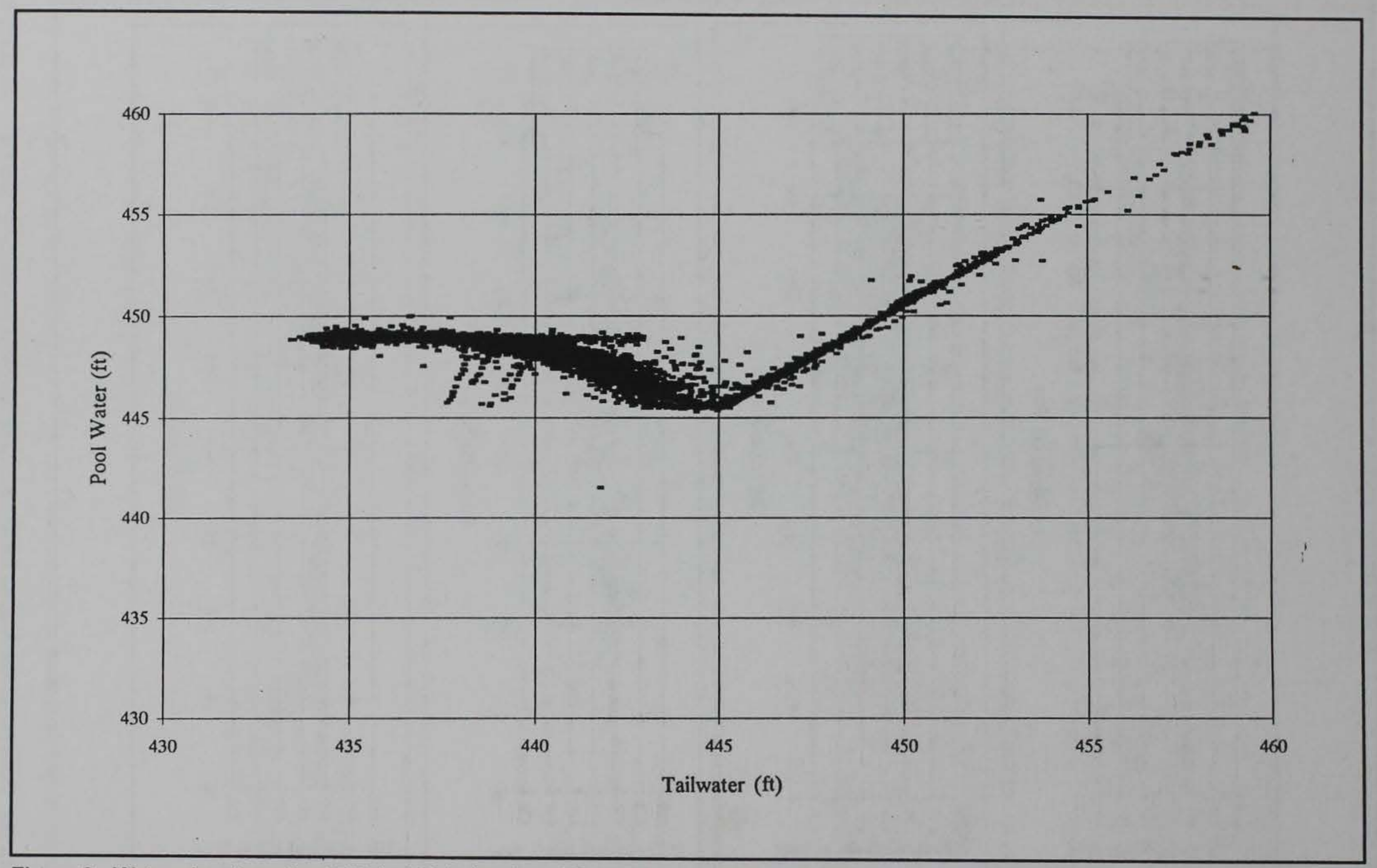

Figure 6. Water elevations for 1975 to 1994 - Lock and Dam 24 


\section{Low tailwater elevation}

It is observed that the first region can be characterized with a high level of control in maintaining the pool water elevation by the lockmaster. The pool water elevation, in this region, is maintained at a constant level regardless of the tailwater elevation. Correlation analyses of pool and tailwater elevations show that the correlation level is not significant. Based on the hydraulic record, statistical characteristics of the pool water elevation in this region were computed. The mean pool water elevation is $448.89 \mathrm{ft}$, and the standard deviation is $0.26 \mathrm{ft}$. The sample size for this region is 3579 , which gives a standard error of 0.0044 . The maximum and minimum pool water elevations are 449.98 and $445.57 \mathrm{ft}$, respectively. The resulting model is shown in Figure 7.

\section{Medium tailwater elevation}

The region of medium tailwater elevation shows some correlation with pool water elevation as shown in Figure 6. Therefore, linear regression analysis was performed resulting in a correlation coefficient of -0.858 . The following linear prediction model of pool water elevation was developed for this region for Lock and Dam 24:

$$
H_{p}=(-0.5531396 \pm 0.0068267) H_{t}+(691.72094 \pm 3.01333)
$$

$$
\text { for } \left.439 \leq H_{t}<445.062 \mathrm{ft}\right)
$$

where $H_{p}$ is the predicted value of $H_{p}$. Each coefficient in the model is provided with its \pm standard error. The standard error of estimates for the model is 0.5611723 based on a sample size in this region of 2356. Both the slope and the intercept in Equation 55 are statistically significant. The resulting model is shown in Figure 7.

\section{High tailwater elevation}

The region of high tailwater elevation shows strong correlation with pool water elevation as shown in Figure 6. Therefore, linear regression analysis was performed resulting in a correlation coefficient of 0.996 . The following linear prediction model of pool water elevation was developed for this region for Lock and Dam 24:

$$
H_{p}=(1.00118 \pm 0.00001525) H_{t} \quad \text { for } H_{t} \geq 445.062 \mathrm{ft}
$$




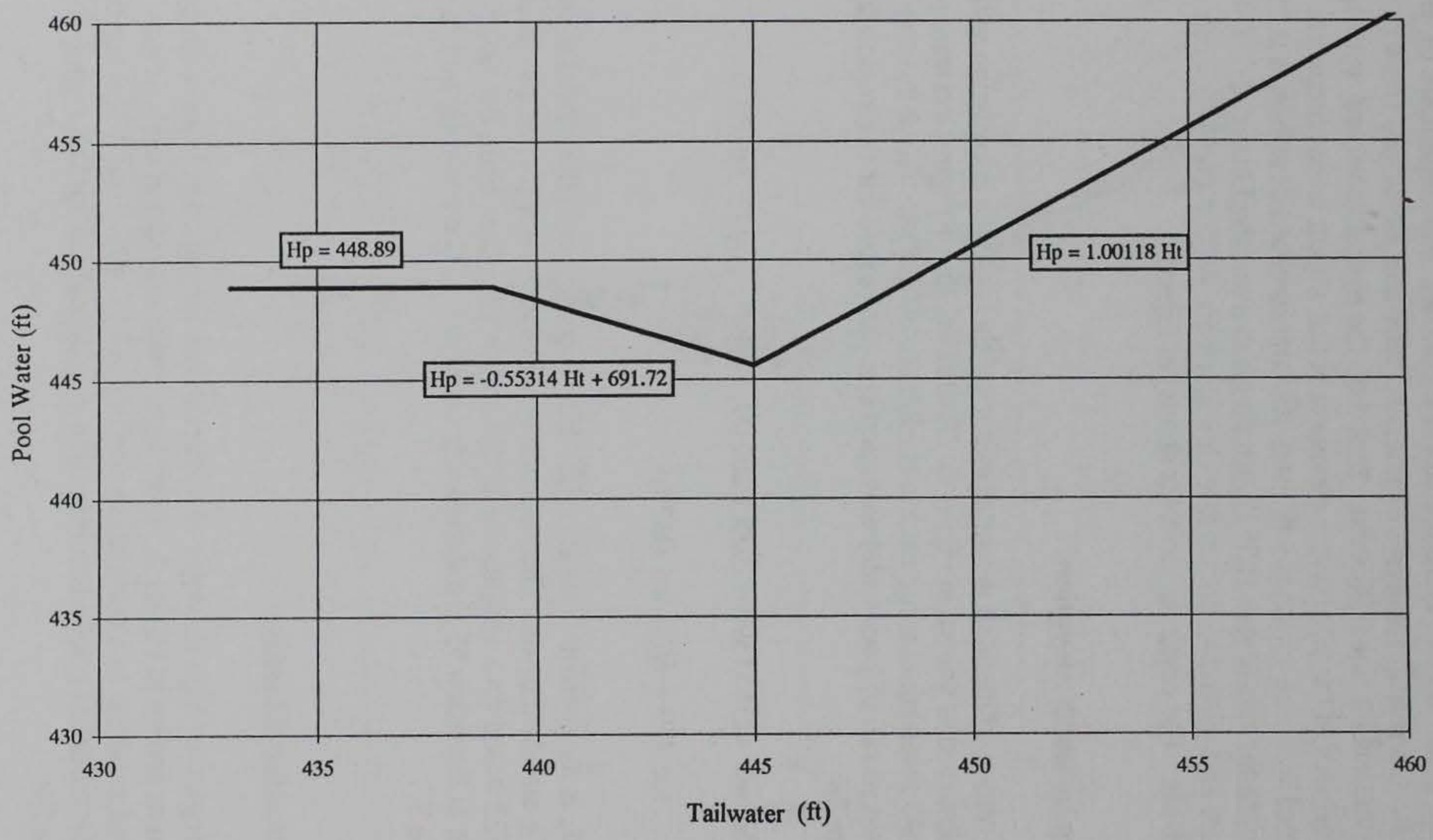

Figure 7. Model for water elevations for 1975 to 1994 - Lock and Dam 24 
The slope coefficient in the model is provided with its \pm standard error. The intercept for this model was determined to be 0 . The standard error of estimates for the model is 0.23762 based on a sample size in this region of 1207 . The resulting model is shown in Figure 7, which can be expressed as

$$
H_{p}= \begin{cases}448.89 \pm 0.0044 & H_{t}<439 f t \\ (-0.5531396 \pm 0.0068267) H_{t}+ & 439 \leq H_{t}<445.062 f t \\ (691.72094 \pm 3.01333) & \\ (1.00118 \pm 0.00001525) H_{t} & H_{t} \geq 445.062 f t\end{cases}
$$

The design pool and tailwater elevations are $449.0 \mathrm{ft}$ and $438.6 \mathrm{ft}$, respectively. Equation $56 \mathrm{~b}$ can be normalized with respect to the design pool and tailwater elevations to obtain the normalized pool water elevation $\left(H_{p n}\right)$ as a function of the normalized tailwater elevation $\left(H_{t m}\right)$ as follows:

$$
H_{p n}= \begin{cases}0.999755 \pm 0.0000097 & H_{t m}<1.000912 \\ (-0.5403274 \pm 0.0066685) H_{t n}+ & 1.000912 \leq H_{t n}<1.0147332 \mathrm{ft} \\ (1.5405812 \pm 0.0067112) & \\ (0.97799 \pm 0.0000148) H_{t m} & H_{t m} \geq 1.0147332 \mathrm{ft}\end{cases}
$$

where the normalized pool and tailwater elevations are given, respectively, by

$$
H_{p n}=\frac{H_{p}}{449.0}
$$

and

$$
H_{t n}=\frac{H_{t}}{438.6}
$$




\section{Hardware Cycles}

The computations of the daily hardware cycles were based on the data obtained from the LPMS and use of the method described in Chapter 4. The daily hardware cycles were computed and adjusted for ice hardware cycles. The adjusted daily hardware cycles are shown in Appendix A. The adjustment for the ice lockages was based on time-lapsed videotapes in the winter months of 1993-1994 for Lock and Dam 22 and Lock and Dam 25 (Patev 1995). The videotapes showed 63 and 75 ice lockages, respectively, over periods of 77 and 65 days, respectively. Therefore, one ice lockage per day was assumed and added to the computed lockage cuts from the LPMS for the months of January and February of each year. Similarly, one ice hardware cycle per day was assumed and added to the computed hardware cycles from the LPMS for the months of January and February of each year.

Using the definition of a lockage cut as the process of passing one cut of a vessel or several vessels through a lock, the number of lockage cuts on monthly and yearly bases are shown in Table 6 . The number of hardware cycles on a daily basis, and on monthly and yearly bases corrected for ice lockages are shown in Appendix A and Table 7, respectively. The number of lockage cuts are shown in Figures 8 and 9 on monthly and yearly bases. The number of hardware cycles are also shown in Figures 10 and 11 on monthly and yearly bases. The number of hardware cycles are shown in Figure 12 on a daily basis. These figures indicate the monthly, seasonal, and yearly variations of these quantities. The intention behind developing these plots was to investigate the need of developing hardware-cycle histograms based on monthly, seasonal, or yearly parameters. However, as described below, the computed small correlation level between water elevation and number of hardware cycles allowed the aggregation of all water-elevation records in one model without regard to monthly, seasonal, or yearly variations.

\section{Tailwater-Hardware Cycles Analysis}

The objective in this section is to aggregate the number of hardware cycles that are associated with the same tailwater elevation based on their daily records obtained in the sections above. A graphical correlation analysis between the hardware cycles and tailwater elevation was performed as shown in Figures 13 and 14. The estimated correlation coefficient is 0.155 which is small indicating that all daily records can be aggregated without regard to monthly, seasonal, or yearly variations. The number of hardware cycles that are associated with the same tailwater elevation were aggregated to obtain a histogram as shown in Figures 15 and 16. The histogram values are shown in Table 8. Based on the daily records of 
tailwater elevations and the corresponding hardware cycles, a weighted average of water elevation was computed to be $440.685 \mathrm{ft}$. The total number of cycles in the entire period is 150,938 . The standard deviation of the weighted tailwater elevation is $4.5817 \mathrm{ft}$. The maximum and minimum tailwater elevations are 453.71 and 433.34 , respectively.

\section{Table 6}

\section{Summary of Lockages from 1980 to 1994 for Lock and Dam 24}

\begin{tabular}{|c|c|c|c|c|c|c|c|c|c|c|c|c|c|c|c|}
\hline \multicolumn{16}{|c|}{ (Assumption: Add one ice cycle per day during Jan and Feb for all years) } \\
\hline \multicolumn{16}{|c|}{ (A lockage is the process to pass through one cut of a vessel, or more than one vessel) } \\
\hline & & & & & & & & & & & & & & & \\
\hline Month & 1980 & 1981 & 1982 & 1983 & 1984 & 1985 & 1986 & 1987 & 1988 & 1989 & 1990 & 1991 & 1992 & 1993 & 1994 \\
\hline January & 124 & 117 & 120 & 164 & 110 & 90 & 114 & 104 & 90 & 57 & 136 & 106 & & 132 & 6 \\
\hline February & 84 & 102 & 81 & 138 & 286 & 71 & 88 & 99 & कृ & 51 & 234 & 123 & 34 & 105 & 94 \\
\hline March & 346 & 566 & 419 & 481 & 608 & 433 & 374 & 447 & 560 & 452 & 685 & 555 & 710 & 466 & \\
\hline April & 606 & 706 & 651 & 493 & 790 & 589 & 483 & 604 & 761 & 726 & 772 & 740 & $7 \pi$ & 390 & \\
\hline May & 602 & 723 & 810 & 695 & 690 & 541 & 515 & 743 & 840 & 789 & 878 & 754 & 836 & ळ्27 & \\
\hline June & $\overline{673}$ & 697 & 718 & 745 & $\approx 0$ & 501 & 554 & 682 & 710 & 803 & 806 & 743 & 814 & 657 & \\
\hline July & 766 & 667 & 669 & 847 & 638 & 614 & 577 & 797 & 766 & 871 & 954 & 899 & 977 & & \\
\hline August & 859 & 803 & 785 & 833 & 691 & 559 & 676 & 838 & 823 & 732 & 886 & 857 & 893 & 241 & \\
\hline September & 841 & 698 & 643 & 819 & 613 & 532 & 583 & 709 & 771 & 707 & 752 & 61 & 709 & 674 & \\
\hline October & 765 & ब25 & 497 & 810 & 604 & 448 & 426 & 700 & 776 & 704 & 689 & 63 & 566 & 654 & \\
\hline November & 685 & 699 & 602 & 793 & 686 & 523 & 648 & 568 & 683 & 690 & 676 & 642 & 538 & & \\
\hline December & 304 & 385 & 324 & 290 & 249 & 198 & 224 & 232 & 259 & 205 & 275 & 160 & 263 & 243 & \\
\hline & & & & & & & & & & & & & & & \\
\hline TOTAL & 6655 & 6788 & ๘19 & 7108 & 6595 & 5099 & 5262 & 6523 & 7131 & 6787 & 7743 & $\dddot{9}$ & 7117 & 4189 & $1 \approx$ \\
\hline
\end{tabular}

Table 7

Summary of Hardware Cycles from 1980 to 1994 for Lock and Dam 24

\begin{tabular}{|c|c|c|c|c|c|c|c|c|c|c|c|c|c|c|c|}
\hline \multicolumn{16}{|c|}{ (Assumption: Add one ice cycle per day during Jan and Feb for all years) } \\
\hline & & & & & & & & & & & & & & & \\
\hline Month & 1980 & 1981 & 1982 & 1983 & 1984 & 1985 & 1986 & 1987 & 1988 & 1989 & 1990 & 1991 & 1992 & 1993 & 1994 \\
\hline January & 179 & 161 & 165 & 234 & 133 & 109 & 146 & 145 & 128 & $\approx$ & 191 & 133 & & 189 & 88 \\
\hline February & 96 & 153 & 97 & 201 & 464 & 86 & 116 & 139 & 124 & 54 & 351 & 172 & 9 & 146 & 128 \\
\hline March & 585 & 968 & 711 & 835 & 1052 & 740 & 633 & 776 & 970 & 788 & 1181 & 970 & 1236 & 811 & \\
\hline April & 1023 & 1217 & 1122 & 893 & 1346 & 1008 & 830 & 1015 & 1293 & 1223 & 1335 & 1276 & 1347 & 675 & \\
\hline May & 1003 & 1220 & 1347 & 1191 & 1180 & 901 & 882 & 1251 & 1405 & 1309 & 1545 & 1264 & 1420 & 1122 & \\
\hline June & 1115 & 1157 & 1222 & 1252 & 1057 & 839 & 899 & 1124 & 1175 & 1330 & 1415 & 1233 & 1383 & 1120 & \\
\hline July & 1250 & 1113 & 1100 & 1429 & 1075 & 976 & 936 & 1302 & 1220 & 1410 & 1589 & 1438 & 1632 & & \\
\hline August & 1379 & 1328 & 1315 & 1495 & 1164 & 928 & 1078 & 1404 & 1323 & 1207 & 1447 & 1352 & 1486 & 421 & \\
\hline September & 1387 & 1155 & 1064 & 1461 & 1013 & 872 & 930 & 1181 & 1261 & 1175 & 1201 & 1146 & 1128 & 1166 & \\
\hline October & 1257 & 1046 & 844 & 1413 & 1026 & 746 & 758 & 119 & 1287 & 1165 & 1176 & 1134 & 937 & 1110 & \\
\hline November & 1158 & 1175 & 1015 & 1354 & 1173 & 886 & 1100 & 970 & 1142 & 1171 & 1155 & 1126 & 918 & & \\
\hline December & 511 & 647 & 552 & 481 & 419 & 319 & 368 & 389 & 431 & 341 & 46 & 276 & 443 & 410 & \\
\hline & & & & & & & & & & & & & & & \\
\hline IAL & 10943 & 11340 & 10554 & 12239 & 11102 & 8410 & 8676 & 10865 & 11759 & 11236 & 13052 & 11520 & 11939 & 7170 & 216 \\
\hline
\end{tabular}




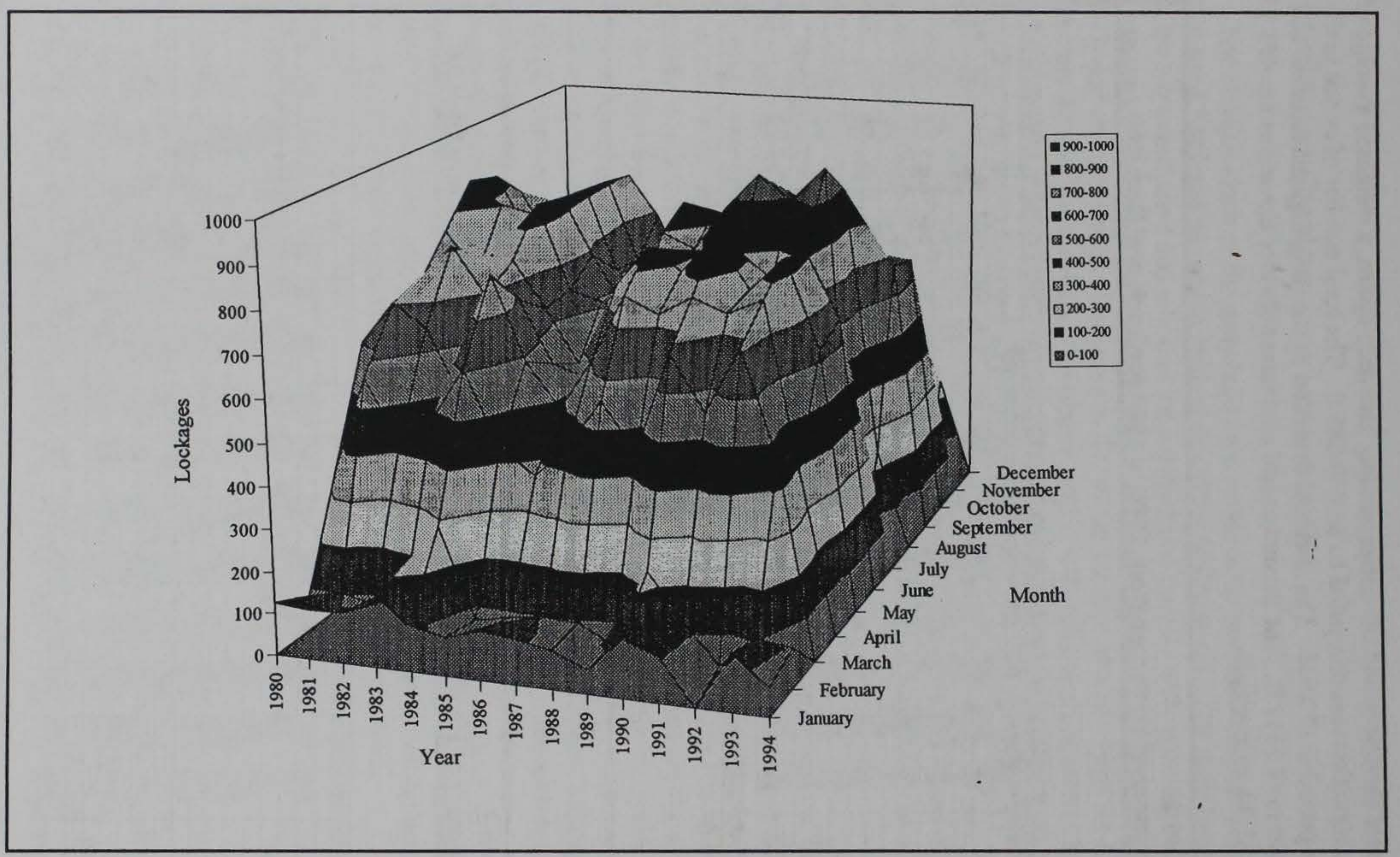

Figure 8. Summary (3-dimensional) of lockages for 1980 to 1994 - Lock and Dam 24 


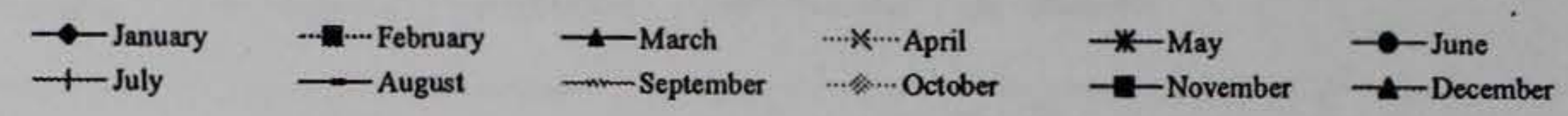

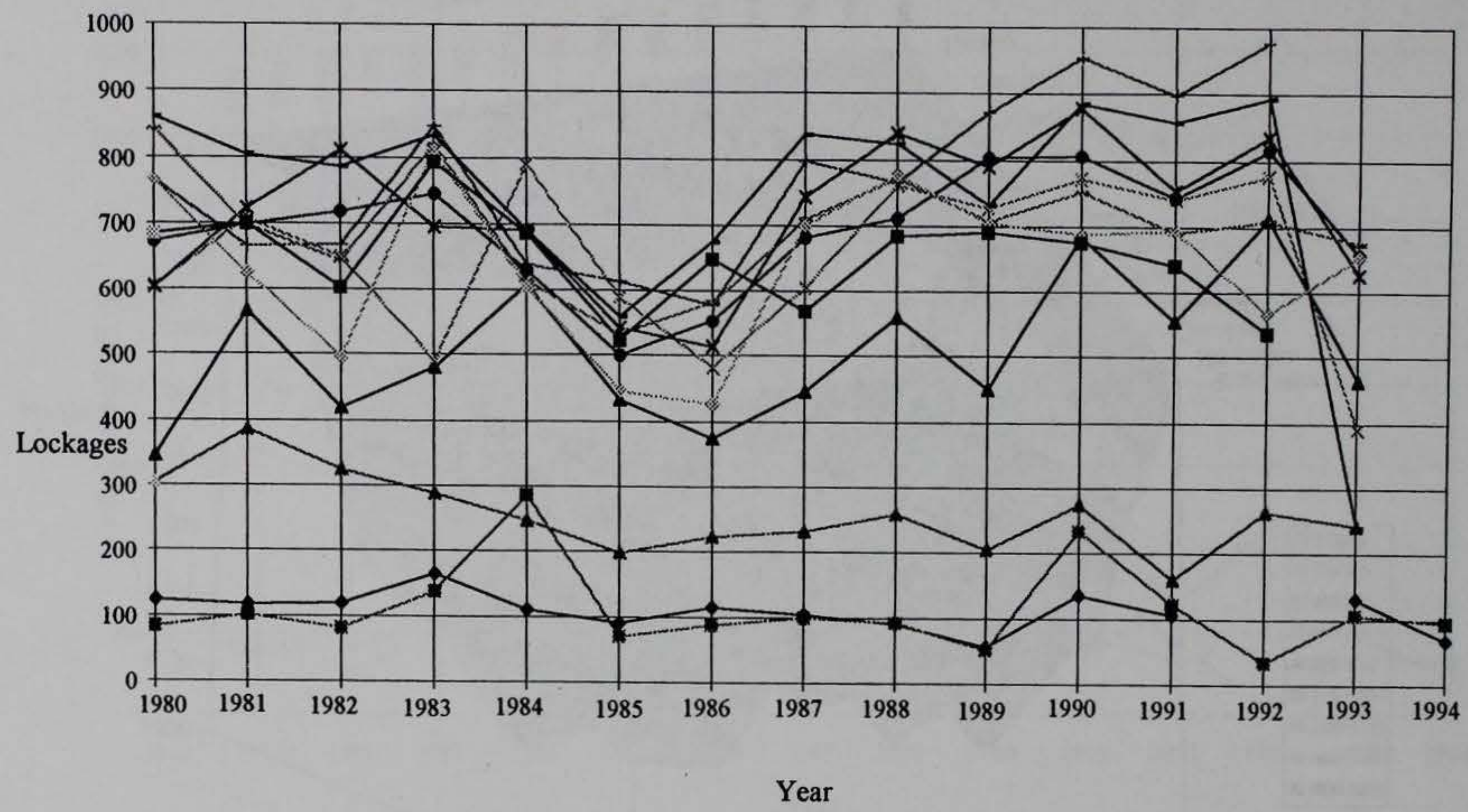

Figure 9. Summary (2-dimensional) of lockages for 1980 to 1994 - Lock and Dam 24 


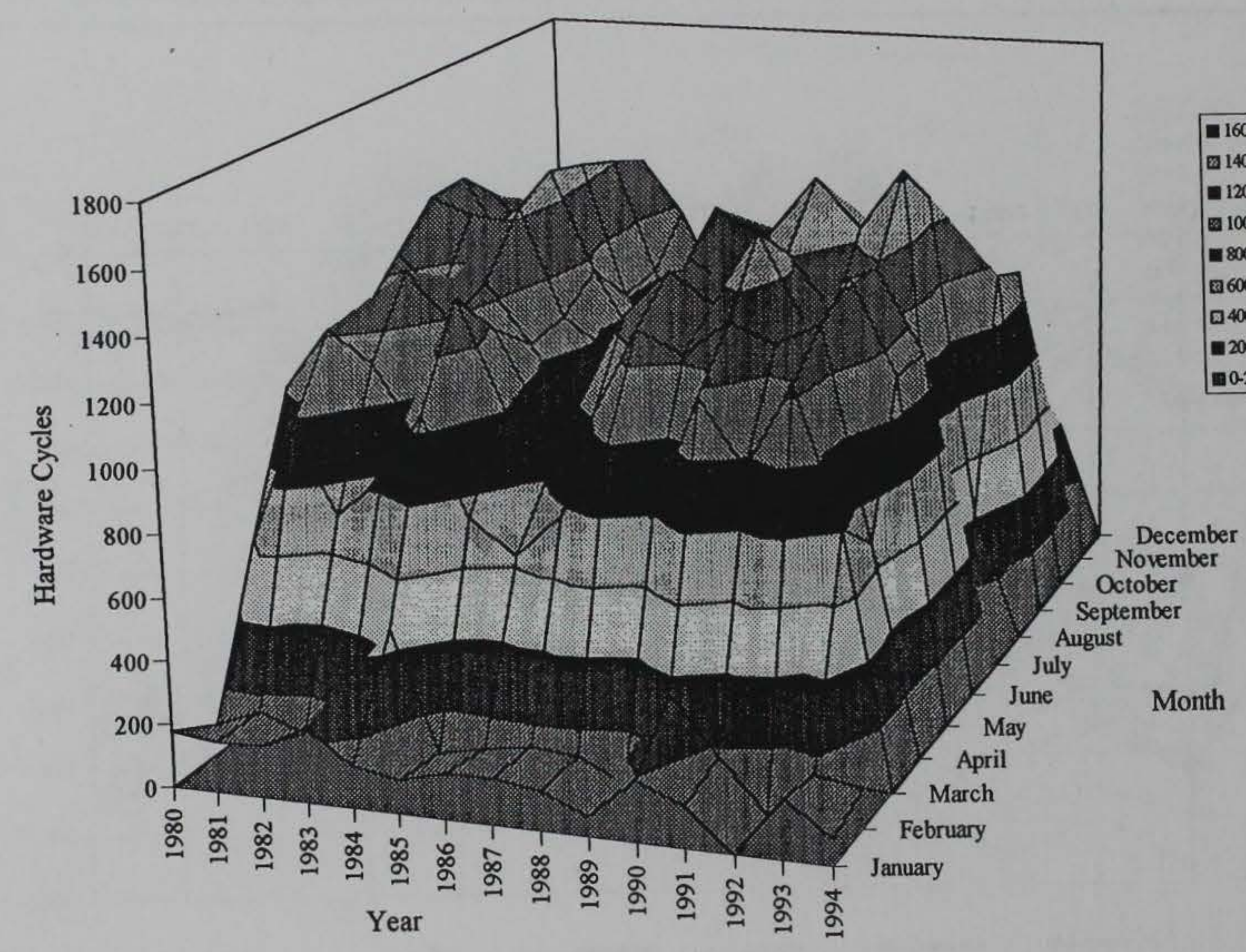

Figure 10. Summary (3-dimensional) of hardware cycles for 1980 to 1994 - Lock and Dam 24 


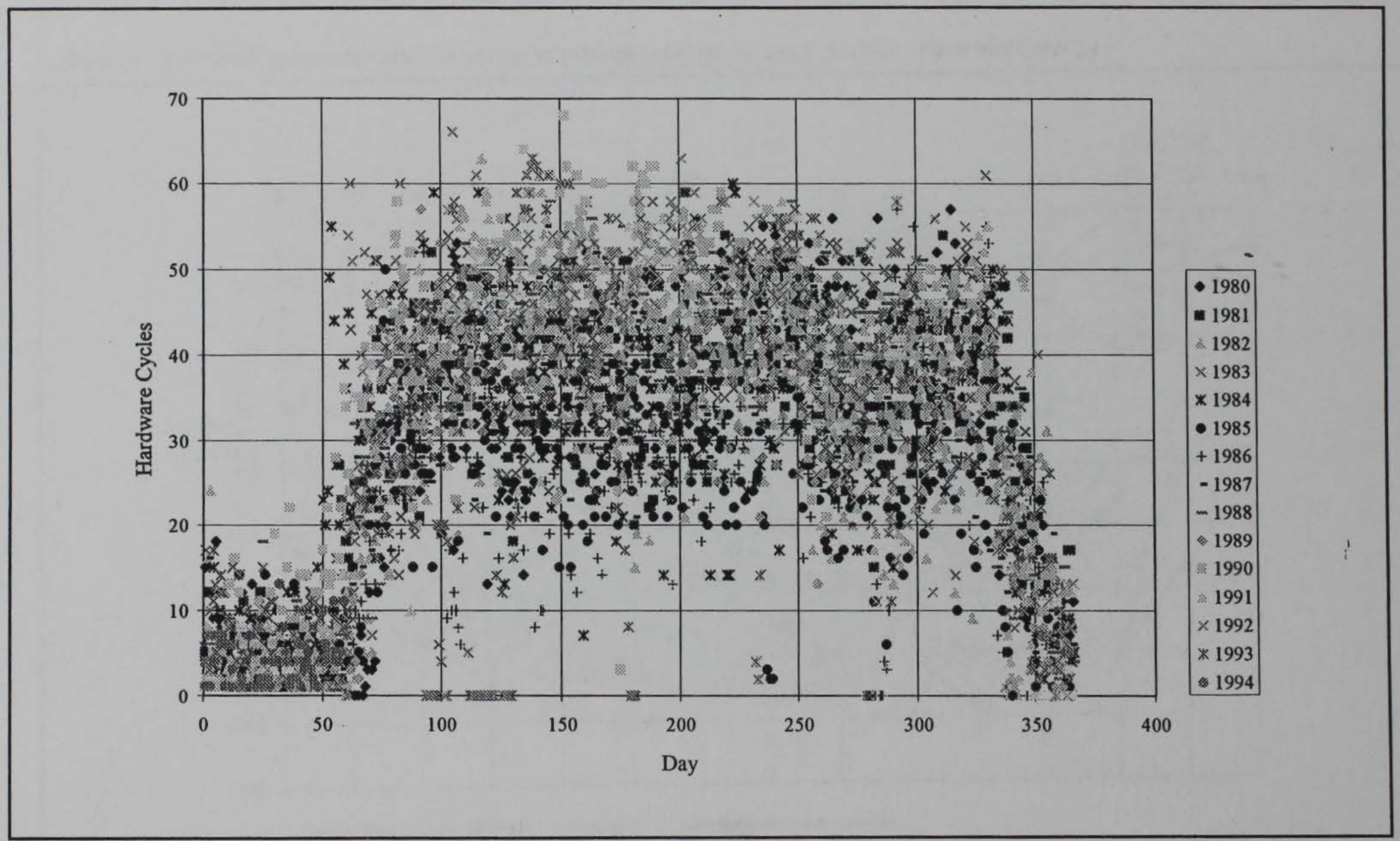

Figure 12. Summary (2-dimensional) by year of hardware cycles for 1980 to 1994 - Lock and Dam 24 


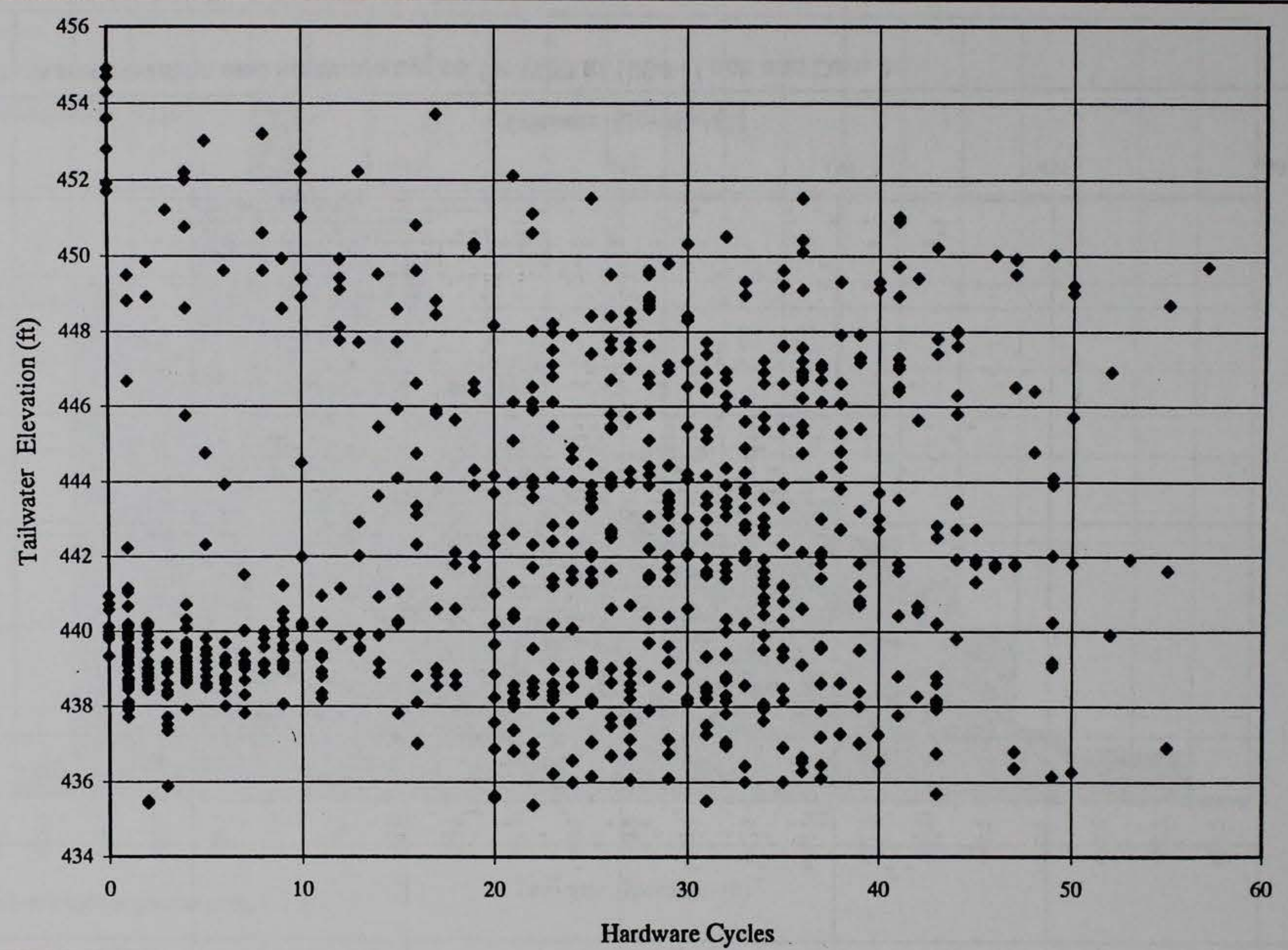

Figure 13. Daily tailwater elevation and hardware cycles for 1985 and 1986 - Lock and Dam 24 


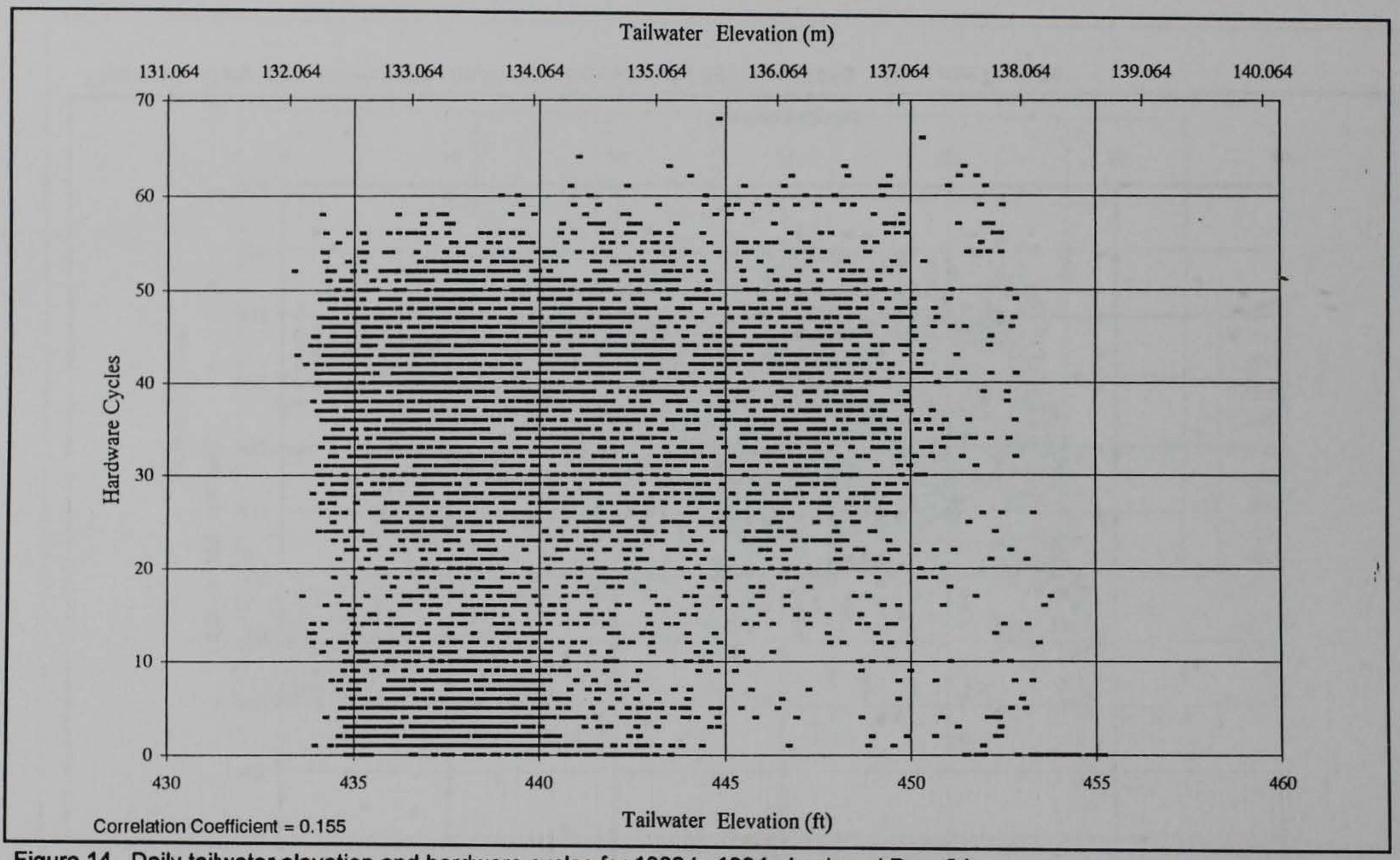

Figure 14. Daily tailwater elevation and hardware cycles for 1980 to 1994 - Lock and Dam 24 


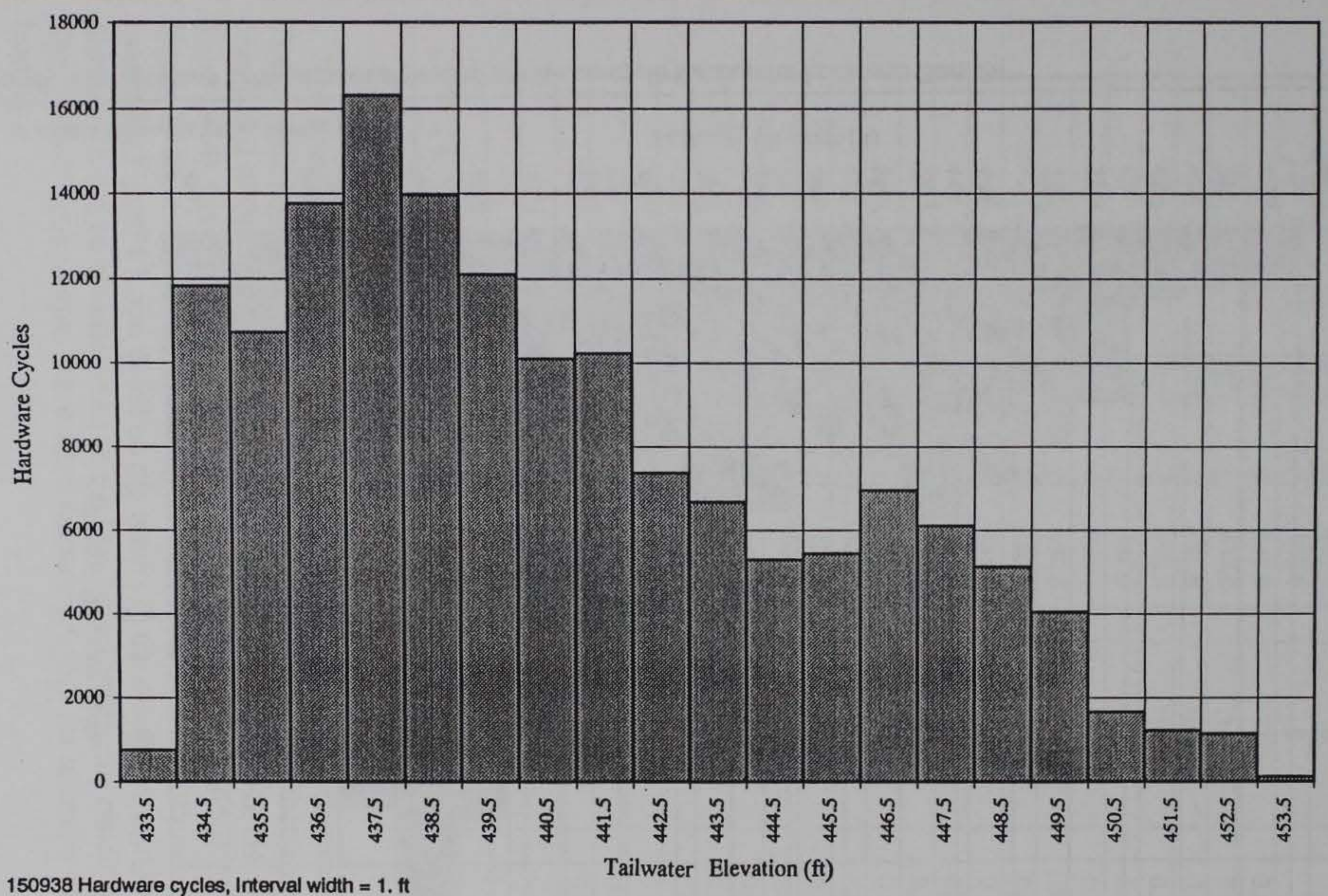

Figure 15. Histogram of tailwater elevation and hardware cycles for Lock and Dam 24 


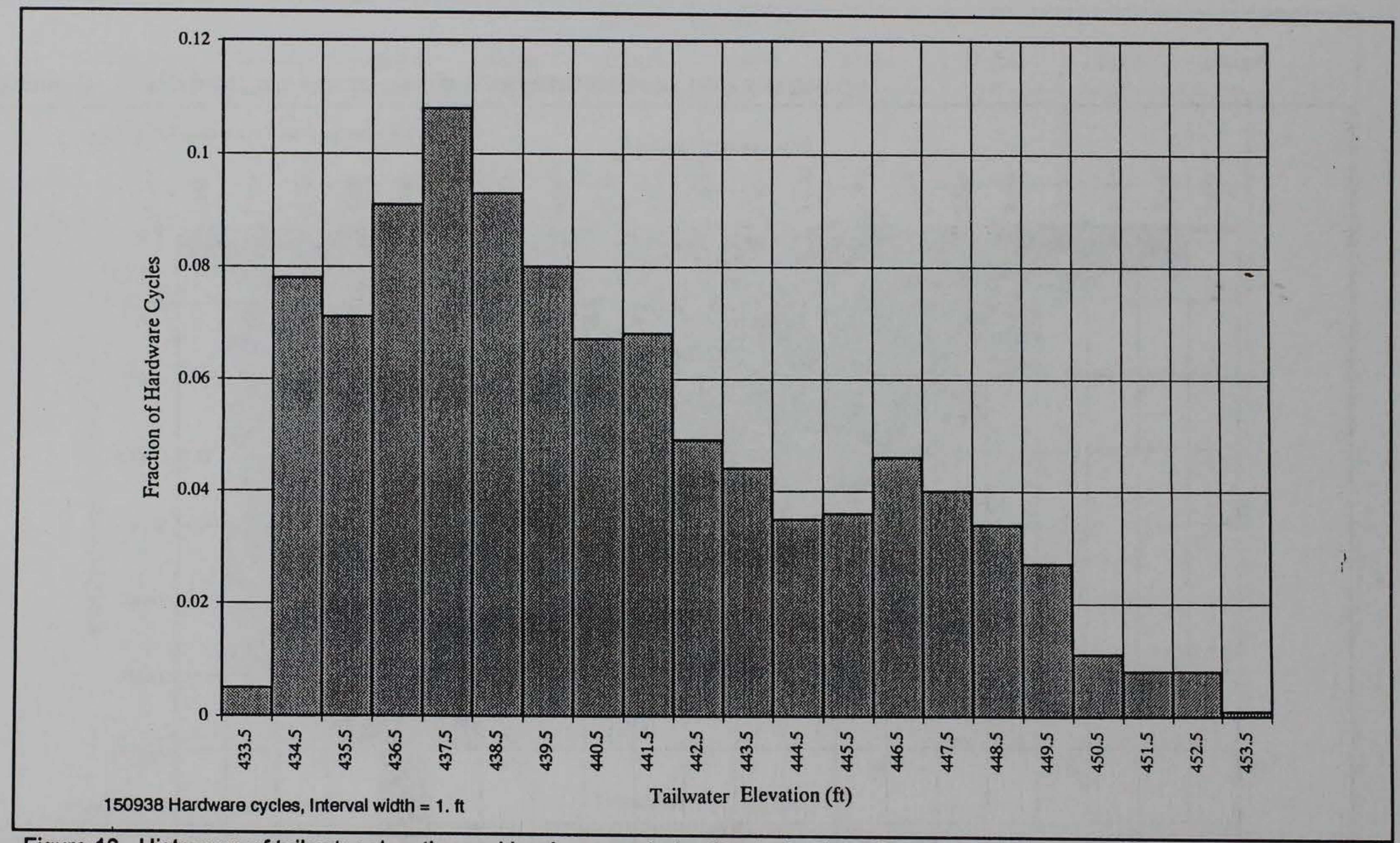

Figure 16. Histogram of tailwater elevation and hardware-cycle fraction for Lock and Dam 24 


\begin{tabular}{|c|c|c|c|c|}
\hline \multicolumn{5}{|c|}{$\begin{array}{l}\text { Table } 8 \\
\text { Data for Tailwater Elevation and Hardware Cycles Histogram }\end{array}$} \\
\hline $\begin{array}{c}\text { Interval Start of } \\
\text { Tailwater (ft) }\end{array}$ & $\begin{array}{l}\text { Interval End of } \\
\text { Tailwater (ft) }\end{array}$ & $\begin{array}{c}\text { Mid-Interval } \\
\text { of Tailwater } \\
\text { (ft) }\end{array}$ & $\begin{array}{l}\text { Count of } \\
\text { Hardware } \\
\text { Cycles }\end{array}$ & $\begin{array}{c}\text { Fraction of } \\
\text { Hardware } \\
\text { Cycles }\end{array}$ \\
\hline 430 & 431 & 430.5 & 0 & 0 \\
\hline 431 & 432 & 431.5 & 0 & 0 \\
\hline 432 & 433 & 432.5 & 0 & 0 \\
\hline 433 & 434 & 433.5 & 755 & 0.005 \\
\hline 434 & 435 & 434.5 & 11827 & 0.078 \\
\hline 435 & 436 & 435.5 & 10726 & 0.071 \\
\hline 436 & 437 & 436.5 & 13762 & 0.091 \\
\hline 437 & 438 & 437.5 & 16306 & 0.108 \\
\hline 438 & 439 & 438.5 & 13966 & 0.093 \\
\hline 439 & 440 & 439.5 & 12097 & 0.08 \\
\hline 440 & 441 & 440.5 & 10099 & 0.067 \\
\hline 441 & 442 & 441.5 & 10225 & 0.068 \\
\hline 442 & 443 & 442.5 & 7359 & 0.049 \\
\hline 443 & 444 & 443.5 & 6670 & 0.044 \\
\hline 444 & 445 & 444.5 & 5302 & 0.035 \\
\hline 445 & 446 & 445.5 & 5445 & 0.036 \\
\hline 446 & 447 & 446.5 & 6949 & 0.046 \\
\hline 447 & 448 & 447.5 & 6110 & 0.04 \\
\hline 448 & 449 & 448.5 & 5133 & 0.034 \\
\hline 449 & 450 & 449.5 & 4047 & 0.027 \\
\hline 450 & 451 & 450.5 & 1669 & 0.011 \\
\hline 451 & 452 & 451.5 & 1229 & 0.008 \\
\hline 452 & 453 & 452.5 & 1143 & 0.008 \\
\hline 453 & 454 & 453.5 & 119 & 0.001 \\
\hline 454 & 455 & 454.5 & 0 & 0 \\
\hline 455 & 456 & 455.5 & 0 & 0 \\
\hline 456 & 457 & 456.5 & 0 & 0 \\
\hline TOTAL & & & 150938 & 1 \\
\hline
\end{tabular}

The resulting histogram can be used to select a probability distribution model. The normal, lognormal, Weibull, and Gumbel probability distributions were considered as candidate models. The chi-square goodness-of-fit test (Ang and Tang 1984) was used to select the best model among the candidate distributions. Figure 17 shows the histogram with the four candidate distributions. By examining Figure 17, and based on the results of the chi-square test, the Weibull distribution can be considered to be the best model among the candidate ones. The Weibull's cumulative distribution function $\left(F_{h_{t}}\left(h_{t}\right)\right)$ for tailwater elevation loading is 


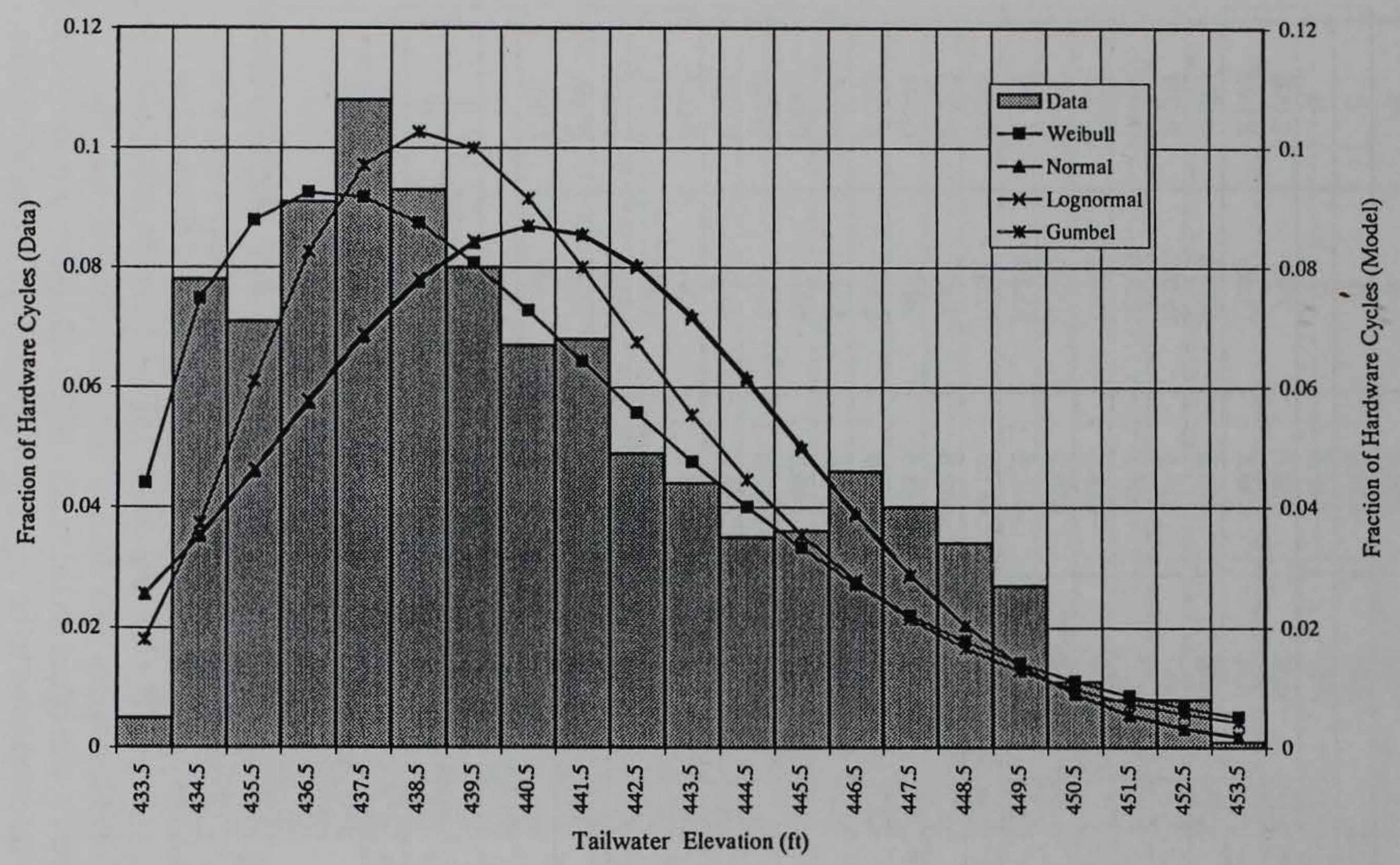

150938 Hardware cycles, Interval width $=1 . \mathrm{ft}$

Figure 17. Histogram of tailwater elevation and hardware-cycle fraction with function fits to data for Lock and Dam 24 


$$
F_{H_{t}}\left(h_{t}\right)=1-\exp \left[-\left(\frac{h_{t}-H_{t \min }}{\left(H_{t \max }-H_{t \min }\right) b}\right)^{a}\right]
$$

where $H_{t \min }=$ minimum tailwater elevation which was taken as $433 \mathrm{ft}, H_{t \max }=$ maximum tailwater elevation which was taken as $454 \mathrm{ft}, H_{t}=$ tailwater elevation loading as a random variable with a given value of $h_{t}$, and $a$ (shape) and $b$ (scale) are the parameters of the distribution. The shape $(a)$ and scale $(b)$ parameters were estimated using the best linear invariant estimation (Mann, Shaffer, and Singpurwalla 1974) to be 1.4909 and 0.3812 , respectively. The mean and variance based on these parameters are $440.23 \mathrm{ft}$ and $24.329 \mathrm{ft}^{2}$, respectively. These moments are approximately equal to the moments computed as the weighted average and variance of tailwater elevation of $440.685 \mathrm{ft}$ and $20.99 \mathrm{ft}^{2}$, respectively. Equation 57 can be expressed in terms of the normalized water elevation $H_{t n}$.

\section{Relationships Among Tonnage, Lockages, Hardware Cycles, and Time}

The objective of this section is to study the relationships for Lock and Dam 24 among tonnage, number of lockages, number of hardware cycles, and time. Figures 18, 19, and 20 show the trend of tonnage, lockages, and hardware cycles. Figures 21,22 , and 23 show the trend of the ratio of tonnage to lockages, the ratio of tonnage to hardware cycles, and the ratio of lockages to hardware cycles, respectively. The last set of figures shows the scatter diagrams for the relationships between lockages and tonnage (Figure 24), hardware cycles and tonnage (Figure 25), and hardware cycles and lockages (Figure 26). The relationship between hardware cycles and lockages, the trend relationship of the annual number of lockages, and the relationship between lockages and tonnage were developed. Then, a tonnage forecast model was developed based on data obtained using the GEM (USACE 1994) for Lock and Dam 24. 


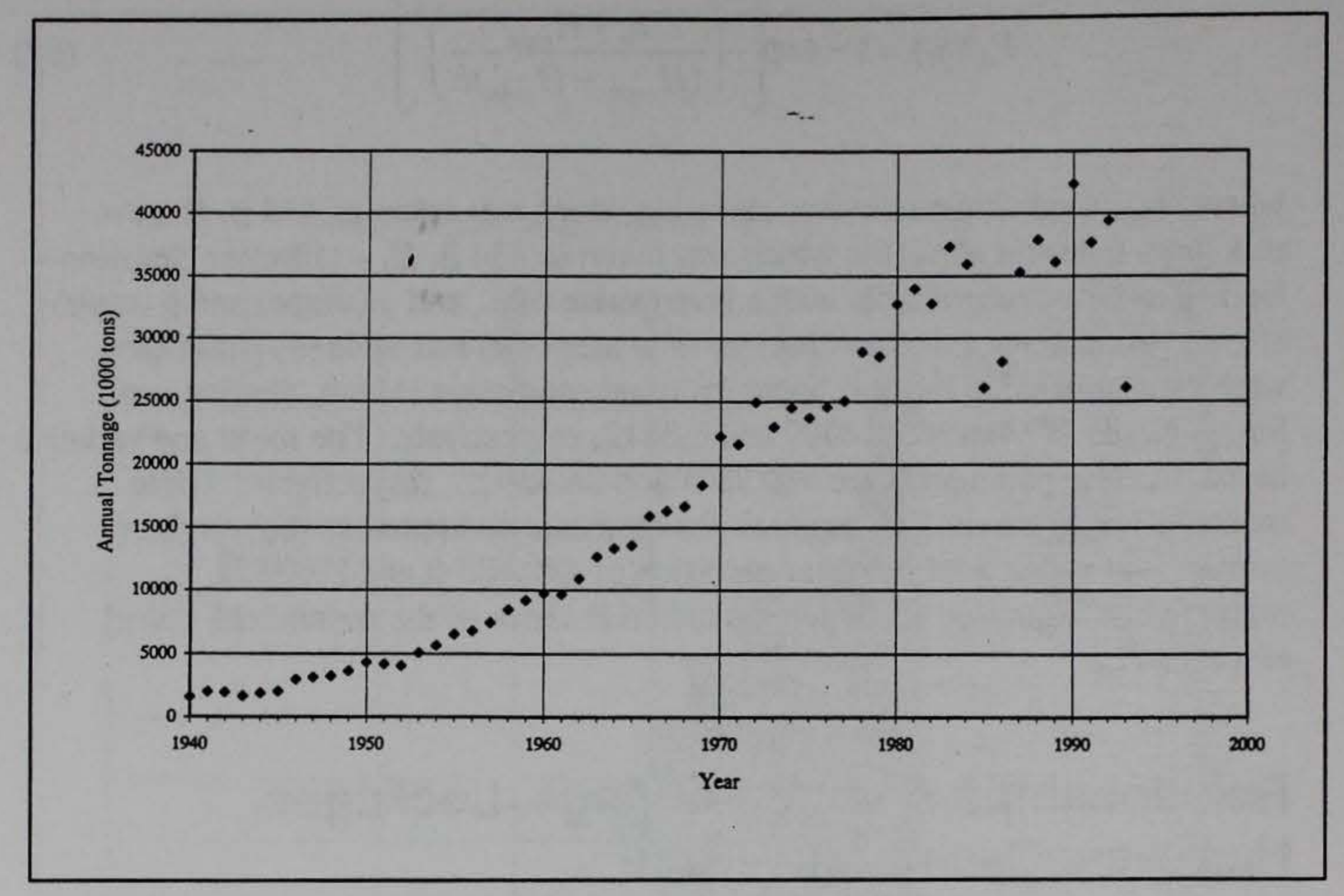

Figure 18. Tonnage trend for Lock and Dam 24

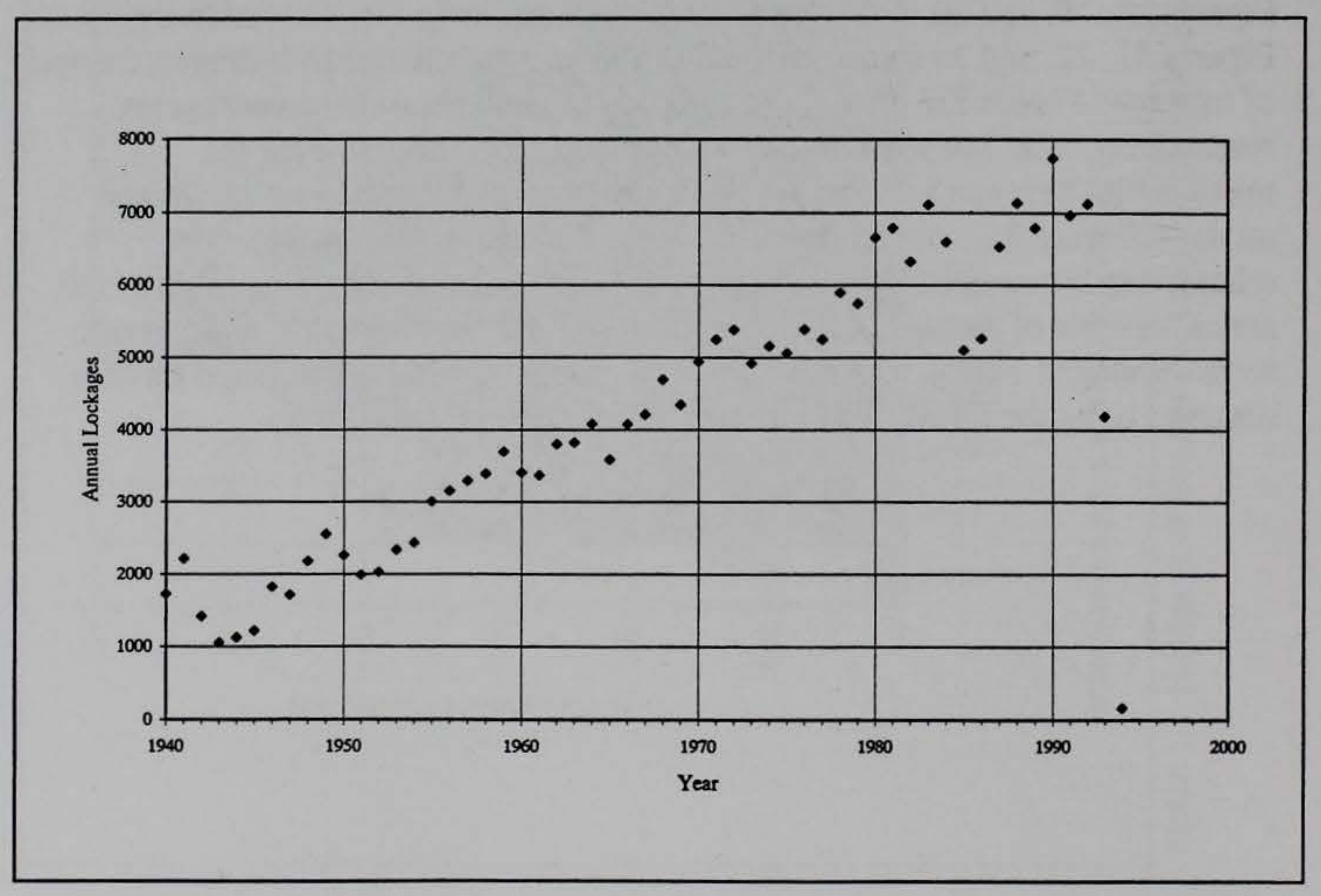

Figure 19. Trend of lockages for Lock and Dam 24 


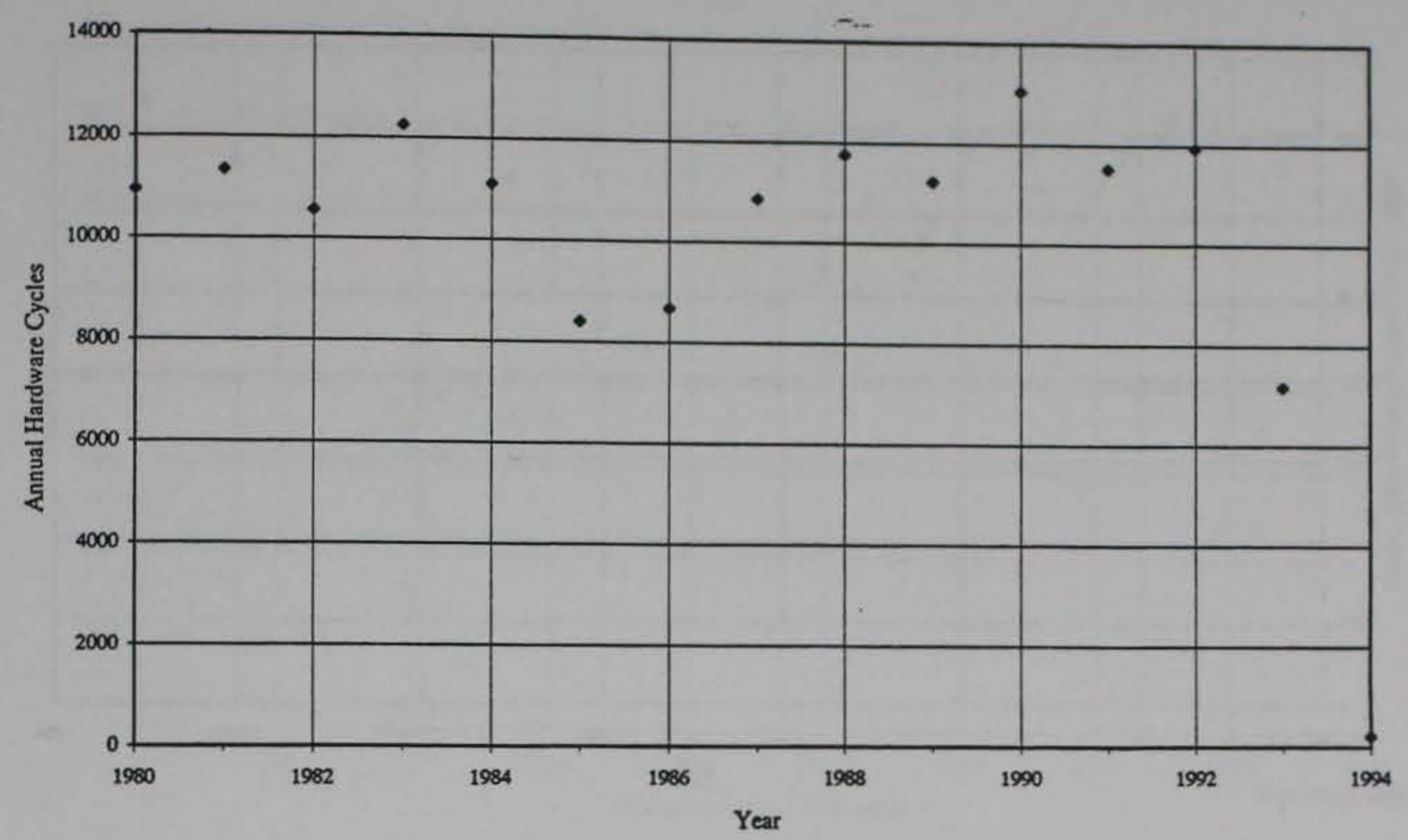

Figure 20. Trend of hardware cycles for Lock and Dam 24

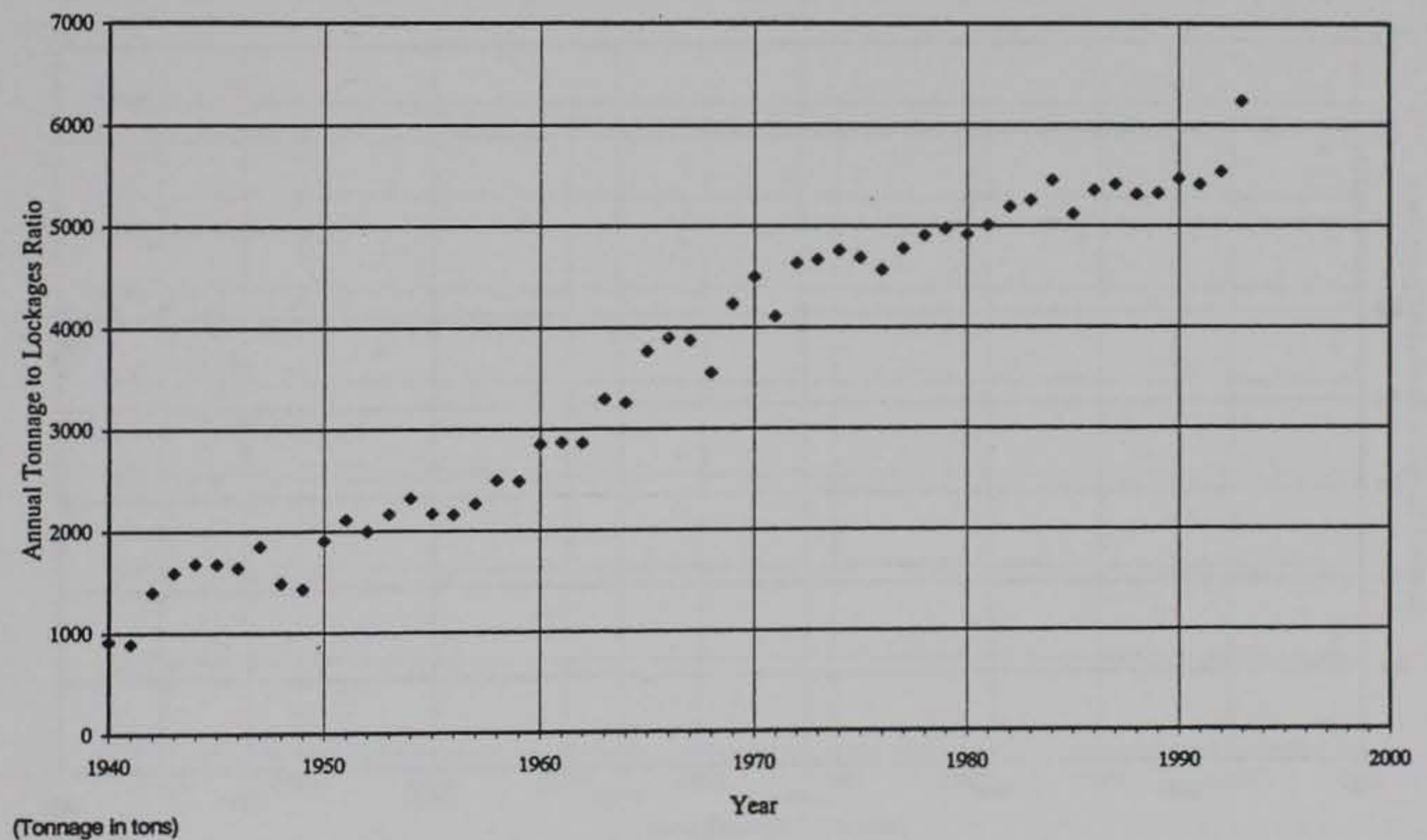

Figure 21. Trend of the ratio of tonnage to lockages for Lock and Dam 24 


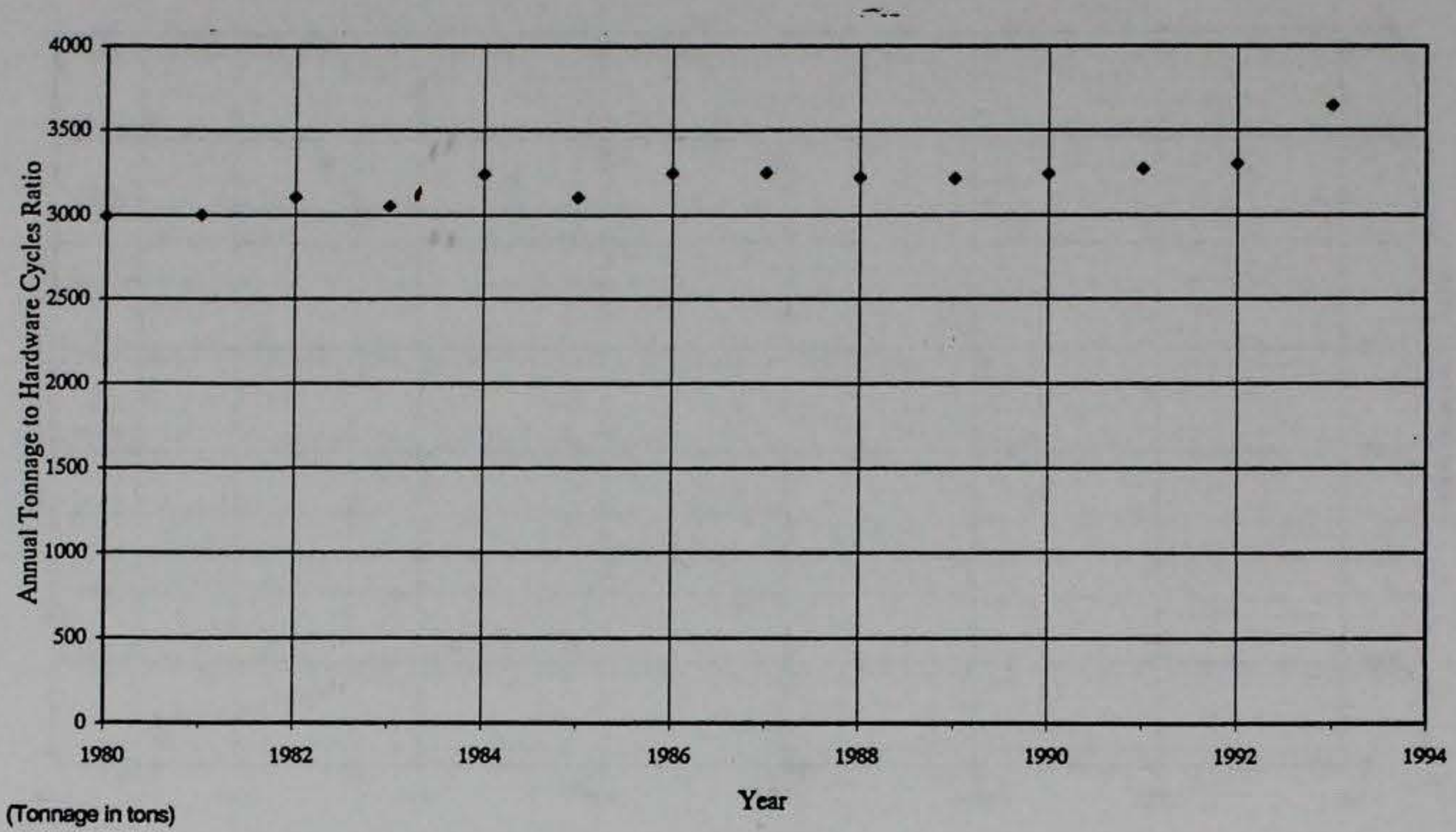

Figure 22. Trend of the ratio of tonnage to hardware cycles for Lock and Dam 24

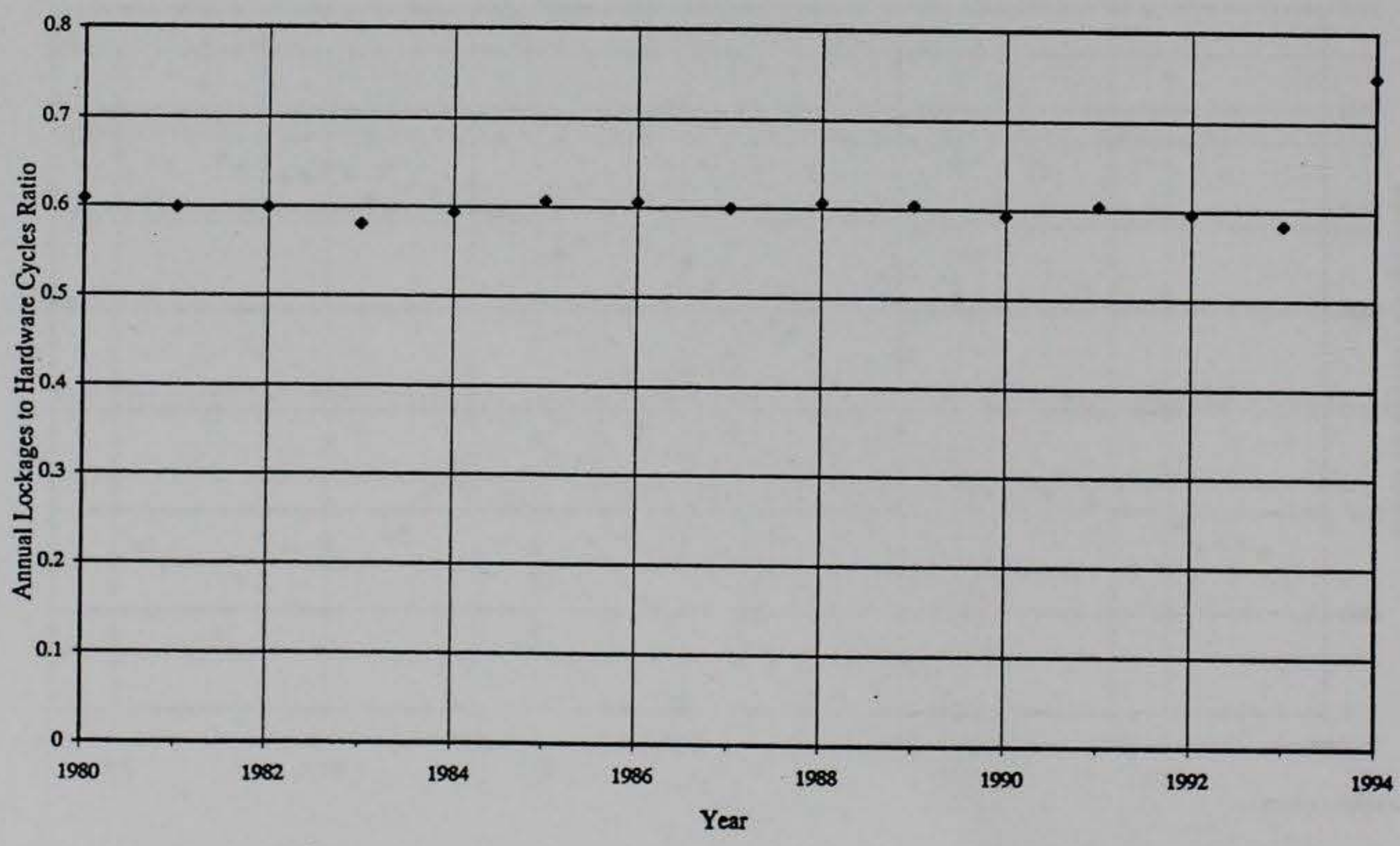

Figure 23. Trend of the ratio of lockages to hardware cycles for Lock and Dam 24 


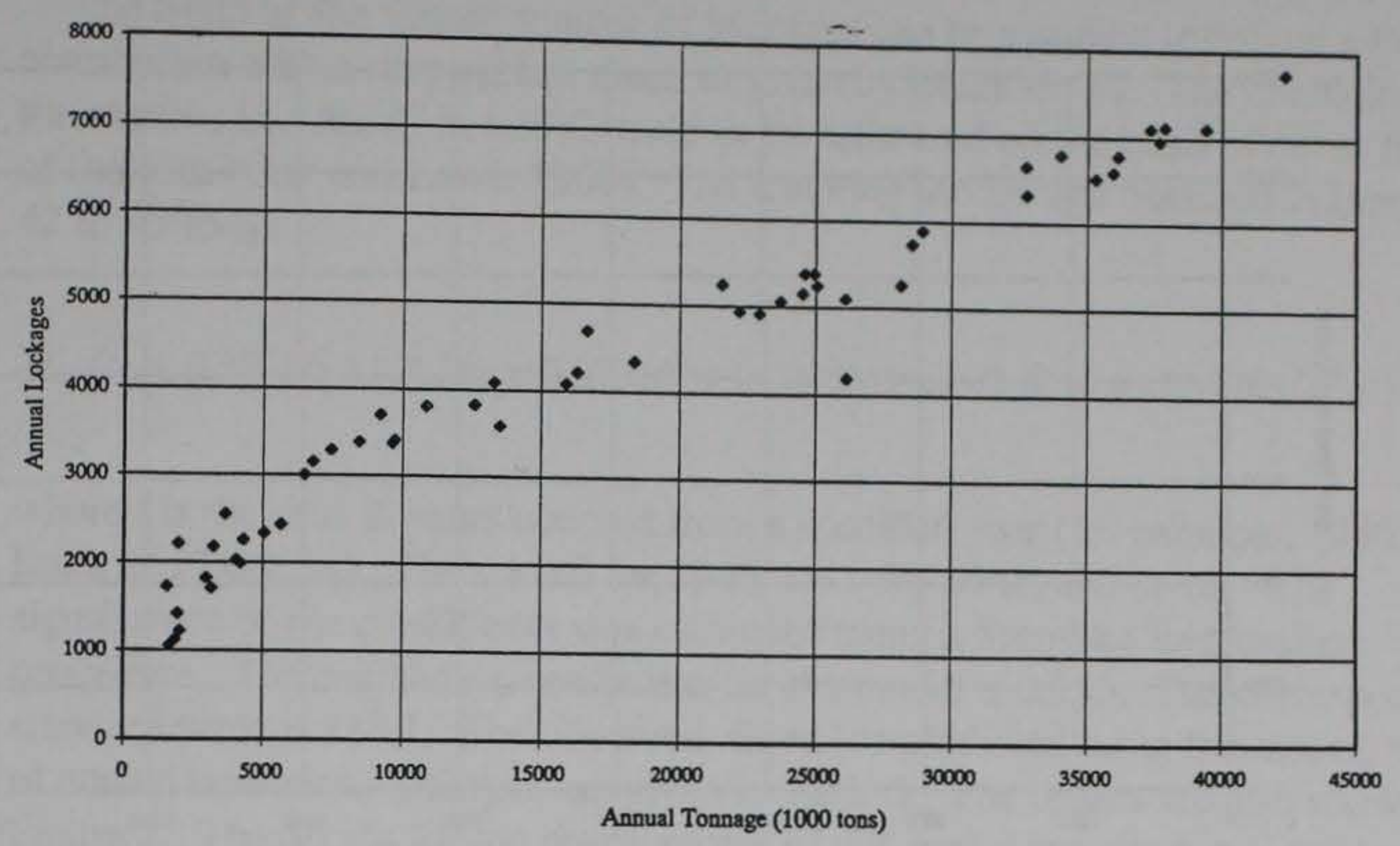

Figure 24. Tonnage and lockages from 1940 to 1994 - Lock and Dam 24

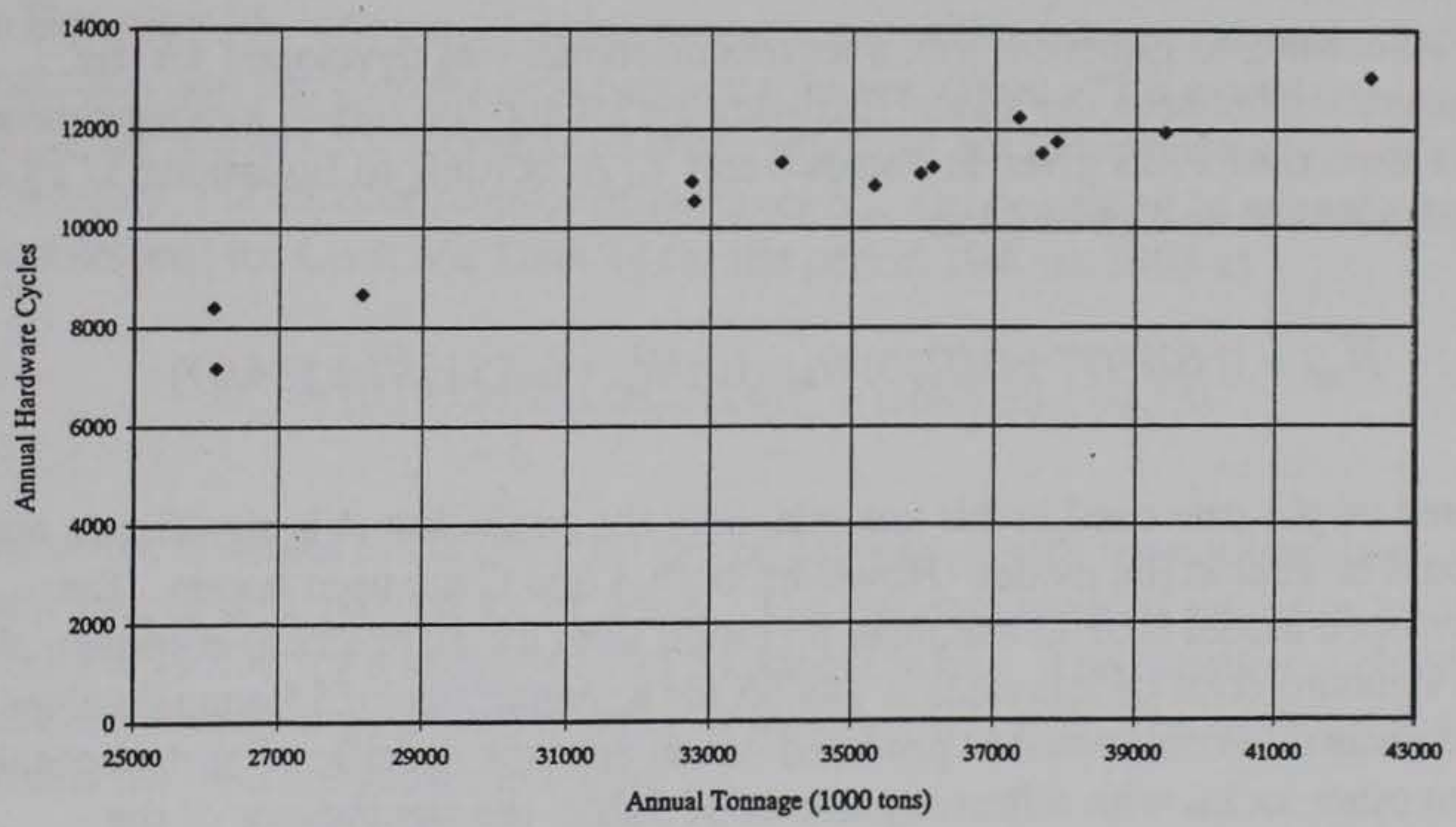

Figure 25. Tonnage and hardware cycles from 1980 to 1994 - Lock and Dam 24 


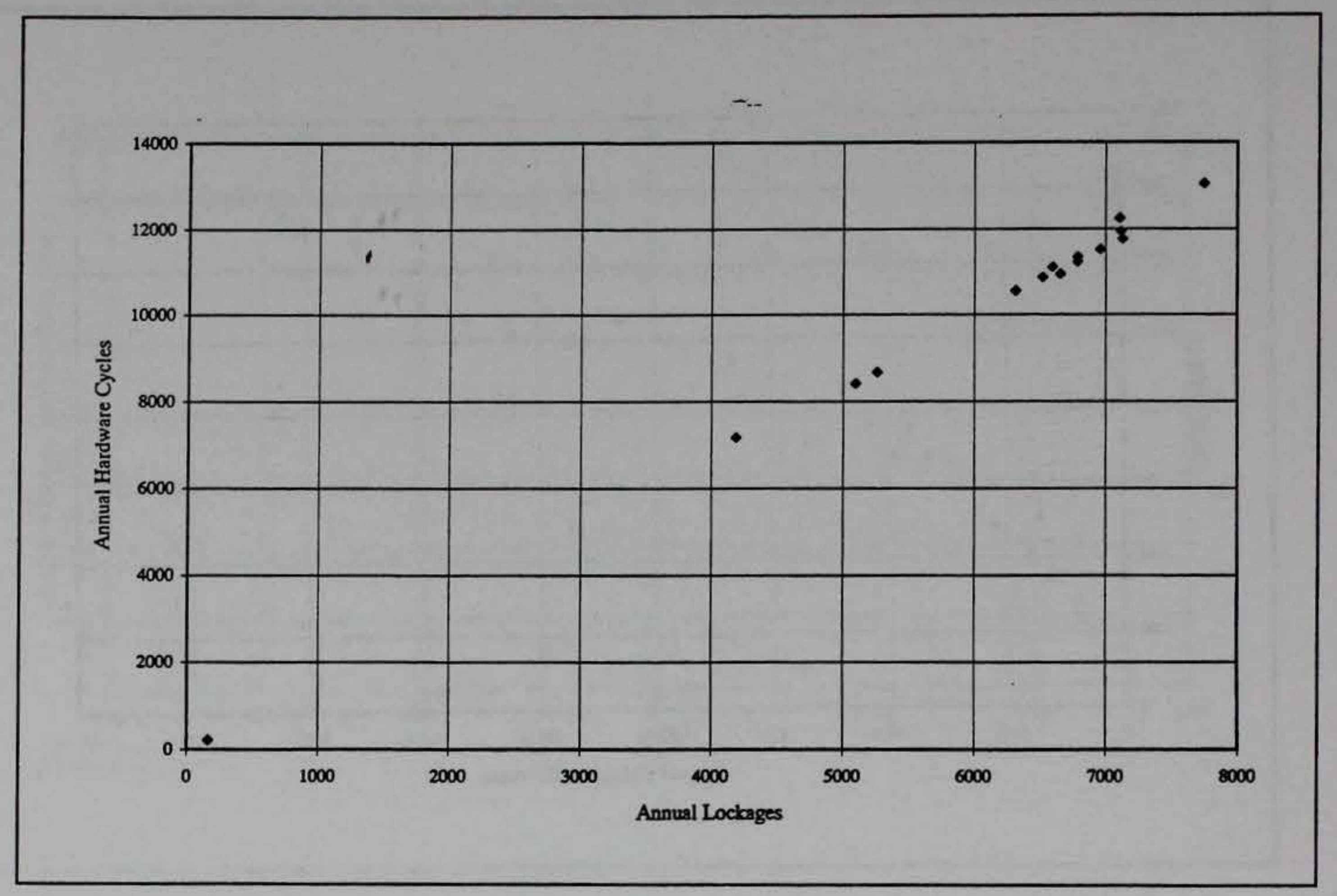

Figure 26. Lockages and hardware cycles from 1980 to 1994 - Lock and Dam 24

\section{Hardware cycles as a function of lockages}

According to Equation 36b, a regression model was developed for the relationship between the annual hardware cycles and the annual lockages using the data from the LPMS given in Tables 6 and 7. According to Equations 37 to 40 , the model can be expressed as

$$
\bar{N}_{H C}=(1.678977 \pm 0.0213) N_{l o c}-(0) N_{l o c}^{2}+(-55.1587 \pm 134.07)
$$

Based on the data used in this analysis, only the coefficient $A$ is significant, and should be kept in the model. However, both $A$ and $C$ are used herein. The developed model is of an adequate precision level for all practical purposes, since the standard error of estimates is 148.85 for a sample size of 15 annual values.

The results and observations provided herein are lock-specific. For data obtained from other locks, with different patterns of traffic, the significance of the coefficients $A, B$, and $C$ can be different. The model of Equation 58 and the data are shown in Figure 1. 


\section{Trend analysis of annual number of lockages}

The trend of the annual number of lockages can be assumed to follow a Poisson distribution with a time variant mean as given by Equation 41 . The coefficients of the model , i.e., $N_{o}, A, B$, and $C$, need to be estimated on the basis of curve fitting of the data (Cox and Lewis 1966). The resulting model was obtained in Equations 42 to 45 to be

$$
N_{\text {loc }}(t)=(1306.66 \pm 1.06) \exp \left((0.050249 \pm 0.003411) t+(-7.4844 \pm 1.2260) \times 10^{-6} t^{3}\right)
$$

where $t$ is the time in years counted from a specified year (for example, 1940 for Lock and Dam 24). Thus, $t=0$ for $1940, t=1$ for 1941 , and so on. The significance of the coefficients was estimated using a Stepwise Regression procedure. The correlation coefficient for the model is 0.955 . The corresponding standard error is 283.1. The observed, fitted (or predicted using the model) values of annual number of lockages are given in Table 3. The results are also shown in Figure 2. The details for the development of this model are given in Equations 42 through 45.

\section{Number of lockages as a function of tonnage}

For cases where data on the annual number of lockages are absent but the annual tonnage data are available, the relationship between annual number of lockages and tonnage can be useful to estimate the number of lockages described in Equation 54. The model development requires the values of annual number of lockages, and the corresponding annual tonnage values. This model does not explicitly account for recreational boats which do not have tonnage values. Therefore, the 4 annual number of lockages $N_{l o c}$ can be related to annual tonnage $T_{n}$ (in kilotons) for Lock and Dam 24 for the period 1940 to 1993 as

$$
N_{\text {loc }}=(0.1432648 \pm 0.00424) T_{n}+(1682.60 \pm 92.13)
$$

where the constant in Equation 60 can be associated with recreational-boat lockages, or with passing ice or debris. The standard error of estimates for this model is 395.96 for a sample of size 54 annual values. The correlation coefficient between annual tonnage and number of lockages is 0.978. The model of Equation 60 and the data are shown in Figure 27.

\section{Tonnage forecast using the GEM}

The GEM was used to obtain tonnage forecasts for Lock and Dam 24 for the years $2000,2010,2020,2030,2040$, and 2050. The GEM results consist of low, 
medium, and high forecasts. Table 9 shows the GEM forecasts for Lock and Dam 24. The relationship of annual lockages as a function of the annual tonnage (Equation 60) was used to obtain annual lockages for Lock and Dam 24 as shown in Table 9. Then the annual hardware cycles as a function of lockages (Equation 58) were used to obtain the annual hardware cycles for Lock and Dam 24 as shown in Table 10. The forecasts of annual tonnage, lockages, and hardware cycles are shown in Figtres 28, 29, 30, respectively.

The GEM tonnage forecast was developed in 1987 for the years 2000,2010 , $2020,2030,2040$, and 2050. Comparing these forecast values with recently reported "real" values as given in Figure 18 shows clearly that the GEM tonnage forecast has actually underestimated tonnage. An assessment of this type needs to be used to evaluate and possibly revise the GEM.

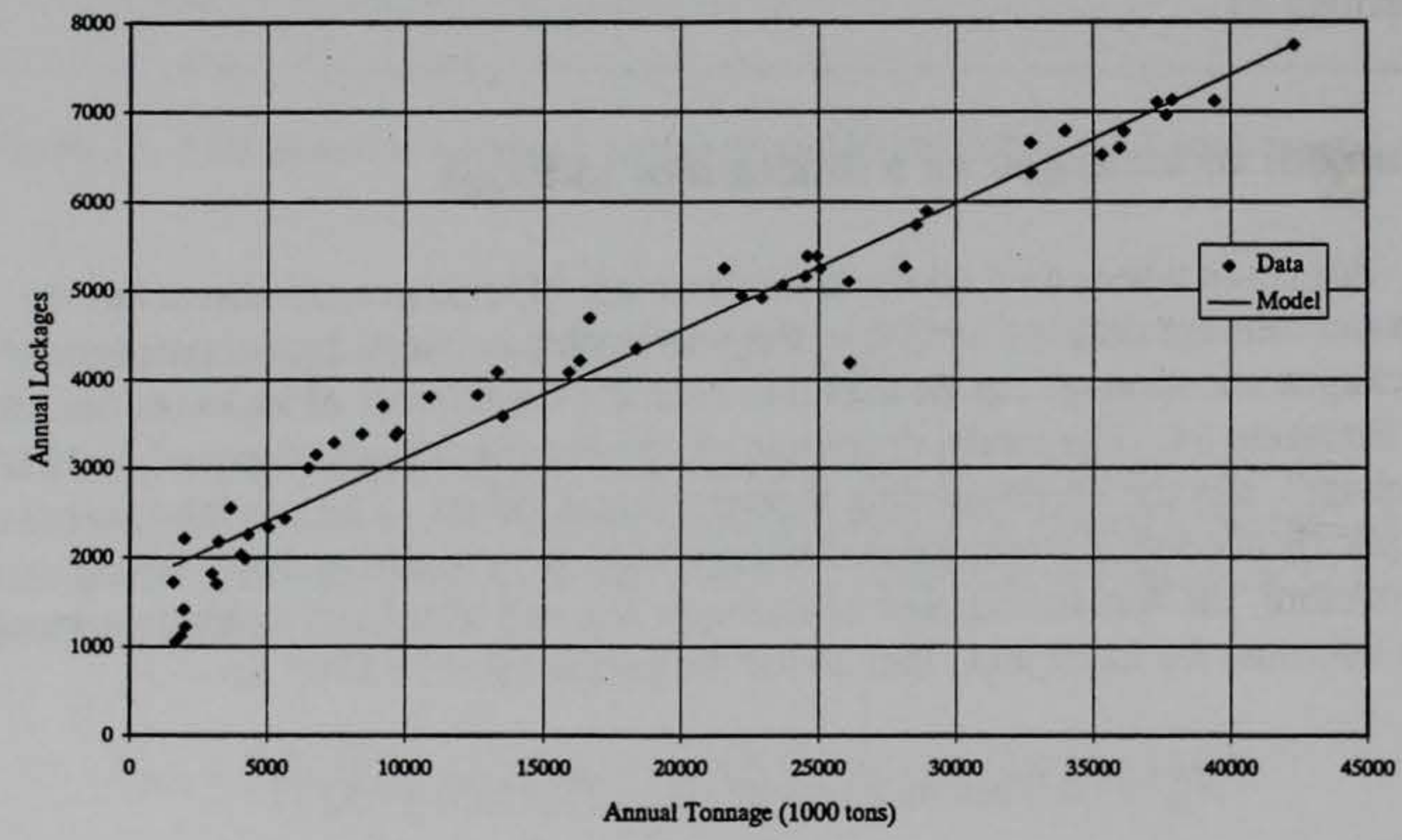

Figure 27. Tonnage and lockages from 1940 to 1994 with regression model - Lock and Dam 24 


\begin{tabular}{l}
\hline \begin{tabular}{|}
\hline $\begin{array}{l}\text { Table 9 } \\
\text { GEM Forecasts of Tonnage and Computed Lockages for Lock and Dam } \\
24\end{array}$ \\
\hline \multicolumn{7}{||c|}{ Tonnage (1000 tons) } & \multicolumn{3}{c||}{ Number of Lockages } \\
\hline Year & High & Medium & Low & High & Medium & Low \\
\hline 2000 & 41362 & 41277 & 41018 & 7609 & 7597 & 7560 \\
\hline 2010 & 41550 & 41496 & 41343 & 7636 & 7628 & 7607 \\
\hline 2020 & 41593 & 41548 & 41503 & 7642 & 7635 & 7629 \\
\hline 2030 & 41622 & 41580 & 41542 & 7646 & 7640 & 7635 \\
\hline 2040 & 41631 & 41607 & 41568 & 7647 & 7644 & 7638 \\
\hline 2050 & 41633 & 41619 & 41595 & 7648 & 7646 & 7642 \\
\hline
\end{tabular}
\end{tabular}

\begin{tabular}{|c|c|c|c|c|c|c|}
\hline \multicolumn{7}{|c|}{$\begin{array}{l}\text { Table } 10 \\
\text { GEM Forecasts of Tonnage and Computed Hardware Cycles for Lock } \\
\text { and Dam } 24\end{array}$} \\
\hline & \multicolumn{3}{|c|}{ Tonnage (1000 tons) } & \multicolumn{3}{|c|}{ Number of Hardware Cycles } \\
\hline Year & High & Medium & Low & High & Medium & Low \\
\hline 2000 & 41362 & 41277 & 41018 & 12775 & 12755 & 12692 \\
\hline 2010 & 41550 & 41496 & 41343 & 12820 & 12807 & 12770 \\
\hline 2020 & 41593 & 41548 & 41503 & 12831 & 12820 & 12809 \\
\hline 2030 & 41622 & 41580 & 41542 & 12838 & 12827 & 12818 \\
\hline 2040 & 41631 & 41607 & 41568 & 12840 & 12834 & 12825 \\
\hline 2050 & 41633 & 41619 & 41595 & 12840 & 12837 & 12831 \\
\hline
\end{tabular}




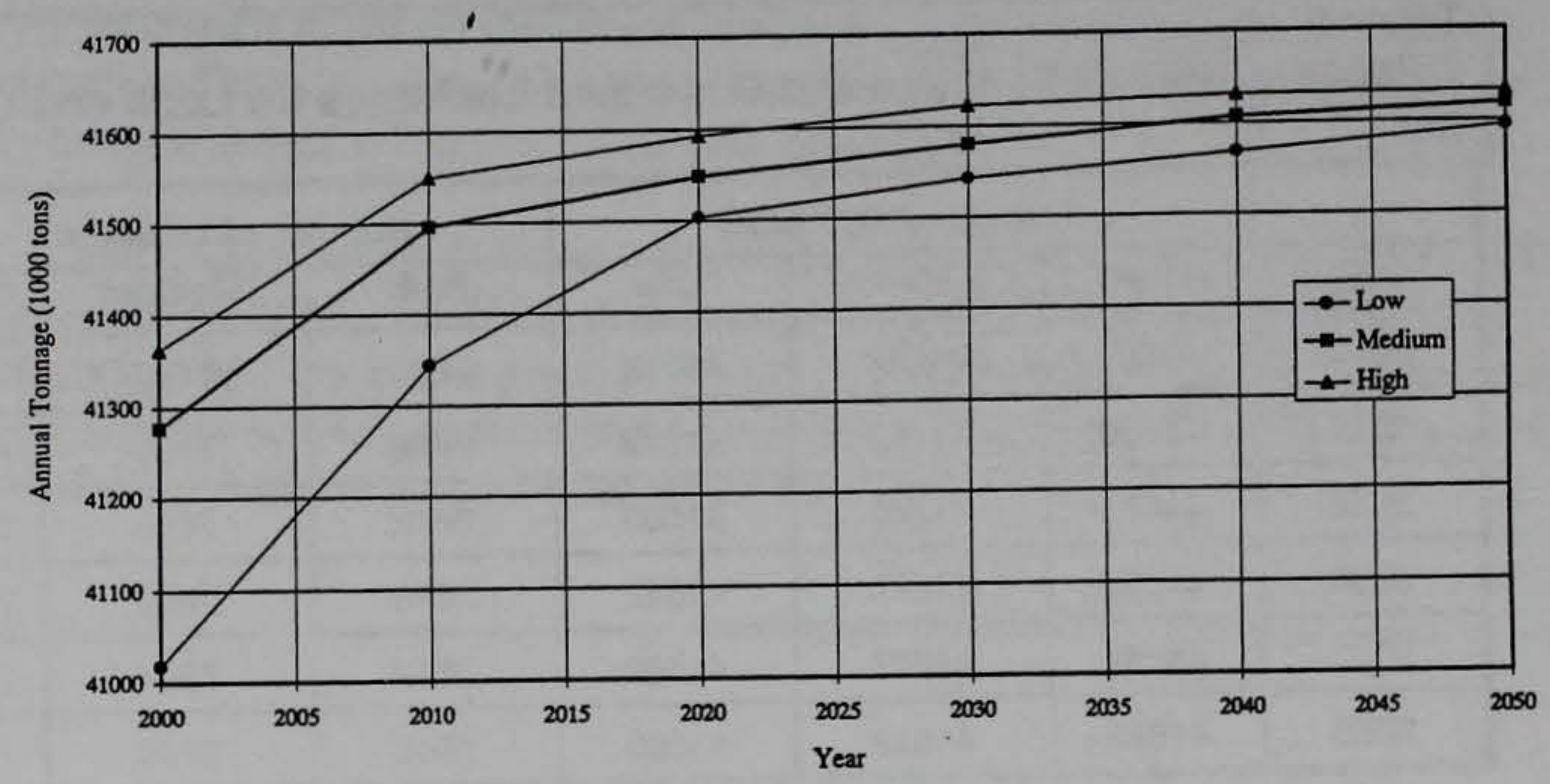

Figure 28. Forecast of annual tonnage for Lock and Dam 24

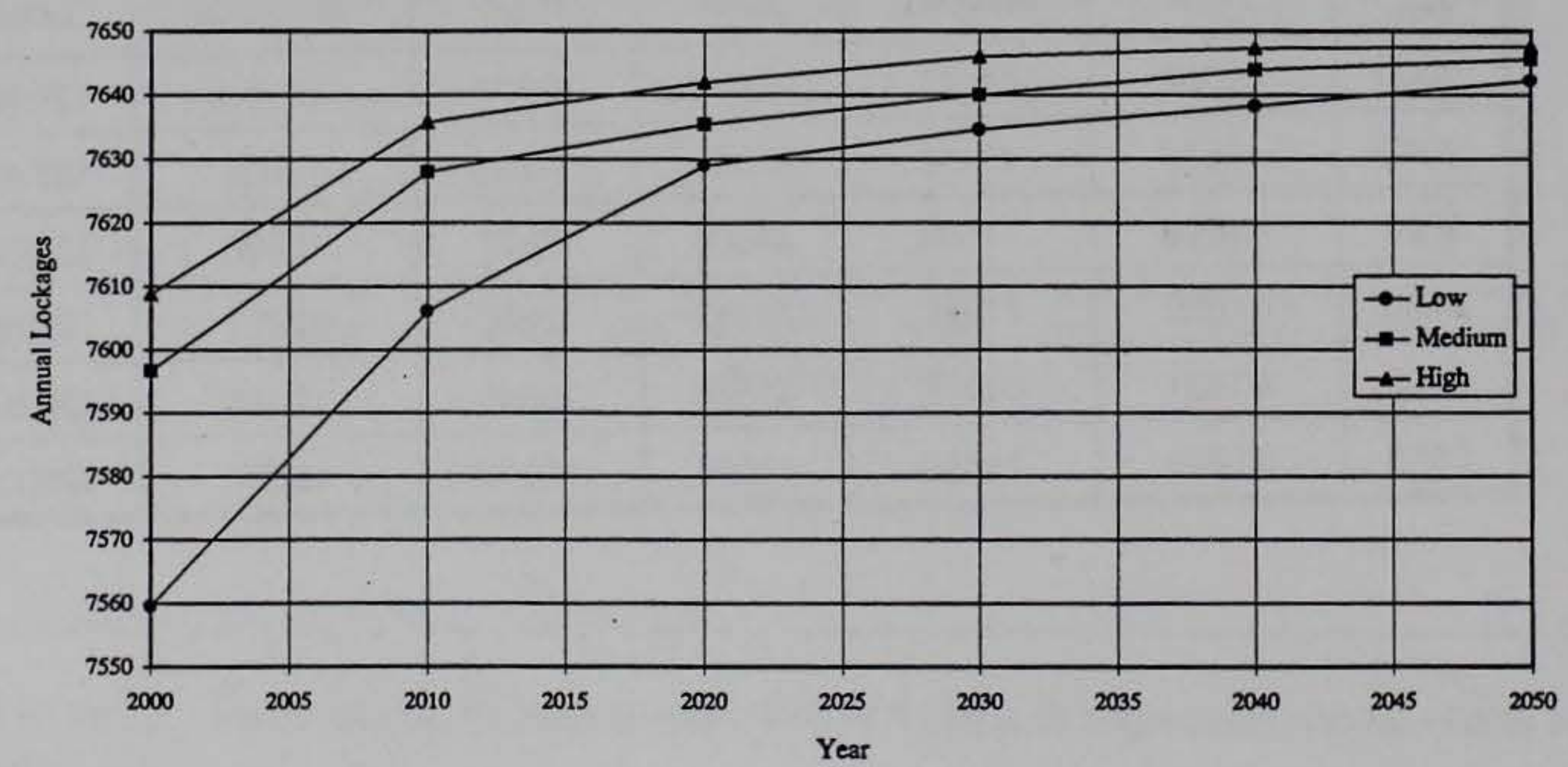

Figure 29. Forecast of annual lockages for Lock and Dam 24 


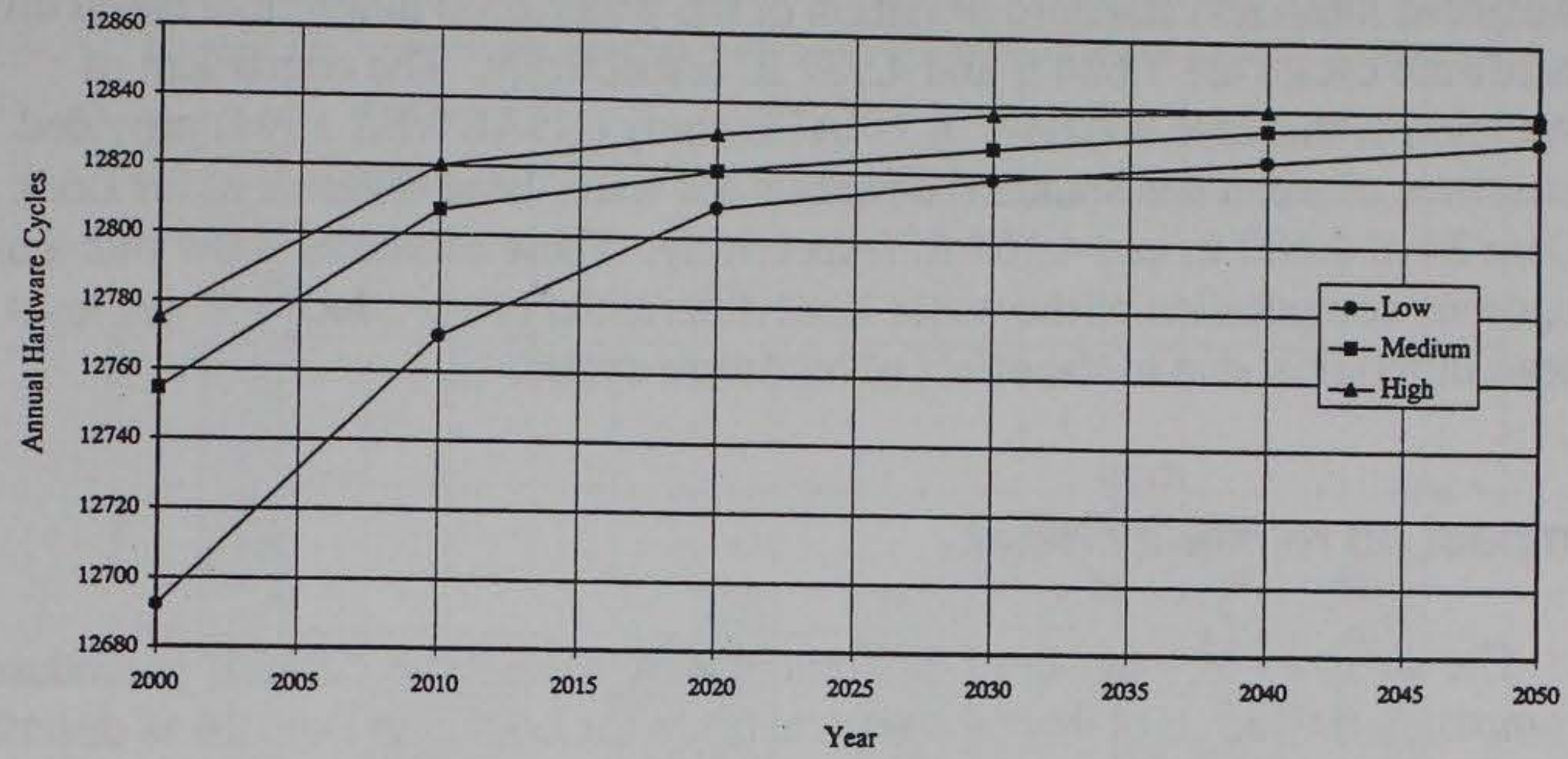

Figure 30. Forecast of annual hardware cycles for Lock and Dam 24

\section{Impact of Results on Fatigue Reliability Assessment}

The impact of the results of this study on fatigue reliability assessment was investigated in two forms, (a) its impact on a computed water-head differential $\left(H_{d}\right)$, and (b) its impact on a computed reliability index $(\beta)$. The former impact assessment is more accurate than the latter one due to approximations employed in the latter assessment. The results reported below can be considered as a preliminary assessment of the effect of the computed water-elevation and hardware cycles on fatigue reliability. A complete assessment of this impact is recommended for a future study.

\section{Impact on water-head differential}

The daily water elevation records were used to compute water-head differential $\left(H_{d}\right)$, for which a histogram was developed without regard to load cycles as shown 
in Figure 31. The mean head differential is $8.267 \mathrm{ft}$; the standard deviation is $4.7636 \mathrm{ft}$; the coefficient of variation is 0.576 ; and the standard error for the mean is $0.0565 \mathrm{ft}$. By accounting for the hardware cycles, the histogram was reevaluated based on Figure 16 and Equation $56 \mathrm{~b}$ as shown in Figure 32. The weighted mean and standard deviation of the water-head differential based on the hardware cycles are $7.624 \mathrm{ft}$ and $4.937 \mathrm{ft}$, respectively. The coefficient of variation in this case is 0.647. A USACE study (USAEWES 1994) provided estimates of mean and standard deviation for water-head differential for Lock and Dam 24 of $9.600 \mathrm{ft}$, and $4.167 \mathrm{ft}$, respectively. These estimates show that a more rigorous computation of the water-head differential can produce a lower level of head differential due to the effect of hardware cycles.

\section{Impact on reliability index}

The statistics of water-head differential were used in the USACE procedure for computing fatigue reliability of a vertical beam for Lock and Dam 24 as described in USACE (1994). The results are shown in Table 11 that demonstrate the effect of water-head differential on the estimated reliability index. The results are approximate since only the mean and standard deviation, not the complete probabilistic characteristics that are available, of the water-head differential were used.

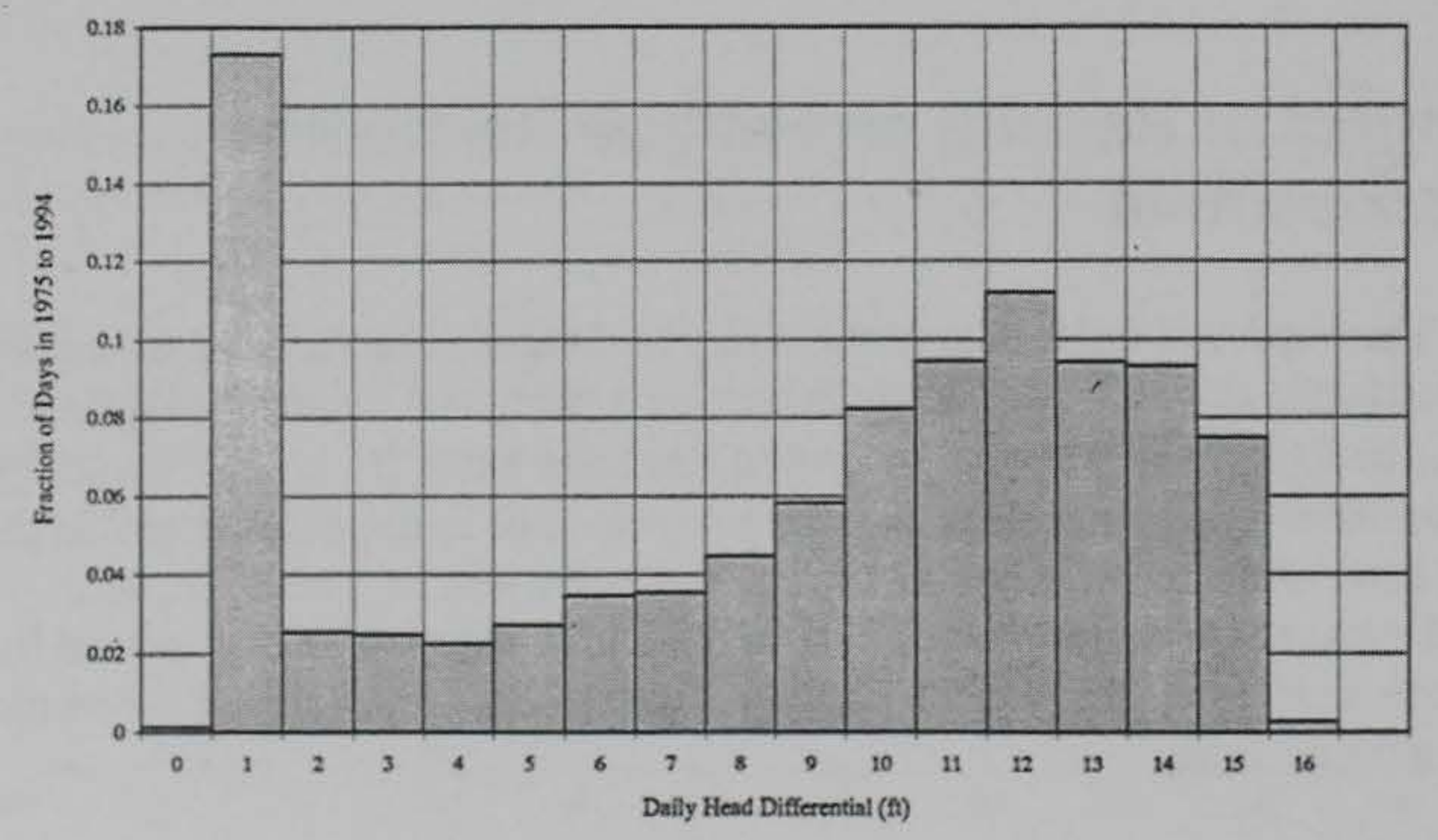

Figure 31. Fraction of days for water-head differential from 1975 to 1994 - Lock and Dam 24 


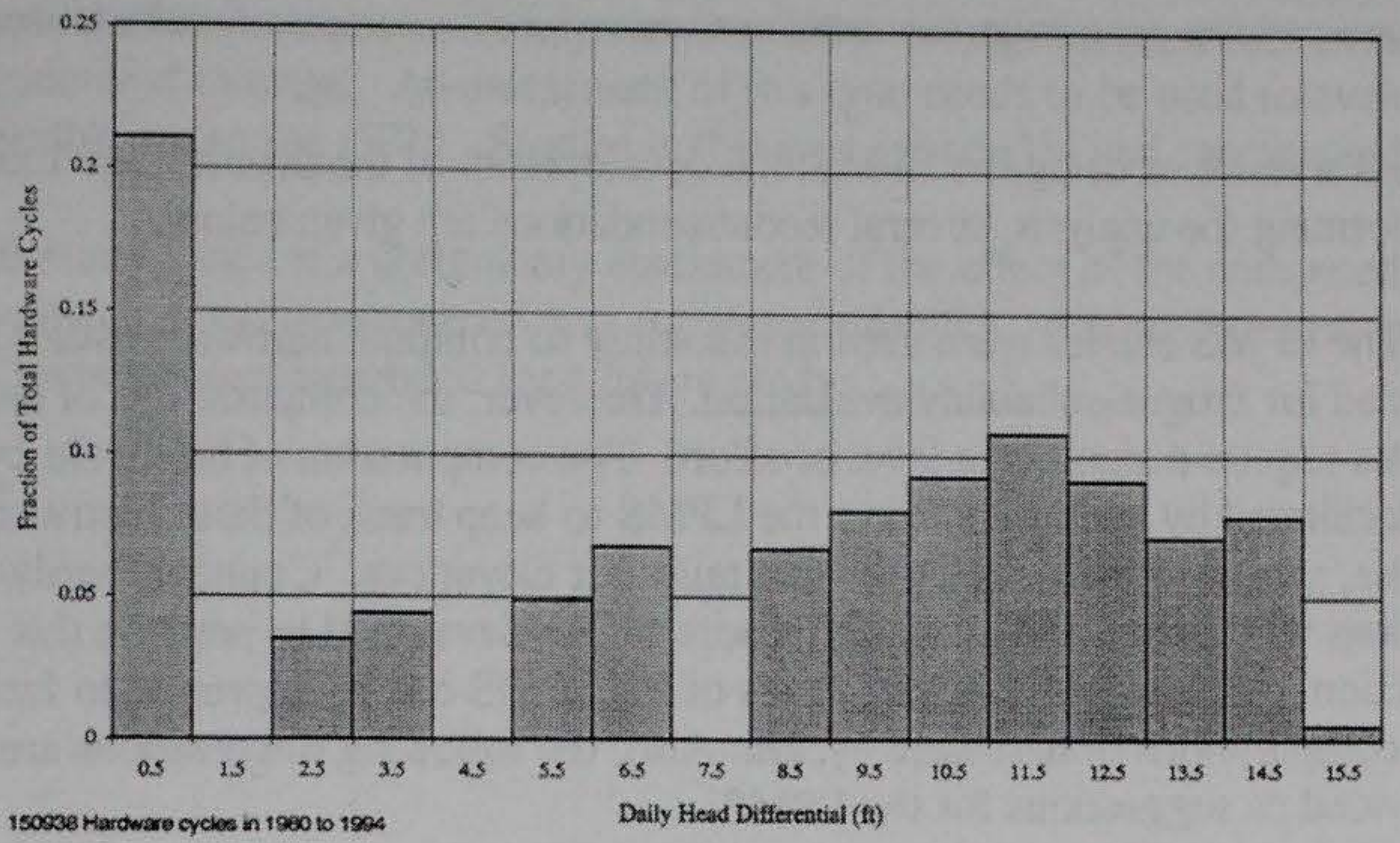

Figure 32. Fraction of total hardware cycles for water-head differential for 1980 to 1994 Lock and Dam 24

\begin{tabular}{|c|c|c|c|c|}
\hline \multicolumn{5}{|c|}{$\begin{array}{l}\text { Table } 11 \\
\text { Impact of Water-Head Differential on Fatigue Reliability }\end{array}$} \\
\hline & \multicolumn{3}{|c|}{ Water-Head Differential } & \\
\hline Method & Mean (ft) & $\begin{array}{l}\text { Standard } \\
\text { Deviation } \\
\text { (ft) }\end{array}$ & $\begin{array}{l}\text { Coefficient of } \\
\text { Variation }\end{array}$ & $\begin{array}{l}\text { Estimated } \\
\text { Reliability } \\
\text { Index }\end{array}$ \\
\hline USACE (1994) & 9.600 & 4.167 & 0.434 & 2.6 \\
\hline Water head only & 8.267 & 4.764 & 0.576 & 2.9 \\
\hline $\begin{array}{l}\text { Water head and } \\
\text { hardware cycles }\end{array}$ & 7.624 & 4.937 & 0.648 & 3.1 \\
\hline
\end{tabular}




\section{Recommendations}

As a result of using the LPMS, the development of the probabilistic model, and performing the analysis, several recommendations are given below.

The LPMS entries were used in this study to compute hardware cycles that are needed for fatigue-reliability evaluation. However, the computations of hardware cycles require a significant level of effort. The computation of hardware cycles can be facilitated by adding a field to the LPMS to keep track of these hardware cycles, associate times, and pool and tailwater elevations. Counting hardware devices with timers and pressure sensors can be developed to perform this function. Alternatively, current fields of the LPMS can be improved to facilitate the computations of hardware cycles. Also, the following observations are provided as suggestions for the LPMS:

a. The current entry and exit types in the LPMS do not necessarily reflect the turnback type if it was delayed, i.e., not immediate to an entry or exit, respectively. Depending on the use of these fields in their current forms, either new fields should be developed that correct for the delayed turnback occurrence, or the current fields should be revised.

$b$. The fields of the LPMS need to be logically connected in order to prevent erroneous entries.

c. Sometimes several vessel records were entered in the LPMS as separate lockages, but these vessels were serviced in the same operation of opening and closing of miter gates. The LPMS does not keep track of these cases, thereby complicating the computation of hardware cycles.

d. Ice and debris lockages are not included in the LPMS. The practice of record keeping needs to be revised to require the inclusion of these lockages.

e. Other operations of the gates for service, inspection, or performance evaluations are not recorded in the LPMS. A similar action to item $d$ is recommended for these operations.

In general, locks and dams on the Mississippi River can be classified into groups. A typical lock can be analyzed from each group, in addition to analyzing several locks in a selected group, to produce a complete understanding of 
hardware cycles of miter gates. Relationships and variability among the groups and within a group can then be studied and understood.

The GEM tonnage forecast was developed in 1987 for the years 2000, 2010, $2020,2030,2040$, and 2050. Comparing these forecast values with recently reported "real" values shows clearly that the GEM tonnage forecast has actually underestimated tonnage. An assessment of this type needs to be used to evaluate and possibly revise the GEM. Studies in this area are needed and recommended.

This study includes a preliminary assessment of the effect of the computed water-elevation and hardware cycles on fatigue reliability. A complete assessment of this impact is recommended for a future study. 


\section{References}

American Society of Civil Engineers Committee on Fatigue and Fracture Reliability. (1982). "Fatigue reliability: Variable amplitude loading," Journal of Structural Division, American Society of Civil Engineers 108(ST1), 47-69.

Ang, A. H-S., and Tang, W. (1984). Probability concepts in engineering planning and design. Volumes I \& II. Wiley, New York.

Ayyub, B. M., and White, G. J. (1990). "Structural life expectancy of marine vessels," Marine Structures 3(4), 301-317.

Ayyub, B. M., White, G. J., Bell-Wright, T. F., and Purcell, E. S. (1990). "Comparative structural life assessment of patrol boat bottom plating," Naval Engineers Journal, American Society of Naval Engineers, 102(3), 253-262.

Ayyub, B.M., White, G.J., and Purcell, E.S. (1989). 'Estimation of the structural service life of boats," Naval Engineers Journal, American Society of Naval Engineers, 101(3), 156-166.

Chen, Y. N., and Mavrakis, S. A. (1988). "Closed-form spectral fatigue analysis for compliant offshore structures," Journal of Ship Research 32(4), 297-304.

Cox, D.R., and Lewis, P.A.W. (1966). The statistical analysis of series of events. John Wiley and Sons, New York.

Fisher, J.W., Albrecht, P.A., Yen, B.T., Klingerman, D.J., and McNamee, B.M. (1974). "Fatigue strength of steel beams with welded stiffeners and attachments," NCHRP Report 206, TRB, Washington, D.C.

Fisher, J.W., Frank, K.H., Hirt, M.A., and McNamee, B.M. (1970). "Effect of weldments on the fatigue strength of steel beams," NCHRP Report 102, TRB, Washington, D.C.

Headquarters, Department of the Army. (1993a). Structural inspection and evaluation of existing welded lock gates. Engineer Technical Letter 1110-2-346, Washington, D.C.

spillway gates. Engineer Technical Letter 1110-2-351, Washington, D.C. 
Madsen, H. O., Skjong, R., and Moghtaderi-Zadeh, M. (1986). "Experience on probabilistic fatigue analysis of offshore structures." Proceedings, 5th International Symposium on Offshore Mechanics and Arctic Engineering. American Society of Mechanical Engineers, New York.

Mann, N.R., Shaffer, R.E., and Singpurwalla, N.D. (1974). Methods for statistical analysis of reliability and life data. John Wiley and Sons, New York.

Munse, W. H., Wilbur, T. W., Tellalian, M. L., Nicoll, K., and Wilson, K. (1982). "Fatigue characterization of fabricated ship details for design," Ship Structure Committee, Report No. SSC-318.

Patev, R.C. (1995). "Physical data collection for lock wall deterioration," Proceedings, Corps of Engineers Structural Engineering Conference, 28-30 August 1995. San Antonio, TX.

Ricles, J.M., and Leger, P. (1993). "Marine component fatigue reliability," Journal of Structural Engineering, American Society of Civil Engineers 119(7), 2215-2234

Sommer, A.M., Nowak, A.S., and Thoft-Christensen, P. (1993). "Probabilitybased bridge inspection strategy," Journal of Structural Engineering, American Society of Civil Engineers 119(12), 3520-3536.

U.S. Army Corps of Engineers. (1990). "Lock performance monitoring system, user manual for data collection and editing, CEAP conversion," Navigation Data Center Report 90-L-3, Alexandria, VA.

Dam 24. St. Louis District, MO. (1993c). Major rehabilitation report, Lock and (1994). The General Equilibrium Model.

Washington, D.C.

U.S. Army Engineer Waterways Experiment Station. (1994). "Reliability analysis of hydraulic steel structures with fatigue and corrosion degradation," (technical report in publication), Vicksburg, MS.

White, G.J., and Ayyub, B.M. (1987). "Reliability-based fatigue design for ship structures," Naval Engineers Journal, American Society of Naval Engineers, 99(3), 135-149.

Wirsching, P. M. (1984). "Fatigue reliability for offshore structures," Journal of Structural Engineering, American Society of Civil Engineers 110(10), 2340-2356. 
Wirsching, P. H., and Chen, Y. N. (1987). "Considerations of probability-based fatigue design for Marine Structures," Proceedings of the Marine Structural Reliability Symposium, Baltimore, MD, 31-43. 


\section{Appendix A}

\section{Daily Hardware Cycles for Lock and Dam 24}

\begin{tabular}{|c|c|c|c|c|c|c|c|c|c|c|c|c|c|c|c|}
\hline & & & & & & & & & & & & & & & \\
\hline Day & 1980 & 1981 & 1982 & \begin{tabular}{|l|l|}
1983 \\
\end{tabular} & 1984 & 1985 & 1986 & 1987 & 1988 & 1989 & 1990 & 1991 & 1992 & 1993 & 1994 \\
\hline 1 & 15 & 5 & 4 & 17 & 4 & 4 & 6 & 15 & 6 & 4 & 1 & 1 & & 4 & \\
\hline 2 & 5 & 1 & 16 & 4 & 7 & 5 & 1 & 16 & 3 & 8 & 2 & 8 & & 7 & \\
\hline 3 & 1 & 12 & 24 & 10 & 1 & 1 & 1 & 2 & 4 & 4 & 3 & 3 & & 3 & \\
\hline 4 & 9 & 4 & 2 & 11 & 15 & 3 & 4 & 9 & 6 & 1 & 5 & 2 & & 47 & $\sqrt{4}$ \\
\hline 5 & 18 & 1 & 2 & 13 & 4 & 4 & 4 & 1 & 3 & 2 & 1 & 4 & & 5 & 7 \\
\hline 6 & 7 & 1 & 9 & 1 & 1 & 9 & 1 & 10 & $\overline{6}$ & 2 & 4 & 1 & & 4 & \\
\hline 7 & 12 & 10 & 10 & 12 & 1 & 2 & 8 & 5 & 7 & 2 & 1 & 1 & & 14 & 6 \\
\hline 8 & 4 & 8 & 1 & 12 & 2 & 2 & 5 & 4 & 1 & 1 & 5 & 6 & & 7 & \\
\hline 9 & 5 & 2 & 12 & 3 & 3 & 9 & 2 & 1 & 1 & 1 & 7 & 7 & & 6 & 1 \\
\hline 10 & 5 & 3 & 3 & 9 & 9 & 1 & 2 & 6 & 1 & 1 & 8 & 3 & & 9 & \\
\hline 11 & 2 & 3 & $\sqrt{1}$ & 5 & 5 & 7 & 9 & 8 & 8 & 2 & 13 & 3 & & 8 & \\
\hline 12 & \begin{tabular}{|c|}
6 \\
\end{tabular} & 3 & $\overline{9}$ & 15 & 4 & 1 & 4 & 1 & 1 & 2 & 4 & 4 & & 6 & $\sqrt{3}$ \\
\hline 13 & 1 & 8 & $\overline{1}$ & 2 & 2 & 1 & 7 & 3 & 1 & 3 & 16 & 2 & & 6 & 1 \\
\hline 14 & 4 & 1 & $\overline{4}$ & 8 & 6 & 1 & 7 & 4 & 1 & 1 & 4 & 2 & & -4 & \\
\hline 15 & 1 & 7 & $\overline{1}$ & 8 & 10 & 14 & 7 & 7 & 1 & 1 & 12 & 7 & & 14 & \\
\hline 16 & 12 & 4 & $\overline{4}$ & 6 & 3 & 1 & 5 & 6 & 1 & 1 & 8 & 4 & & 2 & \\
\hline 17 & 3 & 11 & $\overline{1}$ & 6 & 4 & 1 & 6 & 5 & 8 & 1 & 6 & 8 & & 5 & \\
\hline 18 & 5 & 6 & 10 & 10 & 1 & 5 & 6 & 1 & 1 & 2 & 2 & 5 & & 4 & \\
\hline 19 & 5 & 7 & 3 & 5 & 9 & 4 & 3 & 1 & $\overline{8}$ & 2 & 4 & 8 & & 1 & \\
\hline 20 & 13 & 7 & 1 & 7 & 8 & 1 & 6 & 1 & $I$ & 1 & 7 & 7 & & 5 & \\
\hline 21 & 5 & 6 & 4 & 9 & 1 & 1 & 5 & 8 & f & 3 & 6 & 4 & & 7 & \\
\hline 22 & 3 & 4 & 7 & 5 & 1 & 1 & 4 & 2 & 9 & 1 & 4 & 4 & & 8 & \\
\hline 23 & 2 & 9 & $\overline{1}$ & 4 & 5 & & 11 & 8 & 8 & 1 & 11 & 6 & & 2 & \\
\hline 24 & 7 & 12 & 1 & 1 & 4 & 1 & 6 & 8 & 3 & 1 & 1 & 3 & & 8 & 2 \\
\hline 25 & 9 & 1 & 6 & 15 & 1 & 1 & 9 & 1 & 18 & 3 & 10 & 8 & & 6 & \\
\hline 26 & 7 & 5 & 5 & 2 & 6 & 14 & 4 & 1 & 1 & 1 & 1 & 5 & & 10 & 4 \\
\hline 27 & 4 & 4 & 8 & 9 & 3 & 1 & 1 & 4 & 1 & 1 & 3 & 1 & & 3 & \\
\hline 28 & iी & 4 & $\frac{5}{1}$ & 11 & 4 & 1 & 3 & 1 & 1 & 4 & 12 & 2 & & 1 & \\
\hline 29 & 3 & 4 & $\overline{5}$ & 11 & 4 & 1 & 3 & 1 & 1 & 3 & 6 & 6 & & 5 & \\
\hline 30 & $\frac{4}{4}$ & 3 & $\frac{5}{5}$ & 2 & 4 & 1 & 1 & 4 & 7 & 2 & 19 & 3 & & 4 & $\sqrt{4}$ \\
\hline 31 & 1 & 5 & $\overline{4}$ & 1 & 1) & 10 & 5 & 1 & 7 & 1 & 5 & 5| & & 4 & $\overline{4}$ \\
\hline 32 & की & 5 & $\frac{7}{1}$ & 8 & 1) & 1 & 5 & 6 & 6 & 2 & 8 & 7 & & 8 & 13 \\
\hline 33 & 1 & 8 & $\overline{1}$ & 1 & 5 & 1 & 2 & 4 & 3 & 2 & 10 & 5 & & 4 & \\
\hline 34 & 1 & 3 & $\overline{5}$ & 8 & 6 & 1 & 3 & 1 & 8 & 3 & 5 & 3 & & 2 & 5 \\
\hline 35 & 1 & 5 & $\overline{1}$ & 1 & 12 & 1 & 1 & 4 & 1 & 2 & 15 & 2 & & 2 & \\
\hline 36 & 1 & 1 & 1 & 4 & 6 & 3 & 7 & 4 & 1 & 2 & 22 & 3 & & 4 & 1 \\
\hline 37 & 4 & 4 & $\overline{1}$ & 5 & 4 & 8 & 1 & 5 & 1 & 1 & 9 & 3 & & 1 & \\
\hline 38 & 1 & 8 & $\frac{7}{1}$ & 1) & 12 & 13 & 4 & 12 & 3 & 1 & 7 & 2 & & 7 & 2 \\
\hline 39 & 8 & 7 & 1 & 3 & 4 & 4 & 10 & 2 & 11 & 1 & 9 & 5 & & 4 & \\
\hline 40 & 2 & 1 & 1 & 4 & 8 & 2 & 4 & 1 & 1 & 1 & 1 & 4 & & 10 & 6 \\
\hline 41 & 3 & 1 & $\overline{1}$ & 10 & 4 & 6 & 2 & 1 & 1 & 3 & 14 & 2 & & 4 & \\
\hline 42 & 7 & 1 & 1 & 4 & 4 & 1. & 7 & 2 & 4 & 4 & 8 & 5 & & 6 & 3 \\
\hline 43 & 14 & 3 & 9 & 1 & 2 & 1. & 2 & 9 & 1 & 2 & 14 & 8 & & 6 & 4 \\
\hline 44 & 3 & 2 & $\overline{4}$ & 5 & $\Rightarrow$ & 3 & 1 & 4 & 1 & 1 & 4 & 7 & & 10 & 5 \\
\hline 45 & 7 & 1 & $\overline{1}$ & 111 & 12 & 2 & 1 & 8 & 1 & 1 & 3 & 3 & & 11 & 3 \\
\hline 46 & 1 & 1 & 8 & 7 & 7 & 3 & 1 & 4 & 8 & 1 & 2 & 4 & & 8 & \\
\hline 47 & 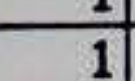 & 1 & & 11 & 6 & 2 & 2 & 10 & 1 & 1 & 12 & 5 & & 1 & \\
\hline
\end{tabular}




\begin{tabular}{|c|c|c|c|c|c|c|c|c|c|c|c|c|c|c|c|}
\hline Day & 1980 & 1981 & 1982 & 1983 & 1984 & 1985 & 1986 & 1987. & 1988 & 1989 & 1990 & 1991 & 1992 & 1993 & 1994 \\
\hline 48 & 5 & 1 & \begin{tabular}{|l|}
1 \\
\end{tabular} & 5 & 15 & 1 & 1 & 5 & 1 & \begin{tabular}{|l|}
3 \\
\end{tabular} & 3 & 2 & & 4 & 1 \\
\hline 49 & 3 & 1 & 1 & 8 & 10 & 2 & 2 & 4 & 6 & 1 & 12 & 8 & & 9 & 1 \\
\hline 50 & 6 & 1 & 1 & 3 & 23 & 4 & 4 & 8 & 5 & 3 & 17 & 7 & & 4 & 10 \\
\hline 51 & 4 & 4 & 1 & 5 & 20 & 2 & 5 & 10 & 2 & 1 & 14 & 8 & & 10 & $\because 6$ \\
\hline 52 & 2 & 4 & 1 & 10 & 24 & 3 & 2 & 2 & 3 & 1 & 22 & 14 & & 5 & 4 \\
\hline 53 & 2 & 1 & 3 & 5 & 49 & 1 & 6 & 4 & 3 & 1 & 13 & 6 & & 1 & 4 \\
\hline 54 & 3 & 6 & 5 & 1 & 55 & 1 & 8 & 3 & 8 & 1 & 14 & 7 & & 4 & 5 \\
\hline 55 & 2 & 10 & 6 & 11 & 44 & 2 & 3 & 2 & 11 & 3 & 11 & 11 & & 9 & 11 \\
\hline 56 & 4 & 1 & 5 & 16 & 27 & 1 & 6 & 6 & 5 & 4 & 28 & 8 & & 1 & 4 \\
\hline 57 & 1 & 27 & 6 & 16 & 20 & 6 & 2 & 11 & 7 & 2 & 16 & 5 & & 1 & 4 \\
\hline 58 & 1 & 23 & 8 & 23 & 4 & 2 & 14 & 3 & 9 & 1 & 22 & 14 & & 2 & 5 \\
\hline 59 & 1 & 22 & 21 & 14 & 39 & 9 & 10 & 4 & 11 & 5 & 36 & 14 & & 8 & 11 \\
\hline 60 & 1 & 18 & 0 & 10 & 36 & 12 & 9 & 4 & 1 & 0 & 34 & 12 & 9 & 2 & \\
\hline 61 & 0 & 16 & 7 & 19 & 45 & 12 & 4 & 6 & 10 & 1 & 26 & 24 & 54 & $\theta$ & \\
\hline 62 & 0 & 24 & 7 & 43 & 21 & 4 & 9 & 13 & 8 & 3 & 24 & 26 & 60 & 5 & \\
\hline 63 & 0 & 15 & 14 & 9 & 22 & 15 & 6 & 11 & 19 & 11 & 24 & 20 & 51 & 12 & \\
\hline 64 & 0 & 25 & 2 & 25 & 20 & 4 & 10 & 28 & 32 & 4 & 35 & 14 & 18 & 24 & \\
\hline 65 & 0 & 35 & 23 & 22 & 30 & 5 & 9 & 20 & 21 & 2 & 23 & 22 & 27 & 23 & \\
\hline 66 & 7 & 25 & 16 & 30 & 32 & 8 & 11 & 15 & 25 & 14 & 35 & 22 & 40 & 20 & \\
\hline 67 & 0 & 25 & 5 & 26 & 34 & 4 & 9 & 20 & 27 & 22 & 34 & 32 & 38 & 23 & \\
\hline 68 & 1 & 31 & 24 & 23 & 34 & 22 & 13 & 30 & 28 & 19 & 41 & 39 & 52 & 22 & \\
\hline 69 & 3 & 30 & 9 & 20 & 39 & 36 & 12 & 24 & 32 & 31 & 39 & 37 & 47 & 36 & \\
\hline 70 & 12 & 26 & 16 & 27 & 34 & 20 & 18 & 17 & 31 & 22 & 35 & 30 & 30 & 30 & \\
\hline 71 & 3 & 32 & 5 & 20 & 45 & 23 & 31 & 24 & 9 & 32 & 46 & 43 & 7 & 24 & \\
\hline 72 & 4 & 31 & 18 & 22 & 16 & 27 & 13 & 22 & 29 & 29 & 39 & 29 & 51 & 26 & \\
\hline 73 & 20 & 42 & 23 & 19 & 51 & 12 & 20 & 33 & 28 & 26 & 41 & 28 & 30 & 16 & \\
\hline 74 & 16 & 22 & 30 & 47 & 23 & 28 & 24 & 23 & 13 & 33 & 39 & 23 & 31 & 39 & \\
\hline 75 & 36 & 43 & 23 & 31 & 27 & 32 & 19 & 33 & 41 & 30 & 37 & 41 & 39 & 36 & \\
\hline 76 & 15 & 30 & 21 & 38 & 30 & 44 & 38 & 31 & 29 & 38 & 46 & 27 & 43 & 30 & \\
\hline 77 & 20 & 38 & 27 & 32 & 37 & 50 & 23 & 25 & 46 & 21 & 30 & 38 & 42 & 41 & \\
\hline 78 & 31 & 27 & 14 & 33 & 32 & 42 & 28 & 17 & 25 & 40 & 42 & 34 & 31 & 19 & \\
\hline 79 & 30 & 26 & 14 & 38 & 47 & 30 & 17 & 32 & 43 & 31 & 38 & 23 & 28 & 26 & \\
\hline 80 & 24 & 44 & 48 & 16 & 23 & 31 & 33 & 34 & 33 & 35 & 45 & 36 & 42 & 38 & \\
\hline 81 & 48 & 31 & 41 & 26 & 38 & 31 & 35 & 38 & 44 & 28 & 54 & 53 & 51 & 26 & \\
\hline 82 & 32 & 39 & 35 & 14 & 24 & 24 & 17 & 36 & 43 & 38 & 58 & 43 & 42 & 41 & \\
\hline 83 & 29 & 33 & 37 & 21 & 43 & 29 & 19 & 28 & 45 & 27 & 44 & 48 & 60 & 34 & \\
\hline 84 & 43 & 38 & 46 & 27 & 47 & 37 & 23 & 30 & 39 & 42 & 50 & 50 & 48 & 24 & \\
\hline 85 & 24 & 41 & 23 & 34 & 39 & 26 & 23 & 34 & 33 & 45 & 49 & 32 & 27 & 28 & \\
\hline 86 & 28 & 37 & 40 & 29 & 32 & 22 & 39 & 31 & 28 & 41 & 37 & 28 & 39 & 27 & \\
\hline 87 & 38 & 24 & 52 & 38 & 31 & 30 & 23 & 35 & 41 & 24 & 52 & 10 & 42 & 35 & \\
\hline 88 & 36 & 45 & 37 & 34 & 41 & 15 & 27 & 31 & 52 & 35 & 22 & 38 & 33 & 20 & \\
\hline 89 & 34 & 46 & 28 & 19 & 41 & 27 & 28 & 31 & 34 & 32 & 42 & 32 & 42 & 39 & \\
\hline 90 & 27 & 29 & 26 & 43 & 32 & 38 & 43 & 20 & 38 & 32 & 20 & 36 & 46 & 40 & \\
\hline 91 & 24 & 21 & 31 & 34 & 42 & 36 & 30 & 28 & 44 & 42 & 37 & 50 & 45 & 39 & \\
\hline 92 & 40 & 35 & 27 & 46 & 40 & 26 & 27 & 33 & 46 & 57 & 43 & 37 & 54 & 34 & \\
\hline 93 & 29 & 46 & 25 & 26 & 53 & 26 & 52 & 25 & 39 & 31 & 48 & 32 & 46 & 39 & \\
\hline 94 & 29 & 44 & 23 & 0 & 42 & 26 & 32 & 31 & 35 & 42 & 48 & 33 & 43 & 34 & \\
\hline
\end{tabular}




\begin{tabular}{|c|c|c|c|c|c|c|c|c|c|c|c|c|c|c|c|}
\hline Day & 1980 & \begin{tabular}{|l|l|} 
\\
\end{tabular} & 1982 & 1983 & 1984 & 1985 & 1986 & 1987 & 1988 & 1989 & 1990 & 1991 & 1992 & 1993 & 1994 \\
\hline 95 & 26 & \begin{tabular}{|l|}
35 \\
\end{tabular} & 35 & \begin{tabular}{|l}
0 \\
\end{tabular} & \begin{tabular}{|l|}
38 \\
\end{tabular} & 26 & 28 & 25 & 46 & 38 & 39 & 30 & 43 & 45 & \\
\hline 96 & 37 & 52 & 44 & 0 & 48 & 15 & $\overline{34}$ & 39 & 36 & 38 & 40 & 41 & 40 & 37 & \\
\hline 97 & 39 & 35 & 31 & 0 & 59 & 38 & 34 & 37 & 36 & 38 & 42 & 34 & 43 & 28 & \\
\hline 98 & 37 & 37 & 31 & 0 & 45 & 44 & 44 & 27 & 46 & 36 & 39 & 42 & 38 & -20 & \\
\hline 99 & 28 & 46 & 33 & 6 & 48 & 41 & 38 & 39 & 37 & 31 & 47 & 45 & 48 & 20 & \\
\hline 100 & 19 & 44 & 46 & 4 & 47 & 37 & 30 & 27 & 47 & 53 & 48 & 49 & 44 & 19 & \\
\hline 101 & 41 & 43 & 38 & $\underline{0}$ & 47 & 41 & 27 & 36 & 34 & 29 & 41 & 40 & 49 & 20 & \\
\hline 102 & 32 & 38 & 45 & 0 & 47 & 39 & 9 & 43 & 43 & 40 & 41 & 37 & 53 & 18 & \\
\hline 103 & 44 & 43 & 27 & 54 & 39 & 37 & 17 & 40 & 44 & 46 & 46 & 27 & 57 & 34 & \\
\hline 104 & 34 & 39 & 47 & 49 & 40 & 29 & 10 & 42 & 42 & 35 & 44 & 40 & 42 & 34 & \\
\hline 105 & 17 & 32 & 33 & 66 & 52 & 28 & 12 & 23 & 45 & 36 & 31 & 35 & 48 & 57 & \\
\hline 106 & 28 & 36 & 37 & 58 & 51 & 36 & 10 & 31 & 43 & 43 & 23 & 42 & 44 & 46 & \\
\hline 107 & 53 & 42 & 19 & 56 & 50 & 18 & 8 & 33 & 48 & 43 & 46 & 35 & 31 & 22 & \\
\hline 108 & 48 & 39 & 31 & 40 & 43 & 36 & 6 & 29 & 50 & 37 & 45 & 55 & 40 & 39 & \\
\hline 109 & 42 & 34 & 57 & 44 & 41 & 48 & $\overline{16}$ & 44 & 45 & 49 & 43 & 46 & 47 & 47 & \\
\hline 110 & 29 & 56 & 41 & 35 & 35 & 32 & 28 & 40 & 53 & 50 & 56 & 42 & 37 & 38 & \\
\hline 111 & 40 & 50 & 40 & 52 & 50 & 44 & 42 & 41 & 43 & 46 & 34 & 36 & 43 & 5 & \\
\hline 112 & 49 & 44 & 39 & 44 & 35 & 34 & 40 & 27 & 45 & 32 & 37 & 40 & 46 & 0 & \\
\hline 113 & 26 & 26 & 37 & 27 & 45 & 26 & 35 & 23 & 43 & 35 & 48 & 50 & 43 & 0 & \\
\hline 114 & 32 & 44 & 54 & 22 & 42 & 26 & 40 & 42 & 43 & 42 & 52 & 46 & 50 & 0 & \\
\hline 115 & 44 & 49 & 50 & 49 & 49 & 38 & 28 & 41 & 46 & 37 & 52 & 47 & 61 & $\underline{0}$ & \\
\hline 116 & 27 & 49 & 25 & 44 & 59 & 34 & 26 & 35 & 39 & 47 & 51 & 48 & 41 & 0 & \\
\hline 117 & 31 & 37 & 63 & 34 & 47 & 44 & 22 & 37 & 43 & 31 & 52 & 51 & 45 & 0 & \\
\hline 118 & 39 & 49 & 40 & 33 & 34 & 30 & 35 & 19 & 44 & 47 & 53 & 51 & 49 & 0 & \\
\hline 119 & 13 & 41 & 38 & 32 & 48 & 33 & 34 & 41 & 43 & 43 & 58 & 59 & 34 & 0 & \\
\hline 120 & 41 & 31 & 35 & 38 & 32 & 40 & 36 & 37 & 44 & 49 & 51 & 56 & 46 & 0 & \\
\hline 121 & 29 & 40 & 40 & 52 & 40 & 37 & 35 & 48 & 45 & 51 & 46 & 45 & 42 & 0 & \\
\hline 122 & 32 & 41 & 37 & 41 & 44 & 31 & 38 & 31 & 38 & 42 & 44 & 32 & 52 & 0 & \\
\hline 123 & 29 & 38 & 47 & 33 & 34 & 21 & 32 & 41 & 47 & 41 & 53 & 43 & 51 & 14 & \\
\hline 124 & 36 & 42 & 45 & 44 & 23 & 32 & 16 & 41 & 36 & 40 & 51 & 25 & 41 & 26 & \\
\hline 125 & 24 & 46 & 39 & 30 & 32 & 25 & 47 & 28 & 41 & 50 & 56 & 49 & 52 & 12 & \\
\hline 126 & 33 & 48 & 45 & 31 & 13 & 31 & 34 & 34 & 40 & 46 & 47 & 50 & 48 & 0 & \\
\hline 127 & 37 & 42 & 34 & 36 & 56 & 41 & 33 & 37 & 51 & 49 & 53 & 42 & 26 & 0 & \\
\hline 128 & 23 & 28 & 53 & 49 & 50 & 25 & 37 & 34 & 50 & 43 & 54 & 53 & 33 & 0 & \\
\hline 129 & 21 & 47 & 47 & 20 & 51 & 25 & 36 & 43 & 44 & 42 & 54 & 34 & 47 & 0 & \\
\hline 130 & 24 & 18 & 43 & 35 & 36 & 34 & 48 & 48 & 40 & 47 & 47 & 45 & 45 & 16 & \\
\hline 131 & 25 & 42 & 38 & 26 & 43 & 29 & 23 & 30 & 44 & 44 & 52 & 41 & 55 & 21 & \\
\hline 132 & 32 & 42 & 33 & 40 & 44 & 35 & 22 & 28 & 44 & 35 & 54 & 24 & 37 & 59 & \\
\hline 133 & 34 & 37 & 49 & 31 & 42 & 29 & 28 & 47 & 46 & 40 & 51 & 35 & 52 & 44 & \\
\hline 134 & 14 & 42 & 44 & 37 & 51 & 24 & 17 & 44 & 44 & 38 & 56 & 47 & 27 & 45 & \\
\hline 135 & 32 & 42 & 33 & 46 & 43 & 23 & 21 & 34 & 45 & 33 & 64 & 43 & 40 & 57 & \\
\hline 136 & 40 & 40 & 36 & 26 & 48 & 26 & 41 & 35 & 57 & 31 & 45 & 33 & 53 & 61 & \\
\hline 137 & 32 & 41 & 59 & 28 & 24 & 32 & 26 & 33 & 47 & 42 & 59 & 43 & 54 & 59 & \\
\hline 138 & 32 & 38 & 39 & 42 & 38 & 31 & 30 & 44 & 43 & 37 & 44 & 45 & 56 & 62 & \\
\hline 139 & 25 & 42 & 46 & 39 & 34 & 21 & 8 & 43 & 40 & 45 & 50 & 59 & 46 & 63 & \\
\hline 140 & 37 & 32 & 45 & 48 & 34 & 30 & 21 & 49 & 36 & 48 & 36 & 51 & 44 & 62 & \\
\hline 141 & 32 & 32 & 40 & 50 & 43 & 29 & 10 & 42 & 47 & 45 & 43 & 25 & 44 & 61 & \\
\hline
\end{tabular}




\begin{tabular}{|c|c|c|c|c|c|c|c|c|c|c|c|c|c|c|c|}
\hline Day & 1980 & 1981 & 1982 & 1983 & 1984 & 1985 & 1986 & 1987 & \begin{tabular}{|l|}
1988 \\
\end{tabular} & 1989 & 1990 & 1991 & 1992 & 1993 & 1994 \\
\hline 142 & 33 & 33 & 59 & 45 & 28 & 17 & 10 & \begin{tabular}{|l|}
39 \\
\end{tabular} & \begin{tabular}{|l|}
48 \\
\end{tabular} & 45 & 52 & 37 & 44 & \begin{tabular}{|l|}
35 \\
\end{tabular} & \\
\hline 143 & 31 & 29 & 54 & 34 & 38 & 35 & 25 & 45 & 46 & 35 & 46 & 37 & 35 & 47 & \\
\hline 144 & 35 & 42 & 43 & 46 & 29 & 32 & 41 & 55 & 50 & 41 & 47 & 56 & 47 & 57 & \\
\hline 145 & 36 & 41 & 37 & 24 & 43 & 42 & 19 & 36 & 42 & 47 & 53 & 43 & 50 & 61 & \\
\hline 146 & 42 & 44 & 36 & 48 & 22 & 34 & 29 & 48 & 58 & 41 & 61 & 41 & 49 & 35 & \\
\hline 147 & 42 & 39 & 40 & 32 & 45 & 41 & 26 & 49 & 47 & 40 & 43 & 46 & 54 & 45 & \\
\hline 148 & 41 & 48 & 42 & 34 & 27 & 29 & 38 & 30 & 50 & 38 & 23 & 43 & 47 & 32 & \\
\hline 149 & 28 & 40 & 46 & 47 & 49 & 15 & 33 & 45 & 49 & 53 & 48 & 24 & 51 & 41 & \\
\hline 150 & 42 & 44 & 52 & 54 & 48 & 24 & 28 & 49 & 43 & 42 & 59 & 40 & 46 & 60 & \\
\hline 151 & 44 & 40 & 46 & 43 & 37 & 21 & 30 & 41 & 49 & 38 & 54 & 33 & 46 & 47 & \\
\hline 152 & 35 & 51 & 49 & 46 & 31 & 42 & 32 & 28 & 43 & 45 & 68 & 42 & 48 & 54 & \\
\hline 153 & 34 & 35 & 49 & 41 & 38 & 20 & 19 & 23 & 40 & 38 & 62 & 41 & 45 & 50 & \\
\hline 154 & 28 & 41 & 48 & 31 & 39 & 15 & 14 & 37 & 32 & 41 & 55 & 44 & 46 & 60 & \\
\hline 155 & 37 & 44 & 51 & 42 & 51 & 28 & 28 & 34 & 40 & 38 & 52 & 33 & 43 & 49 & \\
\hline 156 & 37 & 27 & 49 & 44 & 33 & 31 & 12 & 33 & 49 & 42 & 53 & 29 & 50 & 47 & \\
\hline 157 & 32 & 43 & 35 & 54 & 29 & 37 & 31 & 50 & 50 & 50 & 61 & 55 & 44 & 38 & \\
\hline 158 & 34 & 49 & 56 & 45 & 45 & 25 & 36 & 43 & 35 & 50 & 57 & 54 & 50 & 53 & \\
\hline 159 & 26 & 38 & 57 & 39 & 7 & 20 & 29 & 40 & 41 & 45 & 42 & 55 & 53 & 41 & \\
\hline 160 & 44 & 25 & 35 & 29 & 40 & 29 & 31 & 48 & 35 & 45 & 54 & 36 & 50 & 49 & \\
\hline 161 & 52 & 43 & 34 & 37 & 58 & 18 & 38 & 47 & 38 & 51 & 58 & 29 & 49 & 39 & \\
\hline 162 & 36 & 43 & 52 & 36 & 29 & 23 & 19 & 38 & 41 & 34 & 47 & 34 & 35 & 36 & \\
\hline 163 & 32 & 39 & 54 & 42 & 45 & 23 & 29 & 45 & 56 & 48 & 49 & 35 & 39 & 41 & \\
\hline 164 & 26 & 34 & 55 & 32 & 23 & 21 & 44 & 52 & 33 & 46 & 51 & 46 & 24 & 53 & \\
\hline 165 & 41 & 47 & 43 & 37 & 33 & 24 & 16 & 45 & 40 & 38 & 60 & 37 & 40 & 41 & \\
\hline 166 & 31 & 43 & 52 & 31 & 39 & 36 & 39 & 41 & 50 & 39 & 40 & 34 & 43 & 33 & \\
\hline 167 & 44 & 45 & 39 & 46 & 28 & 27 & 14 & 34 & 29 & 41 & 35 & 51 & 45 & 45 & \\
\hline 168 & 35 & 45 & 39 & 46 & 51 & 27 & 24 & 39 & 43 & 41 & 60 & 42 & 47 & 43 & \\
\hline 169 & 27 & 38 & 41 & 41 & 36 & 21 & 29 & 40 & 34 & 44 & 50 & 47 & $4 ?$ & 47 & \\
\hline 170 & 35 & 29 & 31 & 51 & 32 & 43 & 28 & 25 & 40 & 45 & 42 & 41 & 52 & 56 & \\
\hline 171 & 42 & 42 & 45 & 50 & 34 & 25 & 22 & 29 & 44 & 44 & 52 & 37 & 51 & 48 & \\
\hline 172 & 30 & 39 & 29 & 44 & 47 & 39 & 25 & 33 & 40 & 48 & 47 & 44 & 52 & 34 & \\
\hline 173 & 48 & 42 & 52 & 49 & 18 & 25 & 46 & 42 & 42 & 49 & 32 & 29 & 52 & 47 & \\
\hline 174 & 44 & 35 & 28 & 49 & 27 & 20 & 24 & 31 & 40 & 40 & 24 & 45 & 56 & 22 & \\
\hline 175 & 38 & 39 & 30 & 36 & 37 & 37 & 34 & 40 & 24 & 52 & 3 & 36 & 46 & 33 & \\
\hline 176 & 34 & 26 & 26 & 48 & 21 & 31 & 34 & 30 & 39 & 44 & 34 & 40 & 44 & 36 & \\
\hline 177 & 40 & 51 & 39 & 45 & 33 & 35 & 50 & 33 & 55 & 43 & 34 & 47 & 44 & 17 & \\
\hline 178 & 35 & 26 & 35 & 32 & 48 & 27 & 25 & 41 & 44 & 46 & 46 & 35 & 41 & 8 & \\
\hline 179 & 51 & 42 & 30 & 46 & 38 & 31 & 47 & 37 & 24 & 50 & 48 & 55 & 46 & 0 & \\
\hline 180 & 37 & 36 & 24 & 36 & 28 & 24 & 41 & 45 & 32 & 44 & 37 & 37 & 48 & 0 & \\
\hline 181 & 46 & 20 & 15 & 47 & 38 & 35 & 39 & 21 & 34 & 49 & 62 & 43 & 52 & 0 & \\
\hline 182 & 39 & 30 & 19 & 41 & 32 & 43 & 34 & 44 & 31 & 54 & 58 & 51 & 49 & & \\
\hline 183 & 34 & 27 & 47 & 52 & 42 & 34 & 26 & 41 & 41 & 50 & 55 & 59 & 52 & & \\
\hline 184 & 42 & 28 & 60 & 56 & 30 & 28 & 25 & 45 & 31 & 48 & 57 & 53 & 58 & & \\
\hline 185 & 41 & 29 & 50 & 44 & 48 & 37 & 49 & 50 & 47 & 54 & 61 & 48 & 54 & & \\
\hline 186 & 49 & 39 & 46 & 45 & 37 & 33 & 49 & 54 & 54 & 51 & 60 & 51 & 53 & & \\
\hline 187 & 42 & 22 & 18 & 41 & 44 & 41 & 40 & 31 & 43 & 55 & 54 & 44 & 51 & & \\
\hline 188 & 44 & 22 & 36 & 43 & 36 & 50 & 33 & 43 & 38 & 53 & 62 & 53 & 50 & & \\
\hline
\end{tabular}




\begin{tabular}{|c|c|c|c|c|c|c|c|c|c|c|c|c|c|c|c|}
\hline Day & 1980 & 1981 & 1982 & 1983 & 1984 & 1985 & 1986 & 1987 & 1988 & 1989 & 1990 & 1991 & 1992 & \begin{tabular}{|l|l|}
1993 \\
\end{tabular} & 1994 \\
\hline 189 & \begin{tabular}{|l|}
48 \\
\end{tabular} & 23 & \begin{tabular}{|l}
32 \\
\end{tabular} & \begin{tabular}{|l|}
58 \\
\end{tabular} & 34 & 21 & 29 & 43 & \begin{tabular}{|l|}
27 \\
\end{tabular} & 44 & 45 & 45 & 55 & & \\
\hline 190 & 29 & 49 & 31 & 48 & 25 & 27 & 31 & 31 & 42 & 53 & 62 & 43 & 46 & & \\
\hline 191 & 40 & 48 & 36 & 53 & 36 & 39 & 28 & 42 & 31 & 51 & 45 & 41 & 53 & & \\
\hline 192 & 42 & 48 & 36 & 36 & 27 & 34 & 31 & 44 & 37 & 43 & 52 & 36 & 49 & - & $\cdots$ \\
\hline 193 & 33 & 40 & 30 & 43 & 14 & 43 & 27 & 40 & 26 & 51 & 46 & 56 & 52 & & \\
\hline 194 & 36 & 39 & 25 & 44 & 43 & 32 & 24 & 44 & 39 & 41 & 43 & 51 & 54 & & \\
\hline 195 & 44 & 33 & 25 & 39 & 42 & 21 & 23 & 38 & 41 & 42 & 51 & 47 & 52 & & \\
\hline 196 & 41 & 26 & 44 & 39 & 37 & 42 & 28 & 49 & 23 & 34 & 51 & 36 & 56 & & \\
\hline 197 & 37 & 29 & 30 & 55 & 25 & 23 & 13 & 37 & 38 & 40 & 44 & 49 & 58 & & \\
\hline 198 & 51 & 42 & 35 & 44 & 31 & 27 & 27 & 49 & 49 & 49 & 51 & 30 & 55 & & \\
\hline 199 & 48 & 42 & 45 & 32 & 36 & 34 & 25 & 49 & 40 & 42 & 53 & 49 & 57 & & \\
\hline 200 & 31 & 43 & 45 & 49 & 31 & 32 & 43 & 52 & 33 & 51 & 50 & 38 & 52 & & \\
\hline 201 & 39 & 36 & 37 & 53 & 49 & 22 & 33 & 51 & 36 & 40 & 50 & 46 & 63 & - & \\
\hline 202 & 37 & 36 & 21 & 42 & 29 & 36 & 22 & 36 & 40 & 41 & 56 & 57 & 55 & $z$ & \\
\hline 203 & 46 & 59 & 29 & 43 & 47 & 33 & 29 & 43 & 43 & 35 & 38 & 47 & 52 & & \\
\hline 204 & 32 & 34 & 26 & 48 & 53 & 29 & 28 & 48 & 30 & 48 & 54 & 45 & 51 & & \\
\hline 205 & 36 & 47 & 43 & 47 & 37 & 25 & 26 & 30 & 52 & 48 & 44 & 47 & 50 & & t \\
\hline 206 & 27 & 35 & 40 & 51 & 28 & 37 & 23 & 53 & 46 & 39 & 47 & 46 & 55 & & \\
\hline 207 & 41 & 42 & 33 & 56 & 35 & 27 & 34 & 56 & 42 & 34 & 48 & 48 & 59 & & \\
\hline 208 & 40 & 42 & 28 & 44 & 47 & 31 & 45 & 37 & 41 & 44 & 43 & 48 & 55 & & \\
\hline 209 & 44 & 37 & 54 & 44 & 27 & 27 & 18 & 34 & 53 & 41 & 53 & 48 & 50 & & \\
\hline 210 & 40 & 30 & 21 & 44 & 29 & 21 & 36 & 27 & 38 & 46 & 55 & 35 & 56 & & \\
\hline 211 & 45 & 31 & 34 & 50 & 32 & 27 & 26 & 33 & 26 & 45 & 52 & 53 & 41 & & \\
\hline 212 & 43 & 25 & 44 & 45 & 30 & 20 & 31 & 28 & 47 & 43 & 49 & 38 & 44 & & \\
\hline 213 & 48 & 40 & 49 & 36 & 14 & 49 & 22 & 49 & 46 & 41 & 48 & 46 & 44 & & \\
\hline 214 & 46 & 40 & 49 & 45 & 27 & 37 & 45 & 46 & 38 & 27 & 53 & 45 & 44 & & \\
\hline 215 & 31 & 41 & 46 & 45 & 39 & 37 & 34 & 36 & 52 & 48 & 57 & 40 & 48 & & \\
\hline 216 & 48 & 38 & 49 & 44 & 39 & 40 & 37 & 40 & 41 & 25 & 57 & 47 & 35 & & \\
\hline 217 & 37 & 33 & 47 & 44 & 50 & 29 & 29 & 44 & 39 & 41 & 55 & 38 & 49 & & \\
\hline 218 & 52 & 30 & 33 & 47 & 25 & 37 & 32 & 50 & 47 & 46 & 59 & 46 & 58 & & \\
\hline 219 & 49 & 45 & 50 & 41 & 26 & 24 & 32 & 50 & 47 & 40 & 40 & 51 & 35 & & \\
\hline 220 & 45 & 54 & 47 & 41 & 14 & 20 & 37 & 45 & 47 & 43 & 39 & 37 & 58 & & \\
\hline 221 & 45 & 51 & 48 & 44 & 14 & 33 & 46 & 47 & 54 & 29 & 39 & 44 & 43 & & \\
\hline 222 & 41 & 47 & 42 & 44 & 37 & 29 & 25 & 43 & 42 & 39 & 39 & 44 & 53 & & \\
\hline 223 & 43 & 40 & 50 & 51 & 60 & 22 & 26 & 47 & 49 & 37 & 38 & 49 & 36 & & \\
\hline 224 & 39 & 44 & 52 & 42 & 59 & 20 & 30 & 50 & 43 & 47 & 50 & 42 & 45 & & \\
\hline 225 & 45 & 44 & 32 & 49 & 53 & 43 & 27 & 48 & 45 & 41 & 38 & 47 & 52 & & \\
\hline 226 & 37 & 52 & 35 & 50 & 45 & 25 & 34 & 52 & 49 & 31 & 53 & 45 & 50 & & \\
\hline 227 & 38 & 47 & 34 & 44 & 51 & 41 & 29 & 51 & 47 & 40 & 48 & 45 & 50 & & \\
\hline 228 & 44 & 48 & 29 & 50 & 42 & 23 & 39 & 53 & 38 & 38 & 50 & 50 & 48 & & \\
\hline 229 & 49 & 49 & 37 & 51 & 24 & 31 & 31 & 48 & 30 & 36 & 46 & 53 & 52 & & \\
\hline 230 & 39 & 36 & 44 & 48 & 50 & 36 & 39 & 53 & 42 & 42 & 41 & 49 & 55 & & \\
\hline 231 & 45 & 48 & 43 & 50 & 49 & 24 & 25 & 33 & 34 & 44 & 38 & 46 & 53 & & \\
\hline 232 & 43 & 48 & 43 & 47 & 42 & 38 & 25 & 48 & 39 & 39 & 48 & 42 & 58 & 4 & \\
\hline 233 & 46 & 25 & 49 & 50 & 39 & 26 & 35 & 32 & 51 & 50 & 44 & 37 & 56 & 2 & \\
\hline 234 & 46 & 40 & 52 & 52 & 27 & 31 & $\overline{36}$ & 31 & 48 & 21 & 44 & 35 & 47 & 14 & \\
\hline 235 & 47 & 36 & 40 & 53 & 51 & 21 & 43 & 45 & 34 & 28 & 51 & 41 & 47 & 34 & \\
\hline
\end{tabular}




\begin{tabular}{|c|c|c|c|c|c|c|c|c|c|c|c|c|c|c|c|}
\hline Day & 1980 & 1981 & 1982 & 1983 & 1984 & 1985 & 1986 & 1987 & 1988 & 1989 & 1990 & 1991 & 1992 & 1993 & \begin{tabular}{|l|l|}
1994 \\
\end{tabular} \\
\hline 236 & 55 & 48 & 25 & 56 & 36 & 20 & 44 & 49 & 37 & 41 & 39 & 51 & \begin{tabular}{|l|}
44 \\
\end{tabular} & 32 & \\
\hline 237 & 32 & 43 & 35 & 50 & 39 & 3 & 39 & 42 & 42 & 48 & 51 & 44 & 42 & 49 & \\
\hline 238 & 46 & 40 & 45 & 52 & 30 & 2 & 29 & 41 & 41 & 42 & 57 & 35 & 44 & 36 & \\
\hline 239 & 39 & 39 & 51 & 51 & 38 & 2 & 37 & 42 & 43 & 43 & 42 & 37 & 39 & -41 & \\
\hline 240 & 49 & 50 & 40 & 55 & 29 & 40 & 35 & 47 & 37 & 38 & 46 & 32 & 46 & 47 & \\
\hline 241 & 54 & 39 & 49 & 55 & 27 & 43 & 38 & 44 & 36 & 27 & 49 & 48 & 48 & 50 & \\
\hline 242 & 51 & 52 & 30 & 52 & 17 & 55 & 49 & 48 & 38 & 47 & 40 & 42 & 53 & 56 & \\
\hline 243 & 48 & 41 & 40 & 56 & 49 & 47 & 49. & 50 & 47 & 48 & 48 & 44 & 51 & 56 & \\
\hline 244 & 50 & 37 & 33 & 55 & 36 & 49 & 32 & 45 & 46 & 56 & 55 & 58 & 47 & 55 & \\
\hline 245 & 44 & 34 & 41 & 52 & 49 & 50 & 37 & 51 & 44 & 46 & 47 & 38 & 48 & 31 & \\
\hline 246 & 44 & 51 & 36 & 53 & 39 & 47 & 43 & 43 & 46 & 56 & 49 & 45 & 45 & 54 & \\
\hline 247 & 43 & 42 & 46 & 56 & 44 & 36 & 32 & 51 & 56 & 52 & 41 & 44 & 52 & 41 & \\
\hline 248 & 46 & 43 & 39 & 51 & 43 & 26 & 41 & 54 & 58 & 47 & 45 & 40 & 48 & 54 & \\
\hline 249 & 41 & 41 & 51 & 57 & 42 & 32 & 43 & 54 & 49 & 43 & 37 & 43 & 52 & 39 & \\
\hline 250 & 47 & 48 & 32 & 52 & 31 & 35 & 31 & 54 & 40 & 48 & 56 & 45 & 54 & 26 & \\
\hline 251 & 49 & 39 & 45 & 46 & 32 & 35 & 30 & 44 & 40 & 40 & 50 & 43 & 36 & 54 & \\
\hline 252 & 46 & 43 & 34 & 43 & 27 & 22 & 16 & 40 & 42 & 38 & 39 & 33 & 38 & 34 & \\
\hline 253 & 42 & 47 & 49 & 49 & 30 & 27 & 32 & 46 & 47 & 45 & 52 & 47 & 48 & 46 & \\
\hline 254 & 46 & 40 & 42 & 44 & 27 & 39 & 26 & 34 & 38 & 40 & 30 & 28 & 33 & 50 & \\
\hline 255 & 53 & 29 & 40 & 41 & 47 & 27 & 21 & 50 & 49 & 39 & 40 & 36 & 41 & 47 & \\
\hline 256 & 49 & 41 & 17 & 56 & 38 & 25 & 27 & 48 & 40 & 41 & 23 & 36 & 38 & 41 & \\
\hline 257 & 38 & 47 & 40 & 44 & 42 & 30 & 28 & 43 & 37 & 25 & 44 & 46 & 42 & 37 & \\
\hline 258 & 44 & 33 & 41 & 56 & 33 & 32 & 25 & 42 & 36 & 13 & 32 & 43 & 26 & 35 & \\
\hline 259 & 46 & 39 & 49 & 45 & 40 & 23 & 25 & 40 & 33 & 32 & 53 & 34 & 31 & 44 & \\
\hline 260 & 51 & 42 & 46 & 54 & 33 & 31 & 25 & 24 & 30 & 28 & 41 & 20 & 38 & 31 & \\
\hline 261 & 51 & 34 & 19 & 51 & 35 & 18 & 33 & 31 & 44 & 26 & 35 & 38 & 42 & 29 & \\
\hline 262 & 47 & 45 & 37 & 47 & 29 & 17 & 32 & 30 & 52 & 34 & 21 & 40 & 44 & 29 & \\
\hline 263 & 48 & 34 & 43 & 46 & 27 & 30 & 35 & 32 & 45 & 32 & 39 & 30 & 28 & 38 & \\
\hline 264 & 46 & 37 & 16 & 53 & 19 & 24 & 28 & 36 & 43 & 45 & 33 & 36 & 43 & 28 & \\
\hline 265 & 56 & 33 & 34 & 46 & 36 & 26 & 34 & 28 & 38 & 39 & 38 & 31 & 25 & 24 & \\
\hline 266 & 48 & 23 & 25 & 42 & 35 & 26 & 36 & 28 & 36 & 37 & 35 & 32 & 34 & 40 & \\
\hline 267 & 48 & 35 & 32 & 53 & 29 & 16 & 22 & 35 & 39 & 49 & 43 & 30 & 30 & 52 & \\
\hline 268 & 40 & 42 & 40 & 46 & 34 & 30 & 36 & 35 & 40 & 41 & 32 & 45 & 27 & 37 & \\
\hline 269 & 51 & 36 & 21 & 45 & 25 & 17 & 43 & 41 & 38 & 36 & 43 & 47 & 25 & 39 & \\
\hline 270 & 42 & 32 & 33 & 35 & 24 & 24 & 25 & 38 & 38 & 42 & 39 & 29 & 43 & 26 & \\
\hline 271 & 48 & 39 & 31 & 47 & 26 & 33 & 31 & 39 & 42 & 28 & 32 & 35 & 30 & 39 & \\
\hline 272 & 51 & 28 & 32 & 51 & 29 & 22 & 36 & 20 & 41 & 36 & 41 & 35 & 24 & 30 & \\
\hline 273 & 43 & 41 & 20 & 45 & 34 & 23 & 25 & 25 & 48 & 41 & 36 & 39 & 40 & 36 & \\
\hline 274 & 39 & 30 & 38 & 47 & 34 & 22 & 35 & 39 & 32 & 35 & 27 & 33 & 23 & 39 & \\
\hline 275 & 27 & 35 & 23 & 39 & 17 & 22 & 36 & 43 & 31 & 29 & 31 & 22 & 30 & 30 & \\
\hline 276 & 35 & 30 & 28 & 41 & 34 & 35 & 17 & 32 & 45 & 37 & 34 & 36 & 31 & 31 & \\
\hline 277 & 41 & 52 & 29 & 46 & 31 & 23 & 0 & 44 & 43 & 37 & 38 & 39 & 35 & 32 & \\
\hline 278 & 46 & 32 & 34 & 52 & 38 & 28 & 0 & 23 & 46 & 39 & 36 & 43 & 35 & 33 & \\
\hline 279 & 51 & 31 & 24 & 49 & 34 & 21 & 0 & 32 & 45 & 28 & 39 & 28 & 39 & 37 & \\
\hline 280 & 44 & 30 & 29 & 51 & 26 & 34 & 0 & 40 & 23 & 41 & 40 & 31 & 39 & 36 & \\
\hline 281 & 47 & 34 & 32 & 53 & 31 & 17 & 0 & 41 & 32 & 40 & 44 & 37 & 20 & 41 & \\
\hline 282 & 30 & 15 & 29 & 48 & 23 & 11 & 0 & 37 & 36 & 38 & 31 & 17 & 37 & 25 & \\
\hline
\end{tabular}




\begin{tabular}{|c|c|c|c|c|c|c|c|c|c|c|c|c|c|c|c|}
\hline Day & 1980 & 1981 & 1982 & 1983 & 1984 & 1985 & 1986 & 1987 & 1988 & 1989 & 1990 & 1991 & 1992 & 1993 & 1994 \\
\hline 283 & 47 & 39 & \begin{tabular}{|l|}
19 \\
\end{tabular} & 40 & 25 & 34 & 13 & 34 & 45 & 41 & 30 & 37 & 11 & \begin{tabular}{|l|}
48 \\
\end{tabular} & \\
\hline 284 & 56 & 38 & 35 & 44 & 34 & 29 & 0 & 29 & 44 & 40 & 35 & 40 & 40 & 42 & \\
\hline 285 & 31 & 34 & 33 & 37 & 33 & 27 & 0 & 30 & 42 & 33 & 31 & 47 & 40 & 42 & \\
\hline 286 & 39 & 32 & 14 & 45 & 27 & 27 & 4 & 32 & 40 & 42 & 30 & 43 & 37 & -37 & \\
\hline 287 & 37 & 26 & 36 & 50 & 39 & 6 & 3 & 35 & 39 & 41 & 36 & 43 & 29 & 31 & \\
\hline 288 & 30 & 39 & 23 & 45 & 37 & 22 & 10 & 43 & 46 & 40 & 43 & 40 & 42 & 19 & \\
\hline 289 & 44 & 27 & 21 & 49 & 38 & 16 & 16 & 34 & 47 & 39 & 33 & 33 & 21 & 11 & \\
\hline 290 & 45 & 34 & 13 & 52 & 15 & 29 & .36 & 41 & 42 & 24 & 40 & 31 & 20 & 25 & \\
\hline 291 & 50 & 38 & 39 & 52 & 46 & 22 & 49 & 45 & 33 & 45 & 32 & 42 & 16 & 46 & \\
\hline 292 & 43 & 31 & 19 & 53 & 43 & 20 & 57 & 43 & 36 & 31 & 40 & 38 & 34 & 58 & \\
\hline 293 & 38 & 24 & 15 & 52 & 33 & 21 & 47 & 44 & 45 & 42 & 38 & 39 & 34 & 37 & \\
\hline 294 & 38 & 44 & 29 & 39 & 34 & 14 & 47 & 36 & 46 & 43 & 42 & 43 & 36 & 43 & \\
\hline 295 & 40 & 39 & 18 & 36 & 48 & 23 & 41 & 42 & 42 & 36 & 47 & 40 & 34 & 37 & \\
\hline 296 & 45 & 37 & 33 & 36 & 38 & 16 & 26 & 44 & 41 & 33 & 29 & 34 & 20 & 30 & \\
\hline 297 & 43 & 46 & 42 & 45 & 34 & 38 & 50 & 34 & 42 & 43 & 41 & 49 & 37 & 38 & \\
\hline 298 & 29 & 26 & 17 & 42 & 29 & 28 & 28 & 49 & 45 & 48 & 49 & 37 & 27 & 49 & \\
\hline 299 & 36 & 34 & 22 & 48 & 41 & 33 & 55 & 37 & 43 & 42 & 44 & 40 & 37 & 48 & \\
\hline 300 & 48 & 30 & 22 & 51 & 35 & 29 & 46 & 42 & 44 & 40 & 40 & 39 & 24 & 47 & \\
\hline 301 & 30 & 33 & 51 & 37 & 34 & 32 & 22 & 42 & 42 & 40 & 49 & 35 & 21 & 23 & \\
\hline 302 & 45 & 43 & 36 & 46 & 33 & 23 & 36 & 32 & 42 & 40 & 46 & 36 & 37 & 29 & \\
\hline 303 & 44 & 26 & 25 & 44 & 39 & 19 & 41 & 38 & 51 & 30 & 48 & 24 & 28 & 29 & \\
\hline 304 & 36 & 37 & 16 & 44 & 29 & 25 & 43 & 32 & 45 & 28 & 33 & 38 & 26 & 37 & \\
\hline 305 & 42 & 25 & 27 & 46 & 28 & 24 & 28 & 39 & 44 & 34 & 42 & 37 & 20 & & \\
\hline 306 & 37 & 31 & 30 & 29 & 36 & 35 & 39 & 33 & 48 & 36 & 50 & 42 & 12 & & \\
\hline 307 & 25 & 43 & 31 & 31 & 45 & 30 & 37 & 32 & 35 & 41 & 46 & 40 & 27 & & \\
\hline 308 & 39 & 39 & 22 & 56 & 43 & 32 & 41 & 35 & 37 & 33 & 45 & 22 & 34 & & \\
\hline 309 & 52 & 43 & 44 & 38 & 34 & 36 & 39 & 33 & 38 & 43 & 48 & 41 & 30 & & \\
\hline 310 & 41 & 41 & 36 & 46 & 27 & 41 & 32 & 26 & 40 & 36 & 46 & 32 & 31 & & \\
\hline 311 & 40 & 36 & 23 & 45 & 45 & 26 & 33 & 46 & 26 & 38 & 29 & 40 & 44 & & \\
\hline 312 & 36 & 54 & 49 & 45 & 24 & 36 & 33 & 39 & 34 & 29 & 39 & 28 & 35 & & \\
\hline 313 & 45 & 38 & 29 & 49 & 50 & 31 & 40 & 40 & 48 & 45 & 45 & 49 & 25 & & \\
\hline 314 & 45 & 43 & 37 & 40 & 50 & 35 & 43 & 36 & 43 & 34 & 33 & 42 & 35 & & \\
\hline 315 & 57 & 44 & 37 & 43 & 49 & 34 & 40 & 28 & 38 & 47 & 40 & 26 & 26 & & \\
\hline 316 & 34 & 47 & 38 & 42 & 43 & 23 & 45 & 34 & 37 & 37 & 48 & 12 & 14 & & \\
\hline 317 & 53 & 42 & 34 & 40 & 44 & 10 & 44 & 30 & 37 & 47 & 49 & 22 & 27 & & \\
\hline 318 & 46 & 44 & 31 & 51 & 34 & 33 & 37 & 35 & 48 & 41 & 44 & 43 & 33 & & \\
\hline 319 & 40 & 32 & 34 & 41 & 27 & 19 & 28 & 34 & 38 & 38 & 34 & 24 & 34 & & \\
\hline 320 & 35 & 33 & 46 & 50 & 43 & 44 & 37 & 37 & 46 & 38 & 31 & 27 & 38 & & \\
\hline 321 & 31 & 33 & 40 & 52 & 35 & 44 & 27 & 30 & 38 & 42 & 33 & 27 & 55 & & \\
\hline 322 & 51 & 32 & 27 & 53 & 43 & 31 & 20 & 32 & 33 & 39 & 43 & 48 & 28 & & \\
\hline 323 & 30 & 40 & 9 & 46 & 38 & 26 & 45 & 15 & 38 & 37 & 35 & 32 & 35 & & \\
\hline 324 & 51 & 39 & 42 & 49 & 37 & 17 & 41 & 21 & 37 & 31 & 46 & 51 & 18 & & \\
\hline 325 & 38 & 43 & 37 & 45 & 27 & 15 & 30 & 46 & 49 & 42 & 35 & 46 & 31 & & \\
\hline 326 & 42 & 42 & 17 & 51 & 40 & 30 & 25 & 40 & 38 & 42 & 35 & 50 & 27 & & \\
\hline 327 & 32 & 25 & 44 & 42 & 41 & 25 & 32 & 32 & 30 & 45 & 29 & 54 & 24 & & \\
\hline 328 & 42 & 43 & 36 & 50 & 49 & 28 & 35 & 26 & 40 & 49 & 35 & 47 & 33 & & \\
\hline 329 & 37 & 35 & 36 & 46 & 35 & 20 & 52 & 24 & 38 & 42 & 38 & 52 & 34 & & \\
\hline
\end{tabular}




\begin{tabular}{|c|c|c|c|c|c|c|c|c|c|c|c|c|c|c|c|}
\hline Day & 1980 & 1981 & 1982 & 1983 & 1984 & 1985 & 1986 & 1987 & 1988 & 1989 & 1990 & 1991 & 1992 & 1993 & 1994 \\
\hline 330 & 18 & 45 & 42 & 61 & 44 & 24 & 55 & 17 & 47 & 43 & 39 & 48 & 40 & & \\
\hline 331 & 37 & 47 & 23 & 48 & 42 & 33 & 53 & 27 & 39 & 43 & 39 & 55 & 41 & & \\
\hline 332 & 30 & 31 & 45 & 40 & 26 & 47 & 49 & 33 & 40 & 38 & 34 & 23 & 36 & & \\
\hline 333 & 42 & 37 & 41 & 36 & 50 & 39 & 33 & 39 & 41 & 23 & 27 & 42 & 23 & $\cdots$ & \\
\hline 334 & 38 & 48 & 28 & 43 & 26 & 18 & 7 & 31 & 15 & 38 & 18 & 24 & 17 & & \\
\hline 335 & 14 & 36 & 38 & 48 & 46 & 28 & 19 & 16 & 26 & 29 & 30 & 25 & 31 & 19 & \\
\hline 336 & 36 & 34 & 36 & 50 & 48 & 10 & 5 & 22 & 20 & 28 & 19 & 30 & 18 & 17 & \\
\hline 337 & 18 & 44 & 10 & 49 & 18 & 8 & 18 & 12 & 10 & 19 & 21 & 22 & 25 & 1 & \\
\hline 338 & 44 & 48 & 0 & 38 & 38 & 5 & 23 & 17 & 31 & 29 & 27 & 7 & 29 & 21 & \\
\hline 339 & 19 & 42 & 2 & 44 & 36 & 22 & 14 & 27 & 45 & 24 & 29 & 4 & 18 & 34 & \\
\hline 340 & 29 & 30 & 2 & 21 & 23 & 0 & 15 & 24 & 28 & 14 & 24 & 15 & 31 & 19 & \\
\hline 341 & 34 & 34 & 1 & 13 & 15 & 32 & 12 & 15 & 9 & 13 & 22 & 20 & 8 & 23 & \\
\hline 342 & 17 & 25 & 0 & 12 & 12 & 34 & 13 & 9 & 20 & 15 & 24 & 31 & 37 & 18 & \\
\hline 343 & 22 & 33 & 2 & 16 & 24 & 20 & 20 & 18 & 17 & 28 & 33 & 21 & 10 & 16 & \\
\hline 344 & 27 & 13 & 28 & 18 & 14 & 13 & 16 & 24 & 36 & 12 & 19 & 22 & 24 & 34 & \\
\hline 345 & 18 & 20 & 49 & 11 & 14 & 29 & 21 & 18 & 22 & 14 & 14 & 22 & 10 & 26 & \\
\hline 346 & 20 & 35 & 49 & 31 & 10 & 9 & 0 & 11 & 16 & 11 & 15 & 48 & 16 & 19 & \\
\hline 347 & 25 & 29 & 15 & 10 & 19 & 8 & 11 & 28 & 24 & 27 & 24 & 3 & 11 & 26 & \\
\hline 348 & 10 & 20 & 14 & 8 & 24 & 11 & 23 & 16 & 16 & 11 & 17 & 6 & 3 & 4 & \\
\hline 349 & 19 & 21 & 38 & 16 & 3 & 6 & 16 & 5 & 14 & 8 & 20 & 0 & 27 & 21 & \\
\hline 350 & 13 & 4 & 18 & 7 & 12 & 1 & 7 & 13 & 17 & 12 & 20 & 0 & 3 & 11 & \\
\hline 351 & 13 & 21 & 24 & 0 & 11 & 17 & 15 & 14 & 13 & 10 & 13 & 0 & 40 & 2 & \\
\hline 352 & 14 & 11 & 28 & 4 & 12 & 23 & 11 & 11 & 14 & 10 & 11 & 0 & 22 & 7 & \\
\hline 353 & 20 & 7 & 24 & 11 & 2 & 11 & 25 & 12 & 7 & 8 & 10 & 0 & 7 & 3 & \\
\hline 354 & 16 & 14 & 27 & 7 & 13 & 7 & 6 & 12 & 0 & 4 & 14 & 0 & 15 & 3 & \\
\hline 355 & 14 & 13 & 31 & 16 & 13 & 9 & 9 & 4 & 4 & 4 & 11 & 0 & 11 & 6 & \\
\hline 356 & 14 & 16 & 13 & 16 & 7 & 4 & 11 & 7 & 3 & 0 & 14 & 0 & 7 & 26 & \\
\hline 357 & 1 & 16 & 15 & 16 & 6 & 1 & 7 & 19 & 5 & 3 & 11 & 0 & 3 & 12 & \\
\hline 358 & 11 & 11 & 14 & 12 & 4 & 0 & 4 & 2 & 10 & 1 & 0 & 0 & 13 & 0 & \\
\hline 359 & 4 & 11 & 11 & 4 & 0 & 8 & 13 & 5 & 6 & 0 & 11 & 0 & 4 & 3 & \\
\hline 360 & 7 & 10 & 9 & 3 & 3 & 0 & 7 & 0 & 2 & 3 & 4 & 0 & 13 & 8 & \\
\hline 361 & 11 & 6 & 12 & 0 & 8 & 0 & 9 & 2 & 5 & 1 & 0 & 0 & 10 & 7 & \\
\hline 362 & 9 & 6 & 5 & 0 & 7 & 0 & 4 & 11 & 15 & 3 & 6 & 0 & 5 & 5 & \\
\hline 363 & 0 & 3 & 12 & 0 & 5 & 2 & 5 & 1 & 4 & 0 & 0 & $\overline{0}$ & 0 & 6 & \\
\hline 364 & 7 & 17 & 13 & 0 & 9 & 1 & 4 & 8 & 9 & 0 & 3 & 0 & 2 & 8 & \\
\hline 365 & 8 & 17 & 12 & 0 & 4 & 0 & 5 & 6 & 5 & 0 & 0 & 0 & 8 & 5 & \\
\hline 366 & 11 & & & & 5 & & & & 4 & & & & 13 & & \\
\hline
\end{tabular}




\section{Appendix B}

\section{Notation}

$a$

A

$\alpha$

$b$

$B$

$\beta$

$\beta_{i}$

C

$\mathrm{CNC}$

DR

DY

$\Delta N_{H C}$

$\delta t$

$\delta t_{d}$

$\delta t_{u}$

EOL1

EOL2

ET

$f_{L}(l)$

$F_{L}(l)$

GEM

$\mathrm{HC}$

$h_{t}$

$H_{d}$

$H_{p}$

$H_{p n}$

$H_{t}$

$H_{t n}$

$H_{\text {tmax }}$
Parameter of the Weibull distribution

Monthly fraction of upstream traffic

Regression coefficient

Fraction of traffic moving upstream

Parameter of the Weibull distribution

Regression coefficient

Reliability index

Fraction of vessels in a month from the traffic of a year

Regression coefficient

Corrected number of lockage cuts

Direction of lockage (up or down)

Day of shift

Decrease in the mean of total hardware cycles due to simultaneously servicing multiple boats

Average service time in the lock for a vessel

Service time in the lock for a vessel in downstream traffic

Service time in the lock for a vessel in the upstream traffic

End of lockage time (24 hr) first cut

End of lockage time ( $24 \mathrm{hr}$ ) last cut

Entry type

Probability density function of vessel length $L$

Cumulative distribution function of length of the vessel population

General Equilibrium Model

Number of hardware cycles

Tailwater elevation value

Water-head differential

Pool elevation (or height) of water

Normalized pool elevation (or height) of water

Tailwater elevation (or height)

Normalized tailwater elevation (or height)

Maximum tailwater elevation (or height) 
$k$

K

$K_{c}$

$l_{\max }$

LG

LN

LPMS

LT

$\lambda$

$\lambda_{d}$

$\lambda_{u}$

MO

$N_{0}$

$N_{1}$

$\mathrm{N}_{2}$

$\mathrm{NC}$

$N_{\text {cuts }}$

$N_{H C}$

$N_{H C i}$

$N_{k}$

$N L$

$N_{\text {loc }}$

$N_{v}$

$\bar{N}_{v}$

$N_{v d}$

$N_{v i}$

$N_{v u}$

$\bar{N}_{1}$

$\bar{N}_{2}$

$\bar{N}_{k}$

$\bar{N}_{H C}$

$\bar{N}_{H C i}$

$\Delta N_{H C d}$
Minimum tailwater elevation (or height)

Predicted value of $H_{p}$

Number of cuts

Coefficient for expressing seasonal variation in traffic volume and direction

'Mean hardware cycles per lockage

Maximum length of a vessel which can be locked in one operation of a lock

Number of lockages

Lock number

Lock Performance Monitoring System

Lockage type

Rate of vessel arrival at a lock

Poisson arrival rate to a lock of vessels for downstream traffic

Poisson arrival rate to a lock of vessels for upstream traffic

Month of shift

Model coefficient

Number of vessels which are not cut

Number of vessels which are cut into two parts

Number of lockage cuts

Number of cuts

Total number of hardware cycles

Number of hardware cycles for $i$ cuts

Number of vessels which are cut into $k$ parts

Number of discrete vessel lengths

Number of lockages

Number of vessels arriving at a lock in time $T$

Mean number of vessels arriving in time $T$

Mean number of vessels arriving at a lock in time $T$ from upstream direction

Number of vessels in the $i$ th month for $i=1,2, \ldots$, 12

Mean number of vessels arriving at a lock in time $T$ from downstream direction

Mean number of vessels which are not cut

Mean number of vessels which are cut into two parts

Mean number of vessels which are cut into $k$ parts;

Mean of total number of hardware cycles

Mean number of hardware cycles for $i$ cuts

Mean decrease in the number of hardware cycles in the downstream traffic 


$\begin{array}{ll}\Delta N_{H C u} & \begin{array}{c}\text { Mean decrease in the number of hardware cycles in } \\ \text { the upstream traffic } \\ \Delta N_{H C t}\end{array} \\ p_{L}\left(l_{i}\right) & \begin{array}{c}\text { Mean decrease in the number of hardware cycles } \\ \text { for two-direction traffic }\end{array} \\ p_{s} & \begin{array}{l}\text { Probability mass value of a vessel length } L \\ \text { Probability that a given boat is being serviced } \\ P_{1}\end{array} \\ P_{2} & \text { Primultaneously with other boats } \\ P_{k} & \text { Probability that a vessel is not being cut } \\ \text { SOL1 } & \text { Probability that a vessel is being cut into two parts } \\ t & \text { Start of lockage time (24 hr) } 1 \text { st cut } \\ T & \text { Time in years } \\ T_{i} & \text { Reference time period } \\ \text { TN } & \text { Monthly reference time period for } i=1,2, \ldots, 12 ; \\ T_{n} & \text { Tonnage } \\ \bar{T}_{n} & \text { Annual tonnage } \\ \bar{T}_{0} & \text { Mean annual tonnage } \\ \operatorname{Var}\left(N_{1}\right) & \text { Model coefficient for mean annual tonnage } \\ \operatorname{Var}\left(N_{2}\right) & \text { Variance of number of vessels which are not cut } \\ \operatorname{Var}\left(N_{H C}\right) & \text { Variance of number of vessels which are cut into } \\ \operatorname{Var}\left(N_{k}\right) & \text { two parts } \\ \operatorname{VT} & \text { Variance of total number of hardware cycles } \\ x, X & \text { Variance of number of vessels which are cut into } k \\ \mathrm{XT} & \text { parts } \\ \text { YR } & \text { Vessel type } \\ & \text { Random value or variable }\end{array}$




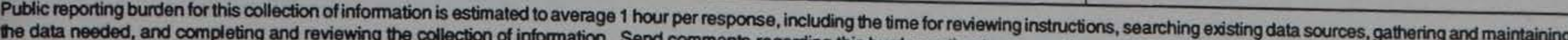

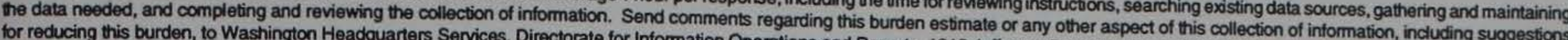

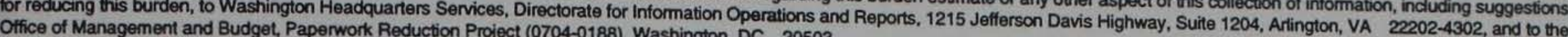
1. ACENCY 20503.
1. AGENCY USE ONLY (Leave blank)
2. REPORT DATE
December 1995
3. REPORT TYPE AND DATES COVERED
Final report

4. TITLE AND SUBTITLE

Loading Cycle for the Fatigue Reliability Analysis of Miter Gates

5. FUNDING NUMBERS

6. AUTHOR(S)

Bilal M. Ayyub

Mark P. Kaminskiy

Robert C. Patev

Mary Ann Leggett

7. PERFORMING ORGANIZATION NAME(S) AND ADDRESS(ES)

BMA Engineering, Inc.

14205 White Water Way, Darnestown, MD 20878-3974;

8. PERFORMING ORGANIZATION

REPORT NUMBER

U.S. Army Engineer Waterways Experiment Station

3909 Halls Ferry Road, Vicksburg, MS 39180-6199

9. SPONSORINGMONITORING AGENCY NAME(S) AND ADDRESS(ES)

U.S. Army Corps of Engineers

Technical Report ITL-95-12

Washington, DC 20314

11. SUPPLEMENTARY NOTES

Available from National Technical Information Service, 5285 Port Royal Road, Springfield, VA 22161.

12a. DISTRIBUTION/AVAILABILTTY STATEMENT

Approved for public release; distribution is unlimited.

12b. DISTRIBUTION CODE

13. ABSTRACT (Maximum 200 words)

Miter gates at navigation locks experience loading cycles from emptying and filling of a lock's chamber as they are opened to allow traffic through the locks. Reliability analysis of miter gates at navigation locks requires definition of (a) nonperformance modes, (b) loads, (c) structural strength, and (d) methods of reliability analysis. Due to the cyclic loading nature of miter gates, the fatigue of critical details requires examination using reliability methods. The assessment of fatigue reliability of these details as a function of time requires the knowledge of strength, stress ranges, and loading cycles for these details.

Prediction of loading cycles on miter gates for use in the assessment of fatigue reliability for miter gates is described. Correlation of field data for pool and tailwater elevations and barge traffic to form a loading histogram to be utilized to better predict the loading history of miter gates is explained.

14. SUBJECT TERMS

Reliability

Miter Gates

Fatigue

Reliability Index

$\begin{array}{ll}\text { Lockages } & \text { Tailwater } \\ \text { Locks } & \text { Pool water } \\ \text { Hardware Cycles } & \text { Loading histogram }\end{array}$

Lockages

Hardware Cycles

Loading histogram
15. NUMBER OF PAGES

91

16. PRICE CODE
17. SECURITY CLASSIFICATION OF REPORT

UNCLASSIFIED
18. SECURITY CLASSIFICATION OF THIS PAGE

UNCLASSIFIED
SECURITY CLASSIFICATION OF ABSTRACT 